\title{
Market Frictions in Entrepreneurial Innovation: Theory and Evidence*
}

\author{
Angela Cipollone $^{\dagger} \quad$ Paolo E. Giordani ${ }^{\ddagger}$
}

\begin{abstract}
We propose a model of entrepreneurial innovation that rationalizes its pattern of boom and bust. In the model, a successful entrepreneurial project is the result of a search and matching process between entrepreneurs and capitalists. A strategic complementarity between the entrepreneurs' demand for funds and the capitalists' supply arises both on the extensive and on the intensive margin. Using data from the Global Entrepreneurship Monitor, and collecting data on the venture capital market of 23 OECD countries plus China for the period 20072015, we find robust evidence of complementarity across the two sides of the market. We also provide a quantitative estimate of a multiplier effect originating from such complementarity.
\end{abstract}

Keywords: entrepreneurship; financial frictions; strategic complementarities; venture capital; multiplier effect.

JEL Classification: 031, C78, L26.

${ }^{*}$ We would like to thank E. Brancati, D. Ferraro, P. Peretto, A. Schoar, J. Zeira for useful comments and/or suggestions. We also thank seminar/conference participants at University of Lovain La Neuve, Rome "La Sapienza", Barcelona GSE Summer Forum 2016, the Searle Center Conference on Innovation Economics (Northwestern University), the CODE Conference (ZEW, Mannheim University), OFCE-SKEMA workshop 2016, the ASSET Conference 2015. All errors are ours.

†CeLEG (Center for Labor and Economic Growth), LUISS "Guido Carli" University, Viale Romania 32, 00197 Roma, Italy. E-mail: acipollone@luiss.it.

${ }^{\ddagger}$ Corresponding author: LUISS "Guido Carli" University, Department of Economics and Finance, Viale Romania 32, 00197 Roma, Italy. Tel.: +39 0685225912. E-mail: pgiordani@luiss.it. 


\section{Introduction}

Suppose you have a promising idea for a new business venture. You find it hard, however, to finance your project from banks or other conventional sources of capital, because of its high degree of uncertainty and/or lack of good collateral. You might then want to turn to other agents, specialized in screening and evaluating innovative business projects exactly like yours. If they judge your project valuable, these agents decide to provide you with the necessary capital, as well as technical and managerial advice, in exchange for an equity stake in the project. In the standard economics terminology, you are referred to as the entrepreneur, and the specialized agents as the capitalists (such as venture capitalists or business angels). The whole process is usually described as one of entrepreneurial innovation.

A distinctive feature of entrepreneurial investments is their higher volatility over time. In Figure 1, we compare the volatility of entrepreneurial investments provided by venture capitalists (VCs) and private equity (PE) funds with that of corporate R\&D investments and of private fixed capital investments carried out in the most innovative sectors (IT, Healthcare and Energy, where most of the entrepreneurial investments are concentrated; see OECD, 2016, Ch. 8). Figure 1 restricts its focus on the EU-27 (left panel) and on the US (right panel) across the time span 2006-2015. It suggests a more pronounced pattern of boom and bust of entrepreneurial investments. ${ }^{1,2}$

\section{INSERT FIGURE 1 HERE}

In this paper, we propose a model of entrepreneurial innovation that may contribute to rationalize this volatility over time, and we then try to validate empirically its main theoretical claims against the available data on the venture capital market.

We use a simple dynamic model in which an entrepreneurial project (or an innovative, start-up firm) is the outcome of a process of search and matching between the two main actors of the entrepreneurial process: those who come up with new ideas, that we call entrepreneurs; and those who screen, select and fund the most valuable ideas, that we call capitalists (or financiers). An innovative venture is the result of a

\footnotetext{
${ }^{1}$ Volatility is measured as percentage deviation of investment components from their HodrickPrescott trends with smoothing parameters set at 6.25 (see Ravn and Uhlig, 2002).

${ }^{2} \mathrm{~A}$ similar pattern of boom and bust also arises when we restrict the attention to entrepreneurial investments provided by business angels. The figure is available from the authors upon request.
} 
successful matching between an entrepreneur and a capitalist. ${ }^{3}$

In the baseline model, which is a simple extension of the classical Diamond's (1982) coconut model, entrepreneurs are willing to spend their time and intellectual resources to discover a new idea only if they have a chance to meet a capitalist. On the other hand, capitalists are willing to spend their time and intellectual resources to evaluate the profitability of ideas only if they have the chance to meet valuable entrepreneurs. More generally, the return to becoming an entrepreneur (capitalist) is higher, the higher the number of capitalists (entrepreneurs) in the market. Hence, and as usual in the class of search and matching models (Diamond, 1982, Kiyotaki and Wright, 1993), a thick market externality characterizes the market for entrepreneurial finance, in that the number of innovative entrepreneurs (capitalists) is an increasing function in the number of capitalists (entrepreneurs).

We then extend the model and introduce an endogenous fund-raising stage. After having entered into the market, but before the search\&matching stage, capitalists (say, the "general partners") have to decide how much to raise from external investors (say, the "limited partners"). We show that the amount of funds raised by each capitalist positively responds to the number of entrepreneurs, and viceversa. In other words, the model displays strategic complementarity across the two sides of the market, not only on the extensive, but also on the intensive margin. Such strategic complementarity implies the existence of a multiplier effect, whereby the effect of an exogenous shock on the pace of entrepreneurial innovation is magnified by the self-reinforcing nature of the interaction between entrepreneurs and capitalists. ${ }^{4}$

In the second part of the paper, we test empirically the main theoretical claim of the model, that is, the mutual positive interaction across the two sides of the entrepreneurial finance market, for 23 OECD countries plus China over the period 2007-2015. We gather data on (i) the number of early-stage innovative entrepreneurs from the Global Entrepreneurship Monitor (GEM) and on (ii) the total amount of venture capital funds annually raised for each country (mainly from the venture capital associations' reports). We use the following three approaches to estimate the empirical relationship between

\footnotetext{
${ }^{3} \mathrm{~A}$ more thorough justification of this modeling strategy is provided in Section 2, where we further discuss the relation to the existing literature.

${ }^{4}$ The possibility of a multiplier effect in the entrepreneurial finance market has been previously emphasized by Inderst and Muller (2004), with which this paper is closely related. In Inderst and Muller (2004), however, the existence of the multiplier relies on a different theoretical mechanism (see Section 2 below for more on this point).
} 
these two variables at year-country level: fixed effects estimation (FE), two-stage least squares (2SLS), and Arellano-Bond estimation (Arellano and Bond, 1991).

The whole set of results confirm the existence of a statistically and economically significant complementarity between the number of early-stage innovative entrepreneurs and the amount of VC funds annually raised for each country. In particular, we find that a one percentage point increase in the volume of venture capital raised funds (as a share of GDP) raises the number of innovative entrepreneurs (as a share of adult population) by between 1.4 and 3.2 percentage points. Conversely, a one percentage point rise in the number of innovative entrepreneurs (as a share of adult population) increases venture capital fundraising (as a share of GDP) by between 0.009 and 0.015 .

Based on these estimates, we finally carry out a simple quantitative exercise and obtain a value of the multiplier between 1.01 (from the dynamic panel data estimations) and 1.05 (from the static fixed effects model). This number tells us that a shock to either side of the market produces a final effect on the market equilibrium values of entrepreneurs and capitalists which is between $1 \%$ and $5 \%$ higher than it would have produced in a frictionless financial market. Although clearly not exhaustive, this multiplier effect may contribute to rationalize the pronounced volatility of entrepreneurial investments that we have documented in Figure 1.

The goal of this paper is that of modeling and documenting empirically a peculiar market friction characterizing the process of entrepreneurial innovation. In the words of Phelps (2009, p. 50), "the classical supply-and-demand apparatus does not apply to the core market of capitalist economies - the capital market, particularly the market for capital going to entrepreneurs' innovative projects". In this paper, we provide evidence in favor of this statement. In other words, while in a standard frictionless market, demand and supply are independently determined, in this paper we claim theoretically, and verify empirically, the existence of a mutual positive interaction (a "strategic complementarity") between demand and supply in the market for entrepreneurial finance.

The rest of the paper is organized as follows. Section 2 discusses the related literature. Section 3 develops the model. Section 4 carries out the empirical analysis. Section 5 concludes the paper. Proofs are relegated to a technical appendix at the end of the manuscript. 


\section{Related Literature}

This paper is broadly related to a growing macroeconomic literature focusing on the market frictions in the financing of entrepreneurs and on their aggregate implications (see, for instance, Evans and Jovanovic (1989), Cagetti and De Nardi (2006), Matsuyama (2007), Moll (2014); see also Quadrini (2009) and Buera et Al. (2015) for literature reviews). A stream of this literature has recently started exploring the frictions in the entrepreneurial finance market with the help of search theory (Inderst and Muller (2004), Wasmer and Weil (2004), Sorensen (2007), Silveira and Wright (2016) among others). ${ }^{5}$ The fil rouge linking all these contributions is that they depict the financing of entrepreneurial innovation as a process of search and matching between the demand (entrepreneurs) and the supply (capitalists).

We follow this tradition and capture financial market imperfections via search theory. This modeling strategy is inspired by the following argument. Entrepreneurs and capitalists are heterogeneous in terms of skills, location, beliefs, information etc. It then takes time and resources for an entrepreneur to find and convince a financier about the profitability of her business venture; and it takes time and resources for a financier to select the innovative project that she believes is worth financing. As a result, entrepreneurial finance can be depicted as a decentralized market where heterogeneous entrepreneurs and financiers meet bilaterally according to a matching technology. In the words of Phelps (2009, p. 52), "the capital market is a sort of matching process that matches a financier to an entrepreneur who the former sees as having a model compatible with his own model". Search theory is then a convenient modeling tool to capture succinctly the frictions characterizing the entrepreneurial finance market.

Three contributions deserve special mention inside this literature. The first is the work by Inderst and Muller (2004), who build a search and matching model of entrepreneurial innovation that may give rise to a pattern of boom and bust of entrepreneurial investments. Their theory, however, does not rely on the strategic complementarity across the two sides of the entrepreneurial finance market (indeed, in their model the demand for VC funds -as captured by the number of entrepreneurs- is exogenous): ups and downs are instead due to a self-reinforcing relationship between the profitability of entrepreneurial investments, the entry of venture capitalists and the market valuation of start-ups. The second contribution is the one by Brander and de Bettignies (2009),

\footnotetext{
${ }^{5}$ Prior to finance, search theory has been extensively applied to several fields in economics, such as labor economics, monetary theory, and the theory of marriage.
} 
who explain the (sectorial) pattern of boom and bust in VC investments emphasizing the role of learning-by-doing in the behavior of venture capitalists. The third work is that of Michelacci and Suarez (2004), who analyze the relationship between entrepreneurial finance and the stock market development in the framework of an endogenous growth model. Interestingly, the model may generate multiple Pareto-rankable equilibria as a result of a complementarity across the "going public" decisions of start-up firms. To our knowledge, ours is the first paper that models and documents empirically the existence of a complementarity (along both the intensive and the extensive margin) between the demand and the supply of entrepreneurial finance.

\section{The Theoretical Framework}

We now introduce a search and matching model between entrepreneurs and capitalists characterized by four stages: entry decisions, fund-raising (for capitalists only), search, and exit. In the baseline model of Subsection 3.1, we neglect the fund-raising stage to focus exclusively on the participation decisions of entrepreneurs and capitalists. In Subsection 3.2 we introduce fundraising.

\subsection{The Baseline Model}

The theoretical framework that we present in this section transposes the classical Diamond's (1982) coconut model to the entrepreneurial finance market and extends it to a two-sided search structure. The purpose of the model is that of highlighting the nature of the interdependence across the demand side and the supply side of the market.

The world is populated by a measure $E$ of entrepreneurs and a measure $K$ of capitalists who must decide whether to participate or not in a sort of "fair" (or simply market) of entrepreneurial ideas. Time is continuous, and new ideas arrive randomly to the entrepreneurs according to a Poisson process with (exogenous) instantaneous probability $\sigma$. In order for these raw entrepreneurial ideas to become marketable innovations, however, entrepreneurs need the (technical/managerial) support of capitalists.

Once an entrepreneur has come up with a new idea, she has to decide whether to pursue it by participating in the fair, or abandon it and wait for the next idea. To pursue it, each entrepreneur has to pay a cost $c_{E}$, representing the cost of developing and submitting the project to the financiers. This cost is drawn from a (twice continuously differentiable) cumulative distribution function $G^{E}\left(c_{E}\right)$ in the support $\left[0, \overline{c_{E}}\right]$. If the 
entrepreneur pays her own $c_{E}$, she acquires the right to participate in the fair and hence, as we will see, the chance of matching a capitalist and implement her project.

On the other hand, each capitalist sustains an entry $\operatorname{cost} c_{K}$ to participate in the fair of ideas (the cost of screening, evaluating and selecting the entrepreneurial projects). This cost is idiosyncratic across capitalists and distributed according to a (twice continuously differentiable) cumulative distribution function $G^{K}\left(c_{K}\right)$ in the support $\left[0, \overline{c_{K}}\right]{ }^{6}$

To analyze the entry decisions of entrepreneurs and capitalists into the market, we now need to specify the potential benefits that accrue to them if they pay the entry fee. Let $L_{E} \leq E$ and $L_{K} \leq K$ denote, respectively, the endogenous stock of entrepreneurs and capitalists participating in the fair at each instant of time, that is, those that have paid their respective entry cost. $^{7}$ An entrepreneurial venture is the result of a process of successful search and matching between an entrepreneur and a capitalist both attending the fair. We capture the production process of entrepreneurial ventures via the following aggregate matching function:

$$
M=M\left(L_{E}, L_{K}\right),
$$

with $\partial M / \partial L_{j}>0$ and $\partial^{2} M / \partial L_{j}^{2}<0$ for $j=E, K$, implying positive and decreasing marginal returns to both inputs. We also impose $M\left(L_{E}, 0\right)=M\left(0, L_{K}\right)=0$ (that is, the absence of entrepreneurs or capitalists implies zero successful matches).

The instantaneous probability of matching for, respectively, entrepreneurs and capitalists attending the fair, is then given by

$$
\alpha_{E}=\frac{M}{L_{E}} \text { and } \alpha_{K}=\frac{M}{L_{K}} .
$$

The standard assumptions on the first two derivatives of the matching function imply that $\partial \alpha_{j} / \partial L_{j}<0$ and $\partial \alpha_{j} / \partial L_{-j}>0$ for $j=E, K$. That is to say, the matching probability for an entrepreneur decreases with the number of entrepreneurs and increases with the number of capitalists (and the same holds for capitalists).

Without loss of generality, entrepreneurs and capitalists are assumed risk neutral and to discount the future via the exogenous riskless interest rate $r$. At any point in time, entrepreneurs and capitalists can be in two states: either outside or inside the

\footnotetext{
${ }^{6}$ One might alternatively interpret $c_{E}$ and $c_{K}$ as outside options, that is, as the opportunity costs of devoting to entrepreneurial innovation.

${ }^{7}$ Given that our focus will be on the stationary equilibrium of this economy, we drop time subscripts to ease notation.
} 
fair of entrepreneurial ideas. In order to determine the expected benefits from entry, we need to determine the values of both states for both agents. Let us start with entrepreneurs.

For an entrepreneur, the value of being outside the fair (and thus of waiting for a new idea) is denoted by $V_{E}^{0}$ and defined by the following asset equation:

$$
r V_{E}^{0}=\sigma \int_{0}^{c_{E}^{*}}\left(V_{E}^{1}-V_{E}^{0}-c_{E}\right) d G^{E}\left(c_{E}\right),
$$

where $c_{E}^{*}$ is the highest cost for which there is still entry (to be determined at equilibrium), and $V_{E}^{1}$ represents the value of being inside the fair (that is, the expected payoff associated with the entrepreneurial venture for an entrepreneur attending the fair). In turn, $V_{E}^{1}$ is defined by

$$
r V_{E}^{1}=\alpha_{E} \theta \pi+\delta_{E}\left(V_{E}^{0}-V_{E}^{1}\right),
$$

where $\pi$ represents total profits originating from the entrepreneurial venture, $\theta \in(0,1)$ is the entrepreneurs' fraction of these profits, and $\delta_{E}$ is an exogenous separation rate for entrepreneurs.

These asset equations have the usual interpretations. Equation (3) tells us that, for an entrepreneur, the flow of utility from waiting for a new idea is equal to the instantaneous probability of a new idea times the corresponding payoff, which is given by the capital gain associated with participating in the fair minus the entry cost. Equation (4) says that the flow of utility from venturing into entrepreneurship is equal to the probability of a successful matching with a capitalist times the payoff associated with this chance, plus the expected capital gain (or loss) deriving from exiting from the fair. Note that, in the two expressions above, we have decided to focus directly on the steady state, as we have imposed $\dot{V}_{E}^{h}=0$ for $h=0,1$.

Three implicit assumptions in (4) are worth noticing. First, every match becomes a successful entrepreneurial idea, that is to say, every venture-backed firm raises positive profits. Indeed, observation suggests that only a small fraction of funded projects reaches that stage (anecdotal evidence for VC suggests that this fraction is below 20\%). This hypothesis could be easily relaxed by introducing an implementation stage (as, for instance, in Silveira and Wright, 2016). The second assumption is that, whether or not a successful matching has occurred, all entrepreneurs have a chance $\left(\delta_{E}\right)$ of exiting from the market. In particular, by focusing on the region in which $\delta_{E} \geq \alpha_{E}$, we capture the simple fact of life that some entrepreneurial projects may be discarded by capitalists. 
The third assumption is that, after exiting from the fair, entrepreneurs go back to the initial "inventive" stage (say, by selling their idea -or patent- to a firm which will start production in case of successful matching). ${ }^{8}$ This endless circular process is meant to represent the so called venture capital cycle described by Gompers and Lerner (2004).

We are now ready to characterize the entrepreneurs' net expected benefit from participating into the fair of entrepreneurial ideas. By entering into the fair, an entrepreneur loses $V_{E}^{0}$ and gains $V_{E}^{1}$. As a result, her net expected benefit is measured by the difference $V_{E}^{1}-V_{E}^{0}$. Subtracting (3) from (4), and solving the resulting equation by $V_{E}^{1}-V_{E}^{0}$, we obtain

$$
V_{E}^{1}-V_{E}^{0}=\frac{\alpha_{E} \theta \pi+\sigma \int_{0}^{c_{E}^{*}} c_{E} d G^{E}\left(c_{E}\right)}{\delta_{E}+r+\sigma G^{E}\left(c_{E}^{*}\right)} .
$$

It is easy to prove that the expression above is increasing in $\alpha_{E}$, and thus in $L_{K}$. The intuition is straightforward: the higher the number of capitalists, the higher the matching probability for an entrepreneur, and hence the higher her return from participating in the innovation process.

Let us now turn to capitalists. Their expected payoff associated with being outside the fair is denoted by $V_{K}^{0}$ and defined by the following asset equation:

$$
r V_{K}^{0}=\int_{0}^{c_{K}^{*}}\left(V_{K}^{1}-V_{K}^{0}-c_{K}\right) d G^{K}\left(c_{K}\right)
$$

where $c_{K}^{*}$ is the highest cost for which there is still entry for capitalists, and where $V_{K}^{1}$ represents the expected value from participating in the fair of entrepreneurial ideas. This value is captured by ${ }^{9}$

$$
r V_{K}^{1}=\alpha_{K}(1-\theta) \pi+\delta_{K}\left(V_{K}^{0}-V_{K}^{1}\right)
$$

where $\delta_{K}$ is the exogenous separation rate for capitalists, while $(1-\theta) \pi$ is the capitalists' fraction of the profits prevailing in the market (again, along the steady state it is $\dot{V}_{K}^{h}=0$ for $\left.h=0,1\right)$.

\footnotetext{
${ }^{8}$ In the business literature, individuals with such characteristics are sometimes referred to as a serial entrepreneurs. We might also portray them as Schumpeterian entrepreneurs, given that they dedicate exclusively to innovative ventures.

${ }^{9}$ The implicit assumption here is that each capitalist can enter into one and only one project at a time, and that each entrepreneur needs one and only one capitalist.
} 
In expression (7), we have implicitly supposed that the cost of financing the entrepreneurial project is null (so that the capitalists' contribution to the venture is technical and/or managerial but not financial). This hypothesis will be relaxed later on.

Capitalists' expected benefit from fair attendance is measured by the difference $V_{K}^{1}-V_{K}^{0}$. Again, solving the system made up of (6) and (7) for $V_{K}^{1}-V_{K}^{0}$, we obtain

$$
V_{K}^{1}-V_{K}^{0}=\frac{\alpha_{K}(1-\theta) \pi+\int_{0}^{c_{K}^{*}} c_{K} d G^{K}\left(c_{K}\right)}{\delta_{K}+r+G^{K}\left(c_{K}^{*}\right)},
$$

which is increasing in $\alpha_{K}$, and thus in $L_{E}$.

As usual in this class of models, the allocation of profits between entrepreneurs and capitalists, as captured by the parameter $\theta$, is determined through Nash bargaining. ${ }^{10}$ The optimal sharing rule, $\theta^{*}$, is obtained as

$$
\theta^{*}=\arg \max S_{E}^{\phi} S_{K}^{1-\phi}
$$

where $S_{E}$ and $S_{K}$ denote the entrepreneurs' and the capitalists surpluses to a successful matching, and where $\phi$ denotes the bargaining power of entrepreneurs. In this simple model, in which agents separate exogenously at rates $\delta_{E}, \delta_{K}$, the surpluses (that is, the net gains from a match) are simply given by the profit shares, $S_{E}=\theta \pi$ and $S_{K}=$ $(1-\theta) \pi$. Hence, solving the maximum problem in $(9)$, we simply obtain $\theta^{*}=\phi{ }^{11}$

\subsubsection{Complementarities in Entrepreneurial Finance}

We are now ready to characterize the optimal entry decisions of entrepreneurs and capitalists as well as the stationary equilibrium resulting from their optimal choice behavior. At each point in time, the choice of the $E-L_{E}$ entrepreneurs who are outside the fair, as to whether to pursue their project or abandon it, depends on the relative costs and benefits of the project. The cost $c_{E}$ is distributed according to $G^{E}$, while the benefit is measured by the difference $V_{E}^{1}-V_{E}^{0}$. There exists a marginal

\footnotetext{
${ }^{10}$ An extensive literature has focused on the contractual content of the relationship between entrepreneurs and capitalists (for instance in the presence of moral hazard and adverse selection): see, among others, Keuschnigg (2003), Inderst and Muller (2004), Michelacci and Suarez (2004), Jovanovic and Szentes (2013), Silveira and Wright (2016). On this specific issue see also Gompers and Lerner (2000).

${ }^{11}$ As we will see, in the extended model, $\theta^{*}$ will be a more complex function of the endogenous variables of the model.
} 
entrepreneur for whom $c_{E}^{*}=V_{E}^{1}-V_{E}^{0}$. Substituting for the expression given in (5) (and for $\theta^{*}=\phi$ ), we obtain

$$
c_{E}^{*}=\frac{\alpha_{E} \phi \pi+\sigma \int_{0}^{c_{E}^{*}} c_{E} d G^{E}\left(c_{E}\right)}{\delta_{E}+r+\sigma G^{E}\left(c_{E}^{*}\right)} .
$$

All entrepreneurs whose entry cost is lower than $c_{E}^{*}$ find it profitable to participate in the fair. The expression above links the threshold $\operatorname{cost} c_{E}^{*}$ to the probability of successful matching for entrepreneurs $\alpha_{E}$ : a higher $\alpha_{E}$ causes an increase in the cutoff value of the entry $\operatorname{cost} c_{E}^{*} \cdot{ }^{12}$

Symmetrically, the chance of a successful matching with an entrepreneur is worth $V_{K}^{1}-V_{K}^{0}$ to a capitalist. Given that the cost of this chance $c_{K}$ is distributed according to $G^{K}$, there exists a marginal capitalist for whom $c_{K}^{*}=V_{K}^{1}-V_{K}^{0}$. Substituting for the expression given in (8) and solving by $c_{K}^{*}$, we obtain

$$
c_{K}^{*}=\frac{\alpha_{K}(1-\phi) \pi+\int_{0}^{c_{K}^{*}} c_{K} d G^{K}\left(c_{K}\right)}{\delta_{K}+r+G^{K}\left(c_{K}^{*}\right)} .
$$

All capitalists whose entry cost is lower than $c_{K}^{*}$ find it profitable to participate in the fair. This expression captures the positive relationship between $\alpha_{K}$ and $c_{K}^{*}$.

Finally remind that, along the steady state, the inflows into the fair of ideas must be equal to the outflows for both entrepreneurs and capitalists, that is

$$
\dot{L}_{E}=\sigma\left(E-L_{E}\right) G^{E}\left(c_{E}^{*}\right)-\delta_{E} L_{E}=0
$$

and

$$
\dot{L}_{K}=\left(K-L_{K}\right) G^{K}\left(c_{K}^{*}\right)-\delta_{K} L_{K}=0 .
$$

Equation (12) captures the evolution of entrepreneurs over time. Along the steady state, the number of entrepreneurs deciding to enter into the fair $\left(\sigma\left(E-L_{E}\right) G^{E}\left(c_{E}^{*}\right)\right)$

\footnotetext{
${ }^{12}$ Define

$$
W\left(c_{E}^{*}, \alpha_{E}\right) \equiv \frac{\alpha_{E} \phi \pi+\sigma \int_{0}^{c_{E}^{*}} c_{E} d G^{E}\left(c_{E}\right)}{\delta_{E}+r+\sigma G^{E}\left(c_{E}^{*}\right)}-c_{E}^{*}
$$

as the implicit function of $c_{E}^{*}$ with respect to $\alpha_{E}$. It is immediate to prove, via the implicit function theorem, that $d c_{E}^{*} / d \alpha_{E}>0$.
} 
must equalize the number of entrepreneurs who exit from the fair (whether successfully or not, $\left.\delta_{E} L_{E}\right)$. An analogous interpretation can be given to (13).

Equation (12) can be interpreted as a positive relationship between $L_{E}$ and $c_{E}^{*}{ }^{13}$ A higher value of $c_{E}^{*}$ implies greater entry in the entrepreneurial market. To maintain the steady state, the number of exits must correspondingly increase. Hence, a higher value of $L_{E}$ is required for equation (12) to hold. The same is true, mutatis mutandis, for equation (13) capturing $L_{K}$ as a positive function of $c_{K}^{*}$.

Before defining a stationary equilibrium for this economy, let us characterize the type of interdependence between entrepreneurs and capitalists that is implied by this model. The number of entrepreneurs venturing in innovative projects depends on the number of capitalists deciding to back these projects, as this affects the chance of a successful matching. This relationship is captured by a best-response function for entrepreneurs, $L_{E}\left(L_{K}\right)$, that is implicitly defined by the system made up of (10) and (12). On the other hand, the number of capitalists devoting their time and resources to screening and evaluating innovative projects depends on how many entrepreneurs attend the fair. This relationship is given by the capitalists' best-response function, $L_{K}\left(L_{E}\right)$, defined by the system made up of (11) and (13). We now prove that these two best-response functions are positively sloped.

Lemma 1. Entrepreneurs and capitalists are strategic complements, in that the number of entrepreneurs attending the fair of entrepreneurial ideas is an increasing function of the number of capitalists attending the fair, and viceversa: $d L_{j} / d L_{-j}>0$ $\forall j=E, K$.

Intuitively, a higher number of capitalists participating in the fair raises the chance of a successful matching for entrepreneurs, it makes their participation more profitable, and thus it brings about an increase in the number of entrepreneurs (and viceversa). This complementarity is strategic, as it is the result of endogenous and interdependent entry choices of the two types of agents. This relation will be verified empirically in the next section. We are now ready to define a stationary equilibrium for the baseline model and to study the parameter conditions for its existence.

Definition. A stationary equilibrium for this economy is any positive 4-tuple $\left(L_{E}^{*}, L_{K}^{*}, c_{E}^{*}, c_{K}^{*}\right)$ that solves the four equations (10), (11), (12), (13).

\footnotetext{
${ }^{13}$ This will be explicitly shown in the proof of Lemma 1.
} 
Given that we have not specified the returns to scale of (1), the model may also admit more than one stationary equilibrium (Diamond, 1982, 1984). Moreover, a stationary equilibrium is properly defined when the following conditions are satisfied: (i) $V_{j}^{0}>0$; (ii) $V_{j}^{1}-V_{j}^{0}>0$; (iii) $S_{j}>0$ for $j=E, K$. The first condition states that the asset value of being outside the fair must be positive. ${ }^{14}$ The second condition is a market-participation constraint: given that agents pay a positive entry cost $\left(c_{j}\right)$, the entry benefit $\left(V_{j}^{1}-V_{j}^{0}\right)$ must be positive. Finally, the third condition is a deal-making condition, stating that the surplus originating from the deal must be positive for both agents. In Appendix A, we work out the parameter restrictions ensuring that these conditions are fulfilled: we show that conditions (ii) and (iii) are always satisfied in our model, and we characterize a threshold value of profit $\bar{\pi}$ such that, for any $\pi>\bar{\pi}$, condition (i) is satisfied. ${ }^{15}$ We now pose the following

Assumption 1. We restrict the attention to a parameter space such that $\pi>\bar{\pi}$, where $\bar{\pi}=\max \left\{\bar{\pi}^{E}, \bar{\pi}^{K}\right\}$ and $\bar{\pi}^{j}: V_{j}^{0}\left(\bar{\pi}^{j}\right)=0$ for $j=E, K$.

Let us now emphasize a general property of the stationary equilibrium. The presence of strategic complementarities across the endogenous variables of the model makes the equilibrium subject to a multiplier effect (Cooper, 1999). For instance, a decrease in $\sigma$ directly reduces the payoff to entrepreneurial activities. This, however, is not the end of the story: the lower number of entrepreneurs weakens the incentive to become capitalist, which in turn further lowers the incentive to entrepreneurship. This process continues ad infinitum, describing a vicious circle whereby the aggregate response to the shock is stronger than the initial partial response. More formally, consider $L_{j}=f_{j}\left(L_{-j}, \rho_{j}\right)$ as the (positively sloped) reaction function of agents of type $j$ with respect to the agents of type $-j$ (for $j=E, K$ ), parameterized by $\rho_{j}$ capturing any feature that affects $L_{j}$ other than changes in $L_{-j}$. We are now ready to state the following

Corollary 1. A multiplier effect characterizes the process of entrepreneurial finance, in that the total equilibrium response of entrepreneurs and capitalists to an

\footnotetext{
${ }^{14}$ One may think that both entrepreneurs and capitalists always have an outside option equal to zero.

${ }^{15}$ Since we have not specified an explicit functional form for the matching technology, we write such restrictions implicitly.
} 
exogenous shock is greater than the partial response:

$$
\frac{d L_{j}}{d \rho_{j}}=m \frac{\partial L_{j}}{\partial \rho_{j}} \text { for } j=E, K
$$

where

$$
m=\frac{1}{1-\frac{d L_{E}}{d L_{K}} \frac{d L_{K}}{d L_{E}}}>1
$$

As a result of this multiplier effect, any factor that affects the entrepreneurs' and/or the capitalists' payoff may have a strong impact on the innovation process. We further discuss this issue in the next subsection.

Finally, let us close this section with a comparative statics analysis. The next lemma investigates how $L_{E}^{*}$ and $L_{K}^{*}$ react to changes in the main parameters of the baseline model, namely, $\sigma, \pi, \phi$ and $\delta_{j}$ for $j=E, K$.

Lemma 2. We have

$$
\text { (i) } \frac{d L_{j}^{*}}{d \sigma}>0 \text {; (ii) } \frac{d L_{j}^{*}}{d \pi}>0 \text {; (iii) } \frac{d L_{j}^{*}}{d \delta_{j}}, \frac{d L_{j}^{*}}{d \delta_{-j}}<0 \text {; (iv) } \frac{d L_{j}^{*}}{d \phi} \gtrless 0 \text {, for } j=E, K \text {. }
$$

Lemma 2 tells us that the equilibrium number of entrepreneurs (capitalists) responds positively to both innovation probability $(\sigma)$ and profits $(\pi)$, and negatively to the separation rate of either type of agents $\left(\delta_{j}, \delta_{-j}\right)$. The effect of a change in the bargaining power $(\phi)$ is, instead, ambiguous on both entrepreneurs and capitalists. These results are intuitive: (i) an increase in the arrival rate of innovation $(\sigma)$ has a positive impact on $L_{E}$ and indirectly, through the strategic complementarity, on $L_{K}$; (ii) an increase in innovation profits $(\pi)$ has a positive effect on both $L_{E}$ and $L_{K}$ (both directly and indirectly); (iii) a rise in the separation rate of agents $j\left(\delta_{j}\right)$ has a negative direct effect on $L_{j}$ and a negative indirect effect on $L_{-j}$ (again, because of the strategic complementarity); (iv) a rise in the bargaining power of entrepreneurs $(\phi)$ has a positive direct impact and a negative indirect impact on $L_{E}$ (running through $L_{K}$ ): the overall effect is ambiguous and depends on deep technological parameters of the model (such as the input elasticities of the matching function).

\subsection{Introducing the Fund-Raising Stage}

In the baseline model, the capitalists' contribution was technical/managerial, but not financial. We now extend the basic framework to incorporate a financing stage. Suppose 
that capitalists have to bear a start-up cost $C$ to launch the entrepreneurial project, where $C$ is distributed according to $H^{C}$ in the support $[0, \bar{C}]$. Also suppose that, to cover this cost, capitalists have to raise funds from external investors (the so-called "limited partners" of the venture capital fund). In particular, after having entered into the fair, but before knowing the amount of the start-up cost $C$, capitalists can raise an (endogenous) amount of funds equal to $F$. We now determine the optimal $F^{*}$ and characterize the new stationary equilibrium.

Capitalists (re-)enter the fund-raising stage with $\hat{F}_{-1}$, representing the (possible) excess cash and/or the proceeds, both originating from the previous cycle. ${ }^{16}$ They can only finance those projects whose $C \leq \hat{F}_{-1}+F$ and have to pass all the others. The value function of being in the fund-raising stage (logically in-between entry and matching) with residual capital $\hat{F}_{-1}$ can be expressed as

$$
J_{K}\left(\hat{F}_{-1}\right)=\hat{F}_{-1}+V_{K}^{1}(F)-F
$$

This function tells us that, for the capitalist at this stage, the venture is worth $V_{K}^{1}(F)$ - that is, the value of being inside the fair after having raised an amount $F$, to be determined below- plus what is left from the past round, minus the (endogenous) amount of capital just raised in this cycle. We now characterize the expression for $V_{K}^{1}(F)$. With a slight abuse of notation, we will write $V_{K}^{0}(F), V_{K}^{1}(F), \theta(F)$ as simply $V_{K}^{0}, V_{K}^{1}, \theta$.

Capitalists' asset equations defining $V_{K}^{0}, V_{K}^{1}$ are

$$
r V_{K}^{0}=\int_{0}^{c_{K}^{*}}\left(V_{K}^{1}-V_{K}^{0}-c_{K}\right) d G^{K}\left(c_{K}\right)
$$

and

$$
r V_{K}^{1}=\alpha_{K} \int_{0}^{\hat{F}_{-1}+F}\left[(1-\theta) \pi+\hat{F}_{-1}+F-C\right] d H^{C}+\delta_{K}\left(V_{K}^{0}-V_{K}^{1}\right) .
$$

In the last equation, the argument of the integral is the new payoff associated with a successful matching. The integral over $C$ is only up to $\hat{F}_{-1}+F$ given that, for any

\footnotetext{
${ }^{16}$ The basic formalization of the fund-raising problem is inspired by Silveira and Wright (2016). Differently from theirs, however, our focus is on the "long run" (in the specific sense that, in our model, the number of capitalists is not fixed but endogenously determined). Moreover, to capture the financing cycle, we here suppose that $\hat{F}_{-1}$ is not consumed/returned to the general partners at the end of the cycle but remains available to the capitalists for the current cycle of investment. The solution to the problem changes accordingly.
} 
$C>\hat{F}_{-1}+F$, projects cannot be activated. After the usual algebraic steps on the two asset equations, we can finally write $V_{K}^{1}$ as

$$
V_{K}^{1}=\frac{\alpha_{K}\left[r+G^{K}\left(c_{K}^{*}\right)\right] \int_{0}^{\hat{F}_{-1}+F}\left[(1-\theta) \pi+\hat{F}_{-1}+F-C\right] d H^{C}-\delta_{K} \int_{0}^{c_{K}^{*}} c_{K} d G^{K}\left(c_{K}\right)}{r\left[\delta_{K}+r+G^{K}\left(c_{K}^{*}\right)\right]} .
$$

At equilibrium, a no-arbitrage condition holds that states that the expected present value of committing $F^{*}$ into an entrepreneurial project must be equal to the present value of investing $F^{*}$ in a risk-free asset, that is:

$$
V_{K}^{1}\left(F^{*}\right)=F^{*}
$$

The rest of the model follows, mutatis mutandis, the one developed in Subsection 3.1. The entrepreneurs' decision problem is captured by the following pair of asset equations:

$$
\begin{gathered}
r V_{E}^{0}=\sigma \int_{0}^{c_{E}^{*}}\left(V_{E}^{1}-V_{E}^{0}-c_{E}\right) d G^{E}\left(c_{E}\right) \\
r V_{E}^{1}=\alpha_{E} \theta \pi H^{C}\left(\hat{F}_{-1}+F\right)+\delta_{E}\left(V_{E}^{0}-V_{E}^{1}\right)
\end{gathered}
$$

where the only difference lies in the second equation, in which the expected payoff from matching is now subject to a further layer of uncertainty concerning whether or not the capitalist has enough money to finance the project -which is why $\alpha_{E} \theta \pi$ is multiplied by $H^{C}\left(F_{-1}+F\right)$, denoting the cumulative probability that $C$ is lower than $\hat{F}_{-1}+F$.

Finally, consider the Nash bargaining problem. The capitalists' surplus can be expressed as

$$
S_{K}=(1-\theta) \pi+\hat{F}_{-1}+F-C
$$

while the entrepreneurs' surplus is

$$
S_{E}=\theta \pi H^{C}\left(\hat{F}_{-1}+F\right) .
$$

Again, the solution to the Nash bargaining problem is the value $\theta^{*}$ that maximizes the product $S_{E}^{\phi} S_{K}^{1-\phi}$, where $\phi$ is the entrepreneurs' bargaining power. Solving the maximum problem, we obtain the implicit expression for $\theta^{*}$ as

$$
\theta^{*} \pi=\frac{\phi\left(\pi+\hat{F}_{-1}+F-C\right)}{(1-\phi) H^{C}\left(\hat{F}_{-1}+F\right)+\phi} .
$$




\subsubsection{Complementarities in Entrepreneurial Finance (Extended)}

We can now describe the entry behavior of entrepreneurs and capitalists. Working on the two pairs of capitalists' and entrepreneurs' asset equations, we obtain the two expressions for the net expected benefit from entry for both capitalists $\left(V_{K}^{1}-V_{K}^{0}\right)$ and entrepreneurs $\left(V_{E}^{1}-V_{E}^{0}\right)$. Plugging these expressions into the two optimal entry conditions (still defined by $c_{K}^{*}=V_{K}^{1}-V_{K}^{0}$ and $c_{E}^{*}=V_{E}^{1}-V_{E}^{0}$ ), we finally obtain

$$
c_{K}^{*}=\frac{\alpha_{K} \int_{0}^{\hat{F}_{-1}+F}\left[(1-\theta) \pi+\hat{F}_{-1}+F-C\right] d H^{C}+\int_{0}^{c_{K}^{*}} c_{K} d G^{K}\left(c_{K}\right)}{\delta_{K}+r+G^{K}\left(c_{K}^{*}\right)}
$$

for capitalists and

$$
c_{E}^{*}=\frac{\alpha_{E} \theta \pi H^{C}\left(\hat{F}_{-1}+F\right)+\sigma \int_{0}^{c_{E}^{*}} c_{E} d G^{E}\left(c_{E}\right)}{\delta_{E}+r+\sigma G^{E}\left(c_{E}^{*}\right)}
$$

for entrepreneurs. Finally, the evolution over time of both types of agents is still governed by (12) and (13).

A stationary equilibrium for this economy is a 6 -tuple $\left(L_{E}^{*}, L_{K}^{*}, c_{E}^{*}, c_{K}^{*}, \theta^{*}, F^{*}\right)$ that solves the 6 equations given by (12), (13), (15), (16), (17), (18). ${ }^{17}$ The existence conditions for a stationary equilibrium are still those enunciated in the baseline model, that is, (i) $V_{j}^{0}>0$, (ii) $V_{j}^{1}-V_{j}^{0}>0$, (iii) $S_{j}>0$ for $j=E, K$. As in the baseline model, conditions (ii) and (iii) are always satisfied, while there exists a threshold value of profit $\overline{\bar{\pi}}$ above which condition (i) is satisfied (again, refer to Appendix A for the details). We pose the following

Assumption 2. We restrict the attention to a parameter space such that $\pi>\overline{\bar{\pi}}$, where $\overline{\bar{\pi}}=\max \left\{\overline{\bar{\pi}}^{E}, \overline{\bar{\pi}}^{K}\right\}$ and $\overline{\bar{\pi}}^{j}: V_{j}^{0}\left(\overline{\bar{\pi}}^{j}\right)=0$ for $j=E, K$.

The next proposition analyzes the nature of the interdependence between the demand side of the entrepreneurial finance market, as captured by $L_{E}$, and the supply

\footnotetext{
${ }^{17}$ It can be proven that the comparative statics analysis on $L_{E}^{*}$ and $L_{K}^{*}$ contained in Lemma 2 is still valid in the extended model. Moreover, the same results hold for the equilibrium fund size $F^{*}$ defined in (15): $F^{*}$ responds positively to both innovation probability $(\sigma)$ and profits $(\pi)$, and negatively to the separation rate of either type of agents $\left(\delta_{E}, \delta_{K}\right)$; the effect of a change in the bargaining power $(\phi)$ is, instead, ambiguous. We omit the proofs of these statements as they are not central to the paper. Details are, however, available upon requests from the authors.
} 
side, as captured by $L_{K}$ and $F$. Let us first characterize the three best-response functions (see the proof of Proposition 1 in Appendix A for details). Function $L_{E}\left(L_{K}, F\right)$ is implicitly defined by the system made up of (18) and (12) after substituting for $\theta^{*}$ given in (16) into (18). Function $L_{K}\left(L_{E}, F\right)$ is implicitly defined by the system made up of (17) and (13) after substituting for $\theta^{*}$ given in (16) into (17). Function $F\left(L_{E}, L_{K}\right)$ is implicitly defined by $(15)$ after substituting for $V_{K}^{1}(F)$ as given in (14). We can now state the following

Proposition 1. (i) The number of capitalists attending the fair as well as the amount raised by each capitalist are increasing functions of the number of entrepreneurs attending the fair: a) $\left.d L_{K} / d L_{E}>0, \mathrm{~b}\right) d F / d L_{E}>0$. (ii) The number of entrepreneurs attending the fair is an increasing function of both the number of capitalists attending the fair and of the amount of funds that they raise: a) $d L_{E} / d L_{K}>0$, b) $d L_{E} / d F>0$.

Proposition 1 contains two distinct findings. First, it confirms the finding of Lemma 1 (points (i-a) and (ii-a) of the proposition). This is not trivial given that, in this model extension, we need to take into account the total impact that each endogenous variable has on the others. For instance, $L_{E}$ affects $L_{K}$ not only directly - through the matching probability, as in the baseline model -, but also indirectly - through its effect on $F$. Point (i-a), then, proves that the total impact of $L_{E}$ on $L_{K}$ is strictly positive. Secondly, Proposition 1 shows that, in the entrepreneurial finance market, a complementary relation between demand and supply holds not only on the extensive but also on the intensive margin, as the amount of funds raised by each capitalist responds positively to the number of entrepreneurial ideas, and viceversa (points (i-b) and (ii-b)). The findings of this proposition will be subject to empirical scrutiny in the next section.

Because of the strategic complementarity between the demand side and the supply side proven in Proposition 1, also the stationary equilibrium of the extended model is characterized by the presence of a multiplier effect. Formally, consider $L_{E}\left(L_{K}, F, \rho_{E}\right)$ as the reaction function of entrepreneurs as defined above, and parameterized by $\rho_{E}$ capturing any feature that affects $L_{E}$ other than changes in either $L_{K}$ or $F$. This function represents the demand side of the entrepreneurial finance market. Also define $\Omega_{K}\left(L_{E}, \rho_{K}\right) \equiv L_{K}(\cdot) \cdot F(\cdot)$ as the product of the capitalists' reaction function $\left(L_{K}(\cdot)\right)$ and of the fund size $(F(\cdot))$ as defined above, and where $\rho_{K}$ captures any feature that affects $\Omega_{K}$ other than changes in $L_{E}$. This function represents the supply side of the market. Changes in $\rho_{E}$ and $\rho_{K}$ are then meant to represent exogenous shocks, 
respectively, to the demand and to the supply side of entrepreneurial finance. We are now ready to state the following

Corollary 2. A multiplier effect characterizes the process of entrepreneurial finance, in that the total equilibrium response of the demand and the supply to an exogenous shock is greater than the partial response:

$$
\text { (i) } \frac{d L_{E}}{d \rho_{E}}=m_{E} \frac{\partial L_{E}}{\partial \rho_{E}} \text { and }(i i) \frac{d \Omega_{K}}{d \rho_{K}}=m_{K} \frac{\partial \Omega_{K}}{\partial \rho_{K}}
$$

where $m_{E}, m_{K}>1$.

Because of this multiplier effect, any shock on the demand or on the supply has an amplified effect on the level of innovative activity. This mutual, self-reinforcing, interaction between entrepreneurs and capitalists contributes to explain the high volatility of entrepreneurial investments that we have documented in Figure 1. To use a phrase from Summers (1988), the entrepreneurial equilibrium is fragile, in the sense that it is potentially subject to large fluctuations in the level of activity. In the next section, we give a quantitative estimate to this multiplier effect for the venture capital market.

\section{Empirical Evidence of Complementarities}

This section is devoted to the empirical validation of the model's findings contained in Proposition 1. We introduce the dataset (subsection 4.1), describe the empirical strategy (subsection 4.2), present the results (subsection 4.3), provide a quantitative estimate of the multiplier effect (subsection 4.4) and carry out an empirical analysis based on alternative measures of demand and supply to verify the robustness of our findings (subsection 4.5).

\subsection{Data}

Proposition 1 establishes a relationship among three endogenous variables: $L_{E}$ as the stock of innovative entrepreneurs, $L_{K}$ as the stock of active capitalists, $F$ as the amount of capital raised by each capitalist. A key challenge of our analysis is the search of suitable data to measure these variables. For reasons of data availability and of prominence for the phenomenon of interest, we focus on a sample of 23 OECD countries (Australia, Austria, Belgium, Canada, Denmark, Finland, France, Germany, Greece, 
Ireland, Israel, Italy, Japan, Luxembourg, Netherlands, Norway, Poland, Portugal, Spain, Sweden, Switzerland, United Kingdom and United States) plus China, observed over the period 2007-2015.

The share of early-stage innovative entrepreneurs $\left(l_{E}\right)$. To gain a proxy for the demand of entrepreneurial capital, we gather information from the Global Entrepreneurship Monitor (GEM). The GEM study is an annual survey collecting harmonized data on entrepreneurial aspirations, attitudes and activities of individuals across a wide range of countries (OECD, 2009). It has become a major source for internationally comparative research on entrepreneurship (see, for instance, Koellinger et al. (2007), Koellinger and Thurik (2012), Ardagna and Lusardi (2010)).

We classify an individual as early-stage innovative entrepreneur when this individual meets simultaneously the two following conditions: (i) being a nascent entrepreneur or owner-manager of a new business, (ii) indicating that their product or service is new to at least some customers. We now provide some details about these two requirements.

From the GEM database, we first extract the early-stage entrepreneurial activity indicator, which gives the percentage of 18-64 population who are either nascent entrepreneur or owner-manager of a new business and which is available for the years 2007-2015 in an unbalanced form. ${ }^{18}$ This indicator, however, adopts a broad definition of entrepreneurs (for instance, considering as entrepreneurs also those who are about to open retail store businesses). To restrict our focus on innovative entrepreneurs only, we then combine it with the new product/process early-stage entrepreneurial activity indicator, comprising those entrepreneurs who declare that either their product or the production process is innovative (see Appendix B for details about the exact questions we select). This way, we obtain a proxy for $L_{E}$.

Matching these data with the size of the working-age population by year and country extracted from the Eurostat database, we finally obtain the share of early-stage innovative entrepreneurs as the percentage of working age individuals (between 18 and 64 years old) involved in "innovative early-stage entrepreneurial activity", that is, those who are either nascent entrepreneurs or owner-managers of a new business and indicate that their product or production process is new. We denote it by $l_{E} \equiv L_{E} /$ Adult pop.

\footnotetext{
${ }^{18}$ To be qualified as nascent entrepreneur, one must be actively involved in setting up a business they will own or co-own (this business has not paid salaries, wages, or any other payments to the owners for more than three months); instead, those who are currently owning and managing a running business that has paid salaries, wages, or any other payments to the owners for more than three months, but not more than 42 months, are qualified as owner-managers of a new business.
} 
A summary description of $l_{E}$ across our sample of countries over the period 2007-2015 is provided in Table 1 .

\section{INSERT TABLE 1 HERE}

Throughout 2007-2015, the percentage of early-stage innovative entrepreneurs of the median country is estimated at $3.6 \%$, with relevant cross-country and over-time differences. This percentage has been roughly stable or decreasing until 2010 and starts increasing from 2011, especially in such countries as Austria, Belgium, Canada, France, Ireland, Israel, Sweden and UK (where the difference in the percentage of early-stage innovative entrepreneurs between 2015 and 2007 is above 1 percentage point).

These figures are broadly consistent with those coming from the most recent OECD findings on the patenting activity of young firms. The OECD Science, Technology and Industry Scoreboard (2013) reports the share of young patenting firms and the share of patents filed by young patenting firms for selected OECD countries (namely, Austria, Belgium, Canada, Switzerland, Germany, Spain, Finland, France, UK, Ireland, Italy, Japan, the Netherlands, Norway, Sweden and the United States) between 2009 and 2011. The highest shares of young patenting firms are in Ireland, Norway, the Netherlands, Sweden and UK (over 30\%, in descending order); the countries with a share of young patenting firms below one half that of the top listed countries are Switzerland and Japan (with a percentage below 10\%), followed by Italy (around 15\%). These figures are in line with our data on innovative entrepreneurial activities coming from the GEM database. If we restrict the attention to the early-stage innovative entrepreneurs for the same sample of countries during the same three years (20092011), we find that Austria, Canada, Ireland, the Netherlands, Norway and the US are characterized by a higher percentage of early-stage innovative entrepreneurs compared to the median (all above 3\%). At the other extreme, the countries with the lowest rate of early-stage entrepreneurs reporting innovation activities are Italy and Japan (with a rate below $1.5 \%$ ).

The share of capital raised for entrepreneurial innovation $\left(l_{K}\right)$. To obtain a proxy for the supply of entrepreneurial capital, we focus on the venture capital industry. ${ }^{19}$ Theory suggests a complementary relationship between $L_{E}$ on the one

\footnotetext{
${ }^{19}$ Key references on venture capital include Gompers and Lerner (2004) and Da Rin et Al. (2011). The relative importance of venture capital to spur entrepreneurial investments (as compared to more traditional sources of capital) has been recently analyzed by Cole et Al. (2015).
} 
hand, and $L_{K}$ and $F$ on the other hand. While we do not have specific data on $F$ for each venture capital firm, we do have data, at country level and over the period 2007-2015, for the product variable $L_{K} \cdot F$, that is, for the amount of financial funds annually raised by all venture capital firms in each country.

For European countries, we have gathered information from the European Venture Capital Association (EVCA), which provides the most comprehensive database of European private equity and venture capital statistics in cooperation with PricewaterhouseCoopers. This database has been increasingly exploited for research purposes (see, for instance, Bottazzi et al. (2008, 2016)). For the majority of the remaining countries (Australia, Canada, Israel, Japan, United States), data are obtained from the annual reports of each Venture Capital Association. In particular, data for the United States are based on the aggregate statistics published by the National Venture Capital Association (NVCA) in cooperation with Thomson Financial Securities. These data have also been extensively used in entrepreneurial studies (see, for instance, Bottazzi and Da Rin (2002) for a joint use of EVCA and NVCA databases). Finally, data on China have been collected from Preqin data. The same sources have been utilized to collect the amount of financial funds annually raised by private equity firms, which will be adopted as a control variable.

Dividing $L_{K} \cdot F$ by the GDP, we obtain the second key variable of our empirical exercise, that we denote by $l_{K}$. A summary description of $l_{K}$ across our sample of countries over the period $2007-2015$ is provided in Table 2.

\section{INSERT TABLE 2 HERE}

In our sample, VC raised funds represent a small percentage of GDP, e.g. often less than $0.05 \%$. Notable exceptions are, in descending order, Israel, United States and China where this percentage stands above $0.1 \%$. Looking at the dynamics of the variable throughout 2007-2015, we note that, after a first period of global decline in the venture capital fund-rasing activity, the trend has globally reversed as of 2010 .

Control variables. Earlier studies show that economic and institutional variables, as well as legal and fiscal factors are important determinants of both supply and demand for venture capital finance (see, for example, Armour and Cumming, 2006; Cumming and MacIntosh, 2006; Gompers and Lerner, 2004; La Porta et al. 1997, 1998). Following this literature, we classify the variables potentially affecting either the demand 
or the supply of entrepreneurial capital (or both) into six categories: $(i)$ entrepreneurial attitude, as captured by the number of early-stage non-innovative entrepreneurs (as percentage of 18-64 population, from GEM); (ii) entrepreneurial incentives (from The World Bank (WB)): number of procedures to legally start and formally operate a company, time required to complete each procedure in calendar days, cost required to complete each procedure (as a percentage of per capita income) ${ }^{20}$ (iii) attitude towards innovation: the number of scientific and technical published articles (from WB) as a percentage of 18-64 population, ${ }^{21}$ the number of researchers (per million people) (from OECD statistics), and the number of patent applications from residents (from WB) per 100, 000 population aged 18-64; (iv) indicators of financial development: the amount of new funds raised by private equity firms (as a percentage of GDP), the amount of domestic credit to private sector provided by banks or, more generally, by the financial sector ${ }^{22}$ (both as a percentage of GDP, from WB), the degree of capital market capitalization (as a percentage of GDP, from WB); $(v)$ macroeconomic indicators: the level of GDP (at constant USD), the number of residents between 18 and 64 years old, the GDP growth (from WB), a trend variable and country dummies; (vi) institutional indicators capturing the transparency of the financial market (drawn from WB Doing Business database), including: a) a variable called "Credit Information Coverage" (CIC) which gives the number of individuals and firms (as a percentage of adult population) listed in a database that contains information on their borrowing history, unpaid debts, or credit outstanding during the previous 5 years - available through private credit bureaus or public credit registries, and b) an index for "depth of credit information", which measures the scope and accessibility of credit information distributed by credit bureaus and credit registries.

\footnotetext{
${ }^{20}$ We allow the number and the cost of start-up procedures to interact in shaping the relevance of entrepreneurial incentives. An increasing number of startup procedures should be associated with a smaller percentage of nascent entrepreneurs. However, for a given number of startup procedures, a higher cost might be associated with a larger percentage of nascent innovative entrepreneurs for two reasons. On the one hand, motivated entrepreneurs with a good business idea might be able and willing to support higher startup costs. On the other hand, low start-up costs might spur greater entry from non-innovative entrepreneurs and thus lower the expected returns to innovation. This might be detrimental for entrepreneurial innovation (Baumol, 2010).

${ }^{21}$ Articles are classified by year of publication and assigned to countries on the basis of the institutional address(es) appearing on them.

${ }^{22}$ According to our definiton, the financial sector includes monetary authorities and deposit money banks, as well as other financial corporations such as finance and leasing companies, money lenders, insurance corporations, pension funds, and foreign exchange companies.
} 
Several countries (such as Australia, Canada, Germany, Ireland, Israel, Japan, Norway, Sweden, UK and the US) present a pronounced variation in the percentage of individuals and firms listed in either private credit bureaus or public credit registries. Both databases are aimed at measuring and thus informing about the trustworthiness of borrowers, and they operate to directly facilitate information exchange among creditors. However, the quality and the quantity of information may (and, in fact, sometimes do) differ significantly across the two databases, and a strong heterogeneity might discourage financing decisions. In fact, a financier might want to gather information from both sources so as to create a more comprehensive picture on the trustworthiness of the entrepreneur. If coverage from one source is scarce, information is less complete and, thus, financing decisions may be perceived as riskier. Hence, in order to capture a possible complementarity between private bureaus and public registries, we construct the coefficient of variation between the percentage of coverage from public registries and that from private bureaus. We call it the "coefficient of between database variation" (CIC CDV), and we use it as an explanatory variable for the amount of VC funds raised (both direct and interacted with "Credit Information Coverage").

Our credit information coverage also exhibits a significant time variability, with an increasing trend in almost all countries with a percentage below 100 at the beginning of the considered time span. It is then plausible to suppose that, in such countries and over our time span, the financial market has become more transparent. For this reason, we compute the rolling coefficient of time variation (CTV) of the CIC variable for all countries (and denote it by CIC CTV), and we use it as an explanatory variable for the amount of VC funds raised (both direct and interacted with "Credit Information Coverage"). Since the CIC variable is only available since 2004 (from the "Doing Business" Reports), the length of the rolling period is not constant but increases year by year under the plausible assumption that the whole dynamics might be relevant in explaining the VC fund-raising activity. Further details on the control variables can be found in the summary statistics provided in Tables A1 and A2.

The final outcome is an unbalanced panel dataset of 23 OECD countries plus China, observed over the period 2007-2015 and measured along our two dimensions of interest: the share of early-stage innovative entrepreneurs over adult population $\left(l_{E}\right)$ and the amount of capital annually raised in the VC industry of each country as a percentage of $\operatorname{GDP}\left(l_{K}\right)$. 


\subsection{The Estimation Strategy}

If $L_{E}$ responds positively to both $L_{K}$ and $F$, then an increase in the product variable, $L_{K} \cdot F$, determines an increase in $L_{E}$. On the other hand, if both $L_{K}$ and $F$ respond positively to $L_{E}$, then so does their product, $L_{K} \cdot F$. In other words, Proposition 1 implies complementarity between $L_{E}$ and $L_{K} \cdot F$, and thus between $l_{E}$ and $l_{K}$, our two key empirical variables. We now verify such complementarity in a linear model of $l_{E}$ and $l_{K}$.

\subsubsection{The Static Model}

As a first step, we estimate the following pair of linear equations using a fixed effects method:

$$
\begin{aligned}
& \left(l_{E}\right)_{i, t}=\alpha_{i}+\alpha_{K}\left(l_{K}\right)_{i, t}+\boldsymbol{\alpha}_{\mathbf{x}} \mathbf{x}_{i, t}^{E}+\varepsilon_{i, t} \\
& \left(l_{K}\right)_{i, t}=\beta_{i}+\beta_{E}\left(l_{E}\right)_{i, t}+\boldsymbol{\beta}_{\mathbf{x}} \mathbf{x}_{i, t}^{K}+\eta_{i, t},
\end{aligned}
$$

where $\left(l_{E}\right)_{i t}$ and $\left(l_{K}\right)_{i t}$ are, respectively, our proxies for the share of early-stage innovative entrepreneurs and for the share of capital raised by venture capitalists (as defined above) in country $i$ and in year $t ; \mathbf{x}_{i t}^{E}$ and $\mathbf{x}_{i t}^{K}$ are two vectors of controls including a trend variable; $\alpha_{i}, \beta_{i}$ are country fixed effects; $\varepsilon_{i, t}$ and $\eta_{i, t}$ are disturbance terms. The two key parameters of our analysis are $\alpha_{K}$ and $\beta_{E}$. $\alpha_{K}$ measures the impact of $l_{K}$ on $l_{E}$, while $\beta_{E}$ measures the impact of $l_{E}$ on $l_{K}$. We expect them both significantly positive.

We estimate two specifications of equations (19), (20), which differ according to the controls that we include in them. In the first specification, vector $\mathbf{x}_{i t}^{E}$ includes all variables capturing entrepreneurial attitudes and incentives, attitudes towards innovation, the financial and the macroeconomic indicators, except for the share of funds raised by private equity firms. Vector $\mathbf{x}_{i t}^{K}$ includes the macroeconomic and the financial indicators, the institutional indicators and the number of patent applications from residents as a percentage of 18-64 population. We include patents in $\mathbf{x}_{i t}^{K}$ because they might have a direct effect on the degree of development of the venture capital market, as they act as a signal for markets with the highest rate of start-up quality (Conti et Al., 2013a,b). 
In the second specification, we add the amount of funds raised by private equity firms (as a \% of GDP) to vector $\mathbf{x}_{i t}^{E}$. We do this to verify whether, even after controlling for later stage investment funds, funds raised by venture capitalists still have a significant impact on $l_{E}$. We also add the share of early-stage non-innovative entrepreneurs to vector $\mathbf{x}_{i t}^{K}$, in order to verify whether $l_{K}$ is more responsive to the presence of innovative rather than non-innovative entrepreneurs.

Equations (19), (20) are correctly and consistently estimated via pure fixed effects only if the explanatory variables are distributed independently of the disturbance term. If not, these estimators are likely to be biased. In this respect, our theoretical framework helps us identify the main source of endogeneity, that is, the fact that the explanatory variables are partially determined as a function of each other (reverse causality). Given that the share of early-stage innovative entrepreneurs is a function of the amount of entrepreneurial capital raised and viceversa, $l_{K}$ and $\varepsilon$ are correlated in equation (19) and $l_{E}$ and $\eta$ are correlated in equation (20), making $l_{K}$ and $l_{E}$ endogenous. To address this issue, we employ an instrumental variables (IV) technique to correct for potential endogeneity bias: a two-stage least squares (2SLS) method over the static models specifications described above.

As instruments for $l_{K}$, we employ the whole set of institutional indicators mentioned above: the "credit information coverage" (CIC), the coefficient of time variation of the "credit information coverage" (CIC CTV) and its interaction with "credit information coverage", the coefficient of between databases variation of the "credit information coverage" variable (CIC CDV) and its interaction with "credit information coverage", and the "depth of credit information index". As we said above, a credit bureau and a public registry are databases collecting information on the trustworthiness of borrowers and thus facilitating the exchange of information among financiers. Hence, they are likely to affect entrepreneurs via the supply of funds, that is, by influencing the financiers' willingness to do business with them. The rationale behind the choice of these variables as instruments is the following. As proxies of information transparency in the financial-banking market, they are likely to be positively correlated with the amount of entrepreneurial credit provided by traditional and unconventional lending channels. Since the amount of domestic credit provided by banks, financial sector, private equity and venture capital firms is included in our set of control variables, there is no reason to think that our instruments are directly relevant to nascent innovative 
entrepreneurs. ${ }^{23}$

As instruments for $l_{E}$, in the first specification, we employ: (a) two variables belonging to the category "attitude towards innovation": the number of scientific and technical published articles (over adult population), and the number of researchers (per million people); (b) all the three variables belonging to the category "entrepreneurial incentives": the number of procedures to legally start and formally operate a company, the time and the cost required to complete each procedure (as defined above) (c) the share of early-stage non-innovative entrepreneurs (over adult population). We include variables in (a) because we expect them to only affect directly the demand side of the entrepreneurial finance market, the reason being that innovative entrepreneurial ideas are disproportionately concentrated in such sectors as ICT, biotechnology, energy and environmental technology (OECD, 2016, Ch.8). Hence, diffuse scientific and technical skills imply, coeteris paribus, a greater density of innovative entrepreneurial ideas and, thus, a stronger demand of VC funds. We include variables in (b) as they capture the institutional incentives to entrepreneurship. Hence, they affect the VC fund-raising activity only through their positive effect on entrepreneurial activity. Finally, we include the variable in (c) as proxy for entrepreneurial attitudes. In the second specification, we remove it as instrument to verify that, also in the 2SLS, there is no direct impact on the VC fund-raising activity.

\subsubsection{The dynamic model}

It is plausible to conjecture that VC fundraising and innovative entrepreneurship interact dynamically: the amount of $\mathrm{VC}$ funds raised at time $t$ might affect the future number of early-stage innovative entrepreneurs since these funds might be invested also in future periods. Hence, a larger availability of funds now makes entrepreneurs' access to finance easier, and thus start-ups more likely to be launched both now and in later stages. On the other hand, and for specular reasons, it is equally plausible that the current stock of early-stage innovative entrepreneurs incentivizes the fund-raising activity both now and in the near future.

As a result, to take into account the dynamic complementarity between entrepreneurs and capitalists, we allow $l_{E}$ and $l_{K}$ to depend on their previous realizations as

\footnotetext{
${ }^{23}$ In other words, our institutional indicators satisfy the two properties which are necessary for consistency and to ensure good finite sample performance of the IV-type estimator, that is (1) uncorrelation with the error $\varepsilon$; (2) strong correlation with the regressor vector $x^{E}$ (Greene, 2012).
} 
follows:

$$
\begin{aligned}
& \left(l_{E}\right)_{i, t}=\alpha_{i}+\alpha_{E-1}\left(l_{E}\right)_{i, t-1}+\sum_{j=0,1} \alpha_{K-j}\left(l_{K}\right)_{i, t-j}+\sum_{j=0,1} \boldsymbol{\alpha}_{\mathbf{w}-\mathbf{j}} \mathbf{w}_{i, t-j}^{E}+\boldsymbol{\alpha}_{\mathbf{z}} \mathbf{z}_{i, t}^{E}+\varepsilon_{i, t} \\
& \left(l_{K}\right)_{i, t}=\beta_{i}+\beta_{K-1}\left(l_{K}\right)_{i, t-1}+\sum_{j=0,1} \beta_{E-j}\left(l_{E}\right)_{i, t-j}+\sum_{j=0,1} \boldsymbol{\beta}_{\mathbf{w}-\mathbf{j}} \mathbf{w}_{i, t-j}^{K}+\boldsymbol{\beta}_{\mathbf{z}} \mathbf{z}_{i, t}^{K}+\eta_{i, t},
\end{aligned}
$$

where $\left(l_{E}\right)_{i, t-j}$ are the shares of early-stage innovative entrepreneurs at $t-j,\left(l_{K}\right)_{i, t-1}$ are the shares of venture capital funds raised at $t-j$ (for $j=0,1), w_{i, t}^{E}, w_{i, t}^{K}\left(w_{i, t-1}^{E}\right.$, $\left.w_{i, t-1}^{K}\right)$ are vectors of additional potentially endogenous covariates at time $t(t-1) ; z_{i, t}^{E}$ and $z_{i, t}^{K}$ are vectors of strictly exogenous covariates (see Table 3 ).

\section{INSERT TABLE 3 HERE}

Equations (21) and (22) are estimated via pure fixed effects and via one-step system GMM under two specifications which differ according to the variables included in the vectors of endogenous covariates (see Table 3 ). In the first specification, vector $\mathbf{w}_{i, t}^{E}$ $\left(\mathbf{w}_{i, t-1}^{E}\right)$ only includes the percentage of non-innovative entrepreneurs (over adult population) at time $t$ (at time $t-1)$; in the second specification, vector $\mathbf{w}_{i, t}^{E}\left(\mathbf{w}_{i, t-1}^{E}\right)$ adds the percentage of private equity funds raised at time $t(t-1)$ over GDP, in order to verify the presence of a stronger degree of dynamic complementarity between VC funds and innovative startups. Specularly, in the first specification, vector $\mathbf{w}_{i, t}^{K}\left(\mathbf{w}_{i, t-1}^{K}\right)$ includes the percentage of private equity funds raised at time $t(t-1)$ over GDP; in the second specification, vector $\mathbf{w}_{i, t}^{K}\left(\mathbf{w}_{i, t-1}^{K}\right)$ adds the percentage of non-innovative entrepreneurs (over adult population) at time $t(t-1)$.

In equation (21), the use of $\left(l_{E}\right)_{i, t-1}$ is aimed at strengthening our proxies for entrepreneurial attitudes, while the use of $\left(l_{K}\right)_{i, t-1}$ captures the possibility that entrepreneurs may gain access to venture capital funds raised in the previous year. Similarly, in equation (22), the use of $\left(l_{K}\right)_{i, t-1}$ is justified by the possible autocorrelation of variable $l_{K} \cdot{ }^{24}$ Finally, the use of $\left(l_{E}\right)_{i, t-1}$ is justified by the idea that entrepreneurs may still obtain new funds at later stages.

Vector $\mathbf{z}_{i, t}^{E}$ includes all variables capturing attitudes towards innovation, entrepreneurial incentives, the macroeconomic indicators and the indicators of financial development, except for the amount of new funds raised by private equity firms (as a \%

\footnotetext{
${ }^{24}$ We are agnostic on the direction of such autocorrelation: on the one hand, fundrasing at time $t$ may slow down after a boost in the previous year if funds raised at $t-1$ have only been partially invested (negative autocorrelation). On the other hand, fundrasing at time $t$ may also accelerate to the extent that positive sentiments about investment opportunities prevail (positive autocorrelation).
} 
of GDP). Vector $\mathbf{z}_{i, t}^{K}$ includes the macroeconomic indicators, the indicators of financial development, the institutional indicators and the number of patent applications from residents as a share of adult population.

Since lags of the dependent variables are necessarily correlated with the idiosyncratic errors, traditional static panel data model estimators of the two dynamic equations above are not consistent in panels with a short time dimension (Wooldridge, 2002, Ch. 11). This justifies the adoption of a one-step system GMM, the methodology proposed by Arellano and Bond (1991) - and further developed by Blundell and Bond (1998) - over equations (21) and (22). The one-step system GMM estimator employs an instrumental variable technique to the first-differences of each equation, where the predetermined and endogenous variables in first differences are instrumented with appropriate lags of the specified variables in levels, while strictly exogenous regressors are first-differenced for use as instruments in the first-differenced equation. To improve efficiency, the first-differenced estimator is combined with the estimator in levels, where predetermined and endogenous variables in levels are instrumented with appropriate lags of their own first differences, while the strictly exogenous regressors directly enter the instrument matrix for use in the levels equation. The instruments used for the one-step system GMM estimations of equations (21) and (22) are listed in Table 4. We are now ready to comment the results of our empirical analysis.

\section{INSERT TABLE 4 HERE}

\subsection{Findings}

\subsubsection{The static model}

Our findings confirm the theoretical prediction contained in Proposition 1. The effect of $l_{E}$ on $l_{K}$ and that of $l_{K}$ on $l_{E}$ are both significantly and robustly positive across all alternative model specifications. Table 5 presents the FE and 2SLS estimates of the static model introduced in the previous section.

\section{INSERT TABLE 5 HERE}

Columns 1-2 report the FE estimates of the first specification of the static model. A one percentage point increase in the ratio between VC new funds and GDP is associated with 3.166 percentage points increase in the share of early-stage innovative 
entrepreneurs over working age population $\left(\alpha_{K}=3.166\right)$. At the same time, a one percentage point increase in the share of early-stage innovative entrepreneurs over working age population is associated with 0.014 percentage points increase in the ratio between $\mathrm{VC}$ raised funds and $\operatorname{GDP}\left(\beta_{E}=0.014\right)$.

In column 1 , among the other determinants of $l_{E}$, we find the share of early-stage non-innovative entrepreneurs as highly significant and positive. When startup costs are null, an increasing number of procedures required to register a startup is associated with a lower degree of innovative entrepreneurship. This negative link is likely to be reversed in countries with high startup costs: when the number of procedures is relatively high, we find a positive (and weakly significant) impact of the cost of startup business procedures on the share of early-stage innovative entrepreneurs. As motivated in footnote 20 , this effect might be due to a selection effect: high start-up costs reduce the entry from non-innovative entrepreneurs and thus increase the expected returns to innovation. The coefficient of the number of scientific articles (over adult population) is significantly negative, and this may be due to the characteristics of the measure itself, which counts the number of articles from journals classified by the Institute for Scientific Information's Science Citation Index (SCI) and Social Sciences Citation Index (SSCI) and thus may reflect a significant bias toward English-language journals (WB databank metadata). Hence, the measure is likely to be overestimated for Anglo-Saxon countries (US, UK, Australia and Canada) and underestimated for other -mainly Europeancountries with a relatively high share of innovative entrepreneurs over adult population (such as Germany, Ireland and Norway). Finally, we find evidence of a "scale effect" of GDP and of population on $l_{E}$. A one percent increase in adult population leads to a 0.21 percentage points increase in the share of early-stage innovative entrepreneurs over working age population; conversely, one percent increase in GDP leads to a 0.03 percentage points decrease in the share of early-stage innovative entrepreneurs over working age population.

In column 2 , among the other determinants of $l_{K}$, we find that the availability of more credit information, from either a credit bureau or a credit registry, has a significantly positive impact on the fund-raising activity. As expected, a strong difference in the percentage of adults covered in credit bureau's or credit registry's databases ("Coefficient of between Databases Variation") corresponds to a reduction in the fundraising activity, while a higher time rolling variability of the CIC variable is associated with a more active fund-raising activity. Not surprisingly, this impulse declines as the credit information coverage increases. Finally, the negative impact of the trend variable 
shows a progressive weakening of the VC fund-raising activity during our time span. ${ }^{25}$

Columns 3-4 report the FE estimates of the second specification of the static model. As expected, the coefficients of the two dependent variables decrease: in particular, $\alpha_{K}$ drops to 2.618 while $\beta_{E}$ to 0.011 . Interestingly note that, while the private equity fundraising activity positively (though modestly) affects $l_{E}$ (column 3 , with an estimated impact of around one fifth compared to that of the venture capital fund-raising activity), there is no contribution from non-innovative entrepreneurs on $l_{K}$, thus suggesting that VC fundraising is significantly correlated to the presence of innovative entrepreneurs only (column 4). The estimated impacts of the exogenous variables in (19) remain substantially unaltered. In moving from the first to the second specification of (20), instead, the time variability of the CIC variable becomes not significant in explaining VC fund-raising activity, while the negative role of coefficient of between databases variation is found to decrease as credit information coverage increases.

Columns 5-6 contain the 2SLS estimates of the first model specification. Our parameters of interest are still significantly positive, with the estimated impact of VC raised funds (innovative entrepreneurs) on innovative entrepreneurs (VC raised funds) around 3.073 (0.012). Most of the chosen covariates become significant in explaining the dependent variables. In particular (column 5 ), $l_{E}$ decreases in the number of procedures required to launch a business and, exactly as in the previous estimates, this effect is mitigated by a higher cost of startup procedures. With respect to the financial development indicators, the level of development of the banking sector positively affects $l_{E}$. Also the degree of market capitalization exerts a positive impact on $l_{E}$, which is not surprising given that IPOs are still one of the main exit strategies for successful entrepreneurs. The scale effects of GDP and of population on $l_{E}$ remain unaltered. On the other hand (column 6 ), the exogenous determinants of $l_{K}$ improve their level of significance, and their impacts are quantitatively and qualitatively similar to those estimated under the pure FE estimation. The test of the exogeneity of "early-stage non-innovative entrepreneurs (over adult population)" and the Hansen test of overidentification (excluding suspect orthogonal conditions) fail to reject the null hypotheses that both the smaller set of instruments and the additional, suspect, instrument are valid.

\footnotetext{
${ }^{25}$ Also note that the impact of the GDP level on $l_{K}$ is not significant. This means that, coeteris paribus, the relative importance of $\mathrm{VC}$ fund-raising activity on local economic performance is constant across levels of economic development.
} 
Finally, columns 7-8, which contain the 2SLS estimates of the second model specification, provide similar results. As expected, the degree of complementarity slightly decreases compared to the first specification $\left(\alpha_{K}\right.$ drops to 2.316 while $\beta_{E}$ to 0.009 ). Similarly to what we found under the FE estimation (in columns 3 and 4 ), the private equity fund-raising activity positively (and modestly) affects $l_{E}$, while there is no contribution from non-innovative entrepreneurs on $l_{K}$.

Our goodness-of-fit measures indicate that the model fits the data well. In particular, our underidentification tests - based on the Kleibergen-Paap rk Wald statistics for estimates with heteroskedasticity-robust and clustered standard errors - reject the null hypothesis that the equations are underidentified (that is, the matrices of reduced form coefficients on the excluded instruments are full column rank). The Hansen statistics do not reject the null hypothesis that the instruments are valid instruments (that is, that they are uncorrelated with the error term), and hence the excluded instruments are correctly excluded from the estimated equations. With respect to the weak identification test, the related test statistic when standard errors are clustered is the Kleibergen-Paap rk Wald F-statistic, which reduces to the standard F-statistic on the exclusion of the instruments from the first stage in the special case of a single endogenous regressor. Falling back on the original Staiger and Stock (1997) rule-of-thumb that the F-statistic should be 10 or more, we are able to reject the null hypotheses of weak instruments.

\subsubsection{The dynamic model}

Table 6 presents the FE estimates and the one-step system GMM estimates of the dynamic model introduced above. The latter, which are robust to endogeneity, confirm the existence of a positive dynamic complementarity between the share of early-stage innovative entrepreneurs and the VC fund-raising activity. We comment upon each of them in order.

\section{INSERT TABLE 6 HERE}

Columns 1-2 present results from the dynamic FE estimates of the first specification. Our measure for early-stage innovative entrepreneurs is found to be significantly and positively autocorrelated. The same does not occur for the measure of VC fundraising activity. Moreover, there is no evidence of a dynamic form of complementarity between our dependent variables, and the obtained results are similar to those from the static models ( $\alpha_{K}$ is estimated at 2.627 while $\beta_{E}$ at 0.015 ). 
The FE estimates of the second dynamic specifications (Columns 3-4) provide evidence of a weaker degree of contemporaneous complementarity (especially in terms of significance of the estimated coefficients) between our two variables of interest compared to the first specification. Private equity fund-raising activity and non-innovative entrepreneurs do not seem to significantly affect $l_{E}$ and $l_{K}$, respectively.

Columns 5-6 show the results from the first specification of the one-step system GMM model. Differently from above, both dependent variables are found to be significantly and positively autocorrelated. Moreover, the positive complementarity between $l_{E}$ and $l_{K}$ gains a dynamic form: higher early $\mathrm{VC}$ fund-raising activity $\left(l_{K t-1}\right)$ is found to significantly improve the emergence of innovative startups the year after (with an estimated impact of around 1.4, which is lower compared to the previous dynamic FE estimates). The contribution of early-stage innovative entrepreneurs on VC fundraising activity retains a contemporaneous form (0.012). These estimates for $\alpha_{K}$ and $\beta_{E}$ are substantially confirmed by the results of the second specification of the onestep system GMM model contained in columns 7-8 (which also provide evidence of the positive and modest influence of the private equity fund-raising activity on $l_{E}$ emerged from the static models). Differently from all previous results, however, there is evidence of a positive (although small) contribution from non-innovative entrepreneurs on the contemporaneous VC fund-raising activity.

In all specifications, results from the Arellano-Bond test for zero autocorrelation in first-difference errors show that the null hypothesis of serial uncorrelation is rejected at order 1 but not at higher orders, thus implying that lag order 2 (or higher) variables are valid instruments and that the dynamics (i.e. the use of lag order 1 for potentially endogenous variables) are correctly specified. In all models, the null hypothesis that the population moment conditions are correct is not rejected by the Hansen test.

\subsection{An Estimate of the Multiplier Effect}

Using the coefficients reported in the previous subsection, we can easily produce a quantitative measure of the multiplier. This number is useful to gain a rough idea of the volatility implied by the thick market externality documented above. More formally, solving the linear system composed of (19) and (20) by the two endogenous variables $l_{E}, l_{K}$, we find the usual expression for the multiplier as $m=1 /\left(1-\alpha_{K} \beta_{E}\right)$.

Plugging the results from our estimates of $\alpha_{K}$ and $\beta_{E}$ into this formula, we obtain a value of $m$ between 1.01 and 1.05 (see Tables 5 and 6 ). These numbers tell us that a 
shock to either side of the market - such as a debureaucratization of startup procedures for entrepreneurs, or an improvement in the credit information transparency for the capitalists- produces an impact on the shares of early-stage innovative entrepreneurs and of $\mathrm{VC}$ funds which is between $1 \%$ and $5 \%$ higher than it would have produced in the absence of strategic complementarity. Although not exhaustive, this mutual, self-reinforcing, interaction between entrepreneurs and capitalists may then provide a rationale for the pronounced volatility that we observe in the market for entrepreneurial finance.

\subsection{Empirical Findings under Alternative Measures of De- mand and Supply}

The measures of demand and supply of entrepreneurial finance that we have adopted in our empirical analysis may be objected for a number of reasons. In this section, we discuss these objections, present alternative measures and carry out the empirical analysis using these alternative measures. We show that our findings are robust to such changes. Let us start with discussing the demand side.

Our proxy for the demand of entrepreneurial funds may be too broad. There is no direct evidence that the early-stage innovative entrepreneurs, as defined above, have any intention to submit their projects to a VC firm. Indeed, and especially in those countries where VC is still marginal, they may well be asking for liquidity from other sources of credit, such as banks or other financial institutions. In this sense, our proxy may be overestimating the real demand and thus underestimating the degree of complementarity between demand and supply. Given the specific focus of VC funds on the ICT industry, an alternative proxy for the (potential) demand of venture capital could be given by the share of STEM (Science, Technology, Engineering, Mathematics) researchers employed in the business enterprise sector (as a percentage of total labor force) (source: OECD Main Science and Technology Indicators). Table 7 presents the FE and the one-step system GMM estimates of the static and dynamic models described above, where the demand of entrepreneurial finance is proxied by the share of STEM researchers employed in the business enterprise sector. ${ }^{26}$ For the period and country sample of our interest, this measure is only available in an unbalanced form: the total number of observations drops from 188 to 152 .

\footnotetext{
${ }^{26}$ The instrument matrix is analogous to that in Table 4, with the share of STEM researchers instead of the share of early-stage innovative entrepreneurs collected from the GEM database.
} 


\section{INSERT TABLE 7 HERE}

The results are in line with the previous findings. Columns 1-2 report the FE estimates of the static model (equations (19)-(20)) with the amount of PE funds as an additional control. A one percentage point increase in the share of $\mathrm{VC}$ raised funds over GDP is associated with 2.956 percentage points increase in the share of business STEM researchers over labor force. At the same time, a one percentage point increase in the share of business STEM researchers is associated with 0.043 percentage points increase in the share of VC raised funds over GDP. Findings are qualitatively and quantitatively similar when moving to the dynamic models. Columns 3-4 present the results of the FE dynamic model (equations (21)-(22)), still including the amount of PE funds as additional control: the two key coefficients slightly drop to, respectively, 2.692 and 0.041. Finally, the Arellano-Bond estimations contained in Columns 5-6 broadly confirm these results. ${ }^{27}$ Table 7 also contains the estimate of the multiplier effect: its value, ranging between 1.10 and 1.15, is consistently higher than that previously calculated, thus corroborating the conjecture that the previous model might be underestimating the strength of the complementarity across the two sides of the market.

Turning to the supply side, the choice of measuring the supply of entrepreneurial finance through the share of $\mathrm{VC}$ raised funds can also be questioned for the simple reason that not all VC funds are devoted to the early stages of innovative ventures. ${ }^{28}$ For this reason, we have here decided to restrict the attention to a subset of $\mathrm{VC}$ funds, the so-called early-stage VC funds. Given that the definition of early-stage VC funds may differ across countries, however, we have limited our focus on European countries only, for which the definition of early stage is identical. This more specific focus also allows us to exploit additional information regarding the exit modes and strategies prevalent across European VC funds: it is reasonable to conjecture that the relative

\footnotetext{
${ }^{27}$ The Hansen statistics do not reject the null hypothesis that the instruments are valid (that is, that they are uncorrelated with the error term).

${ }^{28} \mathrm{An}$ additional criticism might be that the economic weight of the VC industry is still modest in several countries, especially across Europe (OECD, 2016), and that funds devoted to innovative ventures may well come either from more traditional sources of finance (such as banks) or from alternative forms of entrepreneurial finance (such as angel investor capital). Our focus on the capital raised by VC firms, however, has the double advantage of being (i) conceptually the closest measure for the supply of entrepreneurial capital contained in the theoretical model (as compared to more traditional forms of finance), and of being (ii) readily available for a relatively high number of countries and years (as compared to other forms of entrepreneurial finance).
} 
importance of different exit modes affects the incentives to become entrepreneur and/or to raise additional funds. We then gather data on yearly divestments in European countries through: (i) IPOs, (ii) mergers\&acquisitions, (iii) buy-outs, and (iv) writeoffs. These data are collected from a unique source, the EVCA, and are thus comparable across countries. $^{29}$

Table 8 contains the empirical findings. The supply of entrepreneurial capital is now sub-divided into two components, early stage and non-early stage shares of entrepreneurial capital (where the latter includes both later-stage VC funds and PE funds). All the estimated models also include the moving average distribution of venture capitalists' divestment amount by divestment mode and the amount of value added from ICT sectors (as a percentage of GDP) as additional controls. ${ }^{30}$ Overall, this second empirical exercise allows us to test whether the complementarity is robust against different preferences and/or opportunities of VC funds over the stage of entrance to and exit from a certain project and against different levels of high-tech industrial concentration.

\section{INSERT TABLE 8 HERE}

Under both static and dynamic models, we find evidence of complementarity only between early-stage innovative entrepreneurs and the early-stage component of the VC funds. Columns 1-3 report the FE estimates of the static model. A one percentage point increase in the share of early-stage VC raised funds is associated with 2.308 percentage points increase in the share of early-stage innovative entrepreneurs. At the same time, a one percentage point increase in the share of early-stage innovative entrepreneurs is associated with 0.007 percentage points increase in the share of early-stage $\mathrm{VC}$ raised funds. On the other hand, there is no evidence of complementarity between early-stage innovative entrepreneurs and non-early stage entrepreneurial capital. We also find a significantly positive effect of divestments through IPOs on early-stage innovative entrepreneurs. Columns 4- 6 add the relevant variables in their lagged form, while columns 7-9 contain the findings obtained from the Arellano-Bond estimation. ${ }^{31}$

\footnotetext{
${ }^{29}$ Due to a lower number of observations and the inclusion of 5 additional controls, country-specific trend are now replaced by an overall trend in order to preserve degrees of freedom.

${ }^{30}$ The share of value added from ICT sectors over GDP has been gathered from the OECD Predict database.

${ }^{31}$ The instrument matrix is analogous to that in Table 4, with the overall time trend instead of country-specific time trend and the differentiation between early-stage and later-stage entrepreneurial capital financing instead of the overall amount of VC raised funds. Standard instruments also include
} 
The estimation results of the dynamic models broadly confirm the findings of the static model. Interestingly, according to both the dynamic FE and the Arellano-Bond estimation results, higher shares of divestments through write-offs, buy-outs and mergers\&acquisitions negatively affect the demand side of the market. Across all estimations, the effect of the amount of value added in ICT sectors over GDP is instead not significantly different from zero. Finally, the "early-stage" multiplier effect is calculated at between 1.011 and 1.017, a range of values that, although obtained from the sub-sample of European countries, is broadly in line with the values obtained in Tables 5 and 6.

\section{Concluding Remarks}

This paper has built a model of the market for entrepreneurial innovation that focuses on the relationship between entrepreneurs and capitalists. A new start-up is the outcome of a search and matching process between an entrepreneur with a new project and a capitalist backing that project. The model has investigated the choice of entrepreneurs and capitalists as to whether or not to participate in a fair of new ideas and has determined the equilibrium number of entrepreneurs and capitalists contributing to the entrepreneurial innovation process along the steady state. The main purpose of the modeling strategy that we have followed has been that of representing the venture capital cycle described in the literature on entrepreneurial finance (Gompers and Lerner, 2004).

The second part of the paper has been devoted to the empirical validation of the main theoretical result of the model. Our findings confirm the existence of a significant complementarity between the demand and the supply side of entrepreneurial capital and thus signal the presence of a thick market externality. Our estimation has also allowed us to obtain a quantitative measure of the multiplier effect in this market which can, at least in part, rationalize the volatility documented in the Introduction.

Let us close the paper hinting at a different line of interpretation of our findings. A salient and well known empirical characteristic of the process of entrepreneurial innovation is its high degree of geographic clusterization..$^{32}$ Several explanations to this the additional variables proxing the distribution of divestment methods and the amount of value added in ICT sectors (over GDP). The Hansen statistics do not reject the null hypothesis that the instruments are valid.

${ }^{32}$ In the US, for example, roughly half of firms financed by venture capitalists are located in three 
phenomenon have been proposed in the literature, which are based on the existence of network externalities, such as input sharing, labor market pooling or knowledge spillovers (see, for instance, Jaffe et al., 1993; Audretsch and Feldman, 1996; Chen et al., 2009). In this paper, we document the existence of a different positive network externality, the one between entrepreneurs and capitalists. This externality might be an additional reason for the observed concentration in space (and not only in time). Pursuing further this line of reasoning and comparing it with alternative, and more consolidated, explanations to the formation of entrepreneurial clusters (as in Guiso and Schivardi, 2011) transcend the scope of this paper and might be an interesting future research avenue.

\section{References}

[1] Ardagna S. and A. Lusardi (2010). "Heterogeneity in the Effect of Regulation on Entrepreneurship and Entry Size". Journal of the European Economic Association, 8(2-3), 594-605.

[2] Arellano, M. and S.R. Bond (1991). "Some Specification tests for Panel Data: Monte Carlo Evidence and an Application to Employment Equations". Review of Economic Studies, 58, 277-298.

[3] Armour, J. and D. Cumming (2006). "The legislative road to Silicon Valley". Oxford Economic Papers, 58, 596-635.

[4] Arrow, K.J. (1962). "Economic welfare and the allocation of resources for invention". In Nelson, R. (Ed.), The Rate and Direction of Inventive Activity, Princeton University Press, Princeton, NJ, USA.

[5] Audretsch, D.B. and M.P. Feldman (1996). "R\&D Spillovers and the Geography of Innovation and Production". American Economic Review, 86(3), 630-640.

[6] Baumol, W. J. (2010). "The Microtheory of Innovative Entrepreneurship". Princeton University Press, New Jersey, US.

cities only, San Francisco, Boston, and New York (Chen et Al., 2009). Similar patterns of concentration can be documented for Europe and Asia: think, for instance, of the entrepreneurial clusters in Herzliya (Israel) or in the Guangdong province (China). 
[7] Blundell, R.W. and S.R. Bond (1998). "Initial Conditions and Moment Restrictions in Dynamic Panel Data Models". Journal of Econometrics, 87, 115-143.

[8] Bottazzi, L. and M. Da Rin (2002). "Venture Capital in Europe and the Financing of Innovative Companies". Economic Policy, 17 (34), 229-269.

[9] Bottazzi, L., M. Da Rin and T. Hellmann (2008). "Who are the active investors?: Evidence from venture capital". Journal of Financial Economics, 89 (3), 488-512.

[10] Bottazzi, L., M. Da Rin and T. Hellmann (2016). "The Importance of Trust for Investment: Evidence from Venture Capital". Review of Financial Studies, 29 (9), 2283-2318.

[11] Brander, J. and J-E. de Bettignies (2009). "Venture capital investment: the role of predator-prey dynamics with learning by doing". Economics of Innovation and New Technology, 18(1), 1-19.

[12] Buera, F.J, J.P. Kaboski and Y. Shin (2015). "Entrepreneurship and Financial Frictions: A Macro-Development Perspective". NBER Working Papers 21107.

[13] Cagetti, M. and M. De Nardi (2006). "Entrepreneurship, Frictions, and Wealth". Journal of Political Economy, 114, 835-870.

[14] Chen, H., P. Gompers, A. Kovner, and J. Lerner (2009). "Buy Local? The Geography of Successful and Unsuccessful Venture Capital Expansion". NBER Working Paper, No. 15102.

[15] Cole, R., D.J. Cumming, and D. Li. (2016). "Do Banks or VCs Spur Small Firm Growth?". Journal of International Financial Markets, Institutions, \& 3 Money, 41, 60-72.

[16] Conti, A., M.C. Thursby and F.T. Rothaermel (2013a). "Show Me the Right Stuff: Signals for High Tech Startups". Journal of Economics \&3 Management Strategy, 20(2), pp. 341-364.

[17] Conti, A., M.C. Thursby and J. Thursby (2013b). "Patents as Signals for Startup Financing". Journal of Industrial Economics, 61 (3), pp. 592-622.

[18] Cooper, R.W. (1999). "Coordination Games, Complementarities and Macroeconomics". Cambridge University Press, Cambridge. 
[19] Cumming, D. and J. G. MacIntosh (2006). "Crowding out private equity: Canadian evidence". Journal of Business Venturing, 21(5), 569-609.

[20] Da Rin, M., T. Hellmann, M. Puri. (2011). "A survey of venture capital research". In: Constantinides, G., et Al. (Eds.), Handbook of the Economics of Finance, Vol.2. North Holland.

[21] Diamond, P. (1982). "Aggregate Demand Management in Search Equilibrium". Journal of Political Economy, 90, 881-894.

[22] Diamond, P. (1984). "Money in Search Equilibrium". Econometrica, vol. 52(1), pp. 1-20.

[23] Evans, D.S. and B. Jovanovic (1989). "An estimated model of entrepreneurial choice under liquidity constraints". Journal of Political Economy, 97(4), 808-827.

[24] Gompers, P.A. and J. Lerner (2000). "Money Chasing Deals? The Impact of Fund Inflows on Private Equity Valuation". Journal of Financial Economics 55, $281-325$.

[25] Gompers, P.A. and J. Lerner (2004). "The Venture Capital Cycle". MIT Press, Cambridge, MA.

[26] Greene, W. H. (2012). Econometric Analysis. Pearson Education Limited, Upper Saddle River, N.J: Prentice Hall.

[27] Guiso, L. and F. Schivardi (2011). "What Determines Entrepreneurial Clusters?". Journal of the European Economic Association, 9(1), 61-86.

[28] Jaffe, A., M. Trajtenberg and R. Henderson (1993). "Geographic Localization of Knowledge Spillovers as Evidenced by Patent Citations". Quarterly Journal of Economics, 63(3), 577-598.

[29] Jovanovic, B. and B. Szentes (2013). "On the Market for Venture Capital". Journal of Political Economy, 121(3), 493-527.

[30] Hall, B.H. and J. Lerner (2010). "The Financing of R\&D and Innovation". In B.H. Hall and N. Rosenberg (eds.), Handbook of The Economics of Innovation, Elsevier-North Holland. 
[31] Inderst, R. and H. Muller (2004). "The Effect of Capital Market Characteristics on the Value of Start-up Firms". Journal of Financial Economics, 72, 319-56.

[32] Keuschnigg, C. (2003). "Optimal Public Policy for Venture Capital backed Innovation". CEPR Discussion Paper No. 3850.

[33] Kiyotaki, N. and R. Wright (1993). "A Search-Theoretic Approach to Monetary Economics". American Economic Review, 83(1), 63-77.

[34] Koellinger, P.D., M. Minniti and C. Schade (2007). "I think I can, I think I can Overconfidence and entrepreneurial behavior". Journal of Economic Psychology, $28(4), 502-527$.

[35] Koellinger, P.D. and A.R. Thurik (2012). "Entrepreneurship and the Business Cycle". The Review of Economics and Statistics, 94(4), 1143-1156.

[36] La Porta, R., F. Lopes-de-Silanes, A. Shleifer and R. W. Vishny (1997). "Legal determinants of external finance". Journal of Finance, 52, 1131-1150.

[37] La Porta, R., F. Lopes-de-Silanes, A. Shleifer and R. W. Vishny (1998). "Law and finance". Journal of Political Economy, 106, 1113-1155.

[38] Michelacci, C. and J. Suarez (2004). "Business Creation and the Stock Market". Review of Economic Studies, 71, 459-481.

[39] Moll, B. (2014). "Productivity Losses from Financial Frictions: Can Self-Financing Undo Capital Misallocation?". American Economic Review, 104, 3186-3221.

[40] OECD (2009). "Measuring Entrepreneurship - A Collection of Indicators". OECDEurostat Entrepreneurship Indicators Programme, OECD Publishing, Paris.

[41] OECD (2013). "OECD Science, Technology and Industry Scoreboard 2013, Innovation for Growth". OECD Publishing, Paris.

[42] OECD (2016). "Entrepreneurship at a Glance 2016". OECD Publishing, Paris.

[43] Phelps, E. (2009). "Toward a Model of Innovation and Performance Along the Lines of Knight, Keynes, Hayek and M. Polanyi". In Z. Acs, D. Audretsch and R. Strom (Eds.), Entrepreneurship, Growth and Public Policy, Cambridge University Press, Cambridge. 
[44] Quadrini (2009). "Entrepreneurship in macroeconomics," Annals of Finance, 5, 295-311.

[45] Ravn, M. O. and H. Uhlig (2002). "On adjusting the Hodrick-Prescott filter for the frequency of observations". Review of Economics and Statistics, 84(2), 371-376.

[46] Silveira, R. and R. Wright (2016). "Venture Capital: A Model of Search and Bargaining". Review of Economic Dynamics, 19, pp. 232-246.

[47] Sorensen, M. (2007). "How Smart is Smart Money? A Two-Sided Matching Model of Venture Capital". Journal of Finance, 62, pp. 2725-2762.

[48] Staiger, D. and J. H. Stock (1997). "Instrumental Variables Regression with Weak Instruments". Econometrica, 65, 557-86.

[49] Summers, L. (1988). "Relative Wages, Efficiency Wages, and Keynesian Unemployment". American Economic Review, 78(2), 383-88.

[50] Wasmer, E. and P. Weil (2004). "The Macroeconomics of Labor and Credit Market Imperfections". American Economic Review, 94, pp. 944-963.

[51] Wooldridge, J.M. (2002). "Econometric Analysis of Cross Section and Panel Data". MIT Press, Cambridge.

\section{A Proofs}

Proof of Lemma 1. The entrepreneurs' reaction function is implicitly defined by the steady state condition

$$
Z\left(L_{E}, L_{K}\right) \equiv \sigma\left(E-L_{E}\right) G^{E}\left(c_{E}^{*}\left(L_{E}, L_{K}\right)\right)-\delta_{E} L_{E}=0
$$

where $c_{E}^{*}\left(L_{E}, L_{K}\right)$ is defined in (10). By the implicit function theorem, we know that

$$
\frac{d L_{E}}{d L_{K}}=-\frac{\frac{d Z}{d L_{K}}}{\frac{d Z}{d L_{E}}},
$$

where

$$
\frac{d Z}{d L_{K}}=\sigma\left(E-L_{E}\right)\left(G^{E}\right)^{\prime} \frac{\partial c_{E}^{*}}{\partial \alpha_{E}} \frac{\partial \alpha_{E}}{\partial L_{K}}
$$

and

$$
\frac{d Z}{d L_{E}}=-\sigma G^{E}+\sigma\left(E-L_{E}\right)\left(G^{E}\right)^{\prime} \frac{\partial c_{E}^{*}}{\partial \alpha_{E}} \frac{\partial \alpha_{E}}{\partial L_{E}}-\delta_{E}
$$


The fact that $\partial c_{E}^{*} / \partial \alpha_{E}, \partial \alpha_{E} / \partial L_{K}>0$ and that $\partial \alpha_{E} / \partial L_{E}<0$ ensures that $d Z / d L_{K}>0$ and $d Z / d L_{E}<0$, and hence that $d L_{E} / d L_{K}>0$. To prove that $d L_{K} / d L_{E}>0$, a totally symmetric argument can be developed starting from the total differentiation of (13) with respect to $L_{E}$.

Parameter restrictions (baseline model). We now implicitly determine the values of $\pi$ above which the three conditions specified above are satisfied.

(i) Solving the two systems, respectively made up of (3), (4) and of (6), (7), we can write the two expressions for $V_{E}^{0}$ and $V_{K}^{0}$ as

$$
\begin{gathered}
V_{E}^{0}=\frac{\sigma\left(\alpha_{E} \phi \pi G^{E}\left(c_{E}^{*}\right)-\left(\delta_{E}+r\right) \int_{0}^{c_{E}^{*}} c_{E} d G^{E}\left(c_{E}\right)\right)}{r\left[\delta_{E}+r+\sigma G^{E}\left(c_{E}^{*}\right)\right]}, \\
V_{K}^{0}=\frac{\alpha_{K}(1-\phi) \pi G^{K}\left(c_{K}^{*}\right)-\left(\delta_{K}+r\right) \int_{0}^{c_{K}^{*}} c_{K} d G^{K}\left(c_{K}\right)}{r\left[\delta_{K}+r+G^{K}\left(c_{K}^{*}\right)\right]} .
\end{gathered}
$$

Denote by $\bar{\pi}^{E}, \bar{\pi}^{K}$ the profit values that solve, respectively, $V_{E}^{0}\left(\bar{\pi}^{E}\right)=0$ and $V_{K}^{0}\left(\bar{\pi}^{K}\right)=0$ as a function of all the model parameters (notice that these equations cannot be solved explicitly, as $\pi$ enters into both equations not only directly but also through $\alpha_{j}$ and $c_{j}^{*}$ for $\left.j=E, K\right)$. Given that $d V_{j}^{0} / d \pi>0$, our condition is satisfied for any $\pi>\max \left\{\bar{\pi}^{E}, \bar{\pi}^{K}\right\}$. In the baseline model, we then restrict the attention to a set of parameters that satisfies that inequality (Assumption 1).

(ii) $V_{j}^{1}-V_{j}^{0}>0$ for $j=E, K$. This condition is always satisfied as the two expressions (5) and (8) are always positive.

(iii) $S_{j}>0$ for $j=E, K$. This condition is always satisfied by definition of $S_{j}$.

Proof of Corollary 1. Consider $L_{E}$ first. By convention, suppose that the demand shock is positive, so that $\partial L_{E} / \partial \rho_{E}>0$ (and that $\partial L_{K} / \partial \rho_{E}=0$ ). Then we have

$$
\frac{d L_{E}}{d \rho_{E}}=\frac{\partial L_{E}}{\partial \rho_{E}}+\frac{d L_{E}}{d L_{K}} \frac{d L_{K}}{d \rho_{E}},
$$

where

$$
\frac{d L_{K}}{d \rho_{E}}=\frac{d L_{K}}{d L_{E}} \frac{d L_{E}}{d \rho_{E}}
$$


Substituting for the last expression into the first, we obtain

$$
\frac{d L_{E}}{d \rho_{E}}=m \frac{\partial L_{E}}{\partial \rho_{E}},
$$

where

$$
m=\frac{1}{1-\frac{d L_{E}}{d L_{K}} \frac{d L_{K}}{d L_{E}}}
$$

which is greater than 1 given that $d L_{E} / d L_{K}, d L_{K} / d L_{E}>0$, as ensured in Lemma 1 . The proof for $L_{K}$ is totally analogous and is thus omitted.

Proof of Lemma 2. Given that we cannot find a closed-form solution to the stationary equilibrium/a, we carry out the comparative statics analysis by applying the implicit function theorem. Denote the generic parameter affecting the equilibrium value of $L_{j}^{*}$ as $\rho$. We will study the effect of a change in $\rho$ on $L_{j}^{*}$ when $\rho=\left\{\sigma, \pi, \delta_{E}, \delta_{K}, \phi\right\}$. Remember that the steady-state equilibrium value of $L_{E}^{*}$ is obtained from (12) after substituting for the value of $c_{E}^{*}$, as given in (10) and which in turn contains the equilibrium value of $L_{K}^{*}$. Totally differentiating $L_{E}^{*}$ and $L_{K}^{*}$, we obtain

$$
\begin{aligned}
\frac{d L_{E}^{*}}{d \rho} & =\frac{\partial L_{E}^{*}}{\partial \rho}+\frac{d L_{E}^{*}}{d c_{E}} \frac{\partial c_{E}^{*}}{\partial \rho}+\frac{d L_{E}^{*}}{d c_{E}} \frac{d c_{E}^{*}}{d L_{K}} \frac{d L_{K}^{*}}{d \rho}, \\
\frac{d L_{K}^{*}}{d \rho} & =\frac{\partial L_{K}^{*}}{\partial \rho}+\frac{d L_{K}^{*}}{d c_{K}} \frac{\partial c_{K}^{*}}{\partial \rho}+\frac{d L_{K}^{*}}{d c_{K}} \frac{d c_{K}^{*}}{d L_{E}} \frac{d L_{E}^{*}}{d \rho} .
\end{aligned}
$$

For ease of exposition, let us write $d L_{j}^{*} / d c_{j} \cdot d c_{j}^{*} / d L_{-j}$ as simply $d L_{j} / d L_{-j}$ for $j=E, K$ (whose sign has been already characterized in Lemma 1). Plugging the second into the first and viceversa, we can rewrite the two total derivatives as

$$
\begin{aligned}
& \frac{d L_{E}^{*}}{d \rho}=\frac{1}{1-\frac{d L_{E}}{d L_{K}} \frac{d L_{K}}{d L_{E}}}\left[\frac{\partial L_{E}^{*}}{\partial \rho}+\frac{d L_{E}^{*}}{d c_{E}} \frac{\partial c_{E}^{*}}{\partial \rho}+\frac{d L_{E}}{d L_{K}}\left(\frac{\partial L_{K}^{*}}{\partial \rho}+\frac{d L_{K}^{*}}{d c_{K}} \frac{\partial c_{K}^{*}}{\partial \rho}\right)\right], \\
& \frac{d L_{K}^{*}}{d \rho}=\frac{1}{1-\frac{d L_{E}}{d L_{K}} \frac{d L_{K}}{d L_{E}}}\left[\frac{\partial L_{K}^{*}}{\partial \rho}+\frac{d L_{K}^{*}}{d c_{K}} \frac{\partial c_{K}^{*}}{\partial \rho}+\frac{d L_{K}}{d L_{E}}\left(\frac{\partial L_{E}^{*}}{\partial \rho}+\frac{d L_{E}^{*}}{d c_{E}} \frac{\partial c_{E}^{*}}{\partial \rho}\right)\right] .
\end{aligned}
$$

We now apply these two formulas for computing our total derivatives when $\rho=$ $\left\{\sigma, \pi, \delta_{E}, \delta_{K}, \phi\right\}$.

(i) $d L_{j}^{*} / d \sigma>0$. The steady-state equilibrium value of $L_{E}^{*}$ is obtained from (12) as

$$
L_{E}^{*}=\frac{\sigma E G^{E}\left(c_{E}^{*}\left(\sigma, L_{K}(\sigma)\right)\right)}{\sigma G^{E}\left(c_{E}^{*}\left(\sigma, L_{K}(\sigma)\right)\right)+\delta_{E}},
$$

where $c_{E}^{*}\left(\sigma, L_{K}(\sigma)\right)$ is given in (10) and thus contains $\sigma$ both directly and through $L_{K}$. Parameter $\sigma$ may then affect the equilibrium value of $L_{E}$ via these three channels. 
Applying the same reasoning to $L_{K}^{*}$, we can write

$$
L_{K}^{*}=\frac{K G^{K}\left(c_{K}^{*}\left(L_{E}(\sigma)\right)\right)}{G^{K}\left(c_{K}^{*}\left(L_{E}(\sigma)\right)\right)+\delta_{K}} .
$$

We then have

$$
\frac{d L_{E}^{*}}{d \sigma}=\frac{1}{1-\frac{d L_{E}}{d L_{K}} \frac{d L_{K}}{d L_{E}}}\left[\frac{\partial L_{E}}{\partial \sigma}+\frac{d L_{E}^{*}}{d c_{E}} \frac{\partial c_{E}^{*}}{\partial \sigma}+\frac{d L_{E}}{d L_{K}}\left(\frac{\partial L_{K}^{*}}{\partial \sigma}+\frac{d L_{K}^{*}}{d c_{K}} \frac{\partial c_{K}^{*}}{\partial \sigma}\right)\right]
$$

and

$$
\frac{d L_{K}^{*}}{d \sigma}=\frac{1}{1-\frac{d L_{E}}{d L_{K}} \frac{d L_{K}}{d L_{E}}}\left[\frac{d L_{K}^{*}}{d c_{K}} \frac{\partial c_{K}^{*}}{\partial \sigma}+\frac{d L_{K}}{d L_{E}}\left(\frac{\partial L_{E}^{*}}{\partial \sigma}+\frac{d L_{E}^{*}}{d c_{E}} \frac{\partial c_{E}^{*}}{\partial \sigma}\right)\right],
$$

which are both strictly positive given that the derivatives inside the square brackets are all strictly positive.

(ii) $d L_{j}^{*} / d \pi>0 . \pi$ affects $L_{j}^{*}$ only via $c_{j}^{*}$, which in turn contains $\pi$ both directly and through $L_{-j}$. We can write

$$
\begin{aligned}
& L_{E}^{*}=\frac{\sigma E G^{E}\left(c_{E}^{*}\left(\pi, L_{K}(\pi)\right)\right)}{\sigma G^{E}\left(c_{E}^{*}\left(\pi, L_{K}(\pi)\right)\right)+\delta_{E}}, \\
& L_{K}^{*}=\frac{K G^{K}\left(c_{K}^{*}\left(\pi, L_{E}(\pi)\right)\right)}{G^{K}\left(c_{K}^{*}\left(\pi, L_{E}(\pi)\right)\right)+\delta_{K}} .
\end{aligned}
$$

We then have

$$
\frac{d L_{E}^{*}}{d \pi}=\frac{1}{1-\frac{d L_{E}}{d L_{K}} \frac{d L_{K}}{d L_{E}}}\left[\frac{d L_{E}^{*}}{d c_{E}} \frac{\partial c_{E}^{*}}{\partial \pi}+\frac{d L_{E}}{d L_{K}}\left(\frac{\partial L_{K}^{*}}{\partial \pi}+\frac{d L_{K}^{*}}{d c_{K}} \frac{\partial c_{K}^{*}}{\partial \pi}\right)\right]
$$

and

$$
\frac{d L_{K}^{*}}{d \pi}=\frac{1}{1-\frac{d L_{E}}{d L_{K}} \frac{d L_{K}}{d L_{E}}}\left[\frac{d L_{K}^{*}}{d c_{K}} \frac{\partial c_{K}^{*}}{\partial \pi}+\frac{d L_{K}}{d L_{E}}\left(\frac{\partial L_{E}^{*}}{\partial \pi}+\frac{d L_{E}^{*}}{d c_{E}} \frac{\partial c_{E}^{*}}{\partial \pi}\right)\right],
$$

which are both strictly positive given that, also in this case, the derivatives inside the square brackets are all strictly positive.

(iii-a) $d L_{j}^{*} / d \delta_{E}<0$. We have

$$
L_{E}^{*}=\frac{\sigma E G^{E}\left(c_{E}^{*}\left(\delta_{E}\right)\right)}{\sigma G^{E}\left(c_{E}^{*}\left(\delta_{E}\right)\right)+\delta_{E}},
$$

where $\delta_{E}$ appears both directly and through $c_{E}^{*}$, and

$$
L_{K}^{*}=\frac{K G^{K}\left(c_{K}^{*}\left(L_{E}\left(\delta_{E}\right)\right)\right)}{G^{K}\left(c_{K}^{*}\left(L_{E}\left(\delta_{E}\right)\right)\right)+\delta_{K}},
$$

where $\delta_{E}$ only appears indirectly via $L_{E}$. 
We then have

$$
\frac{d L_{E}^{*}}{d \delta_{E}}=\frac{1}{1-\frac{d L_{E}}{d L_{K}} \frac{d L_{K}}{d L_{E}}}\left[\frac{\partial L_{E}^{*}}{\partial \delta_{E}}+\frac{d L_{E}^{*}}{d c_{E}} \frac{\partial c_{E}^{*}}{\partial \delta_{E}}+\frac{d L_{E}}{d L_{K}} \frac{d L_{K}^{*}}{d c_{K}} \frac{\partial c_{K}^{*}}{\partial \delta_{E}}\right],
$$

and

$$
\frac{d L_{K}^{*}}{d \delta_{E}}=\frac{1}{1-\frac{d L_{E}}{d L_{K}} \frac{d L_{K}}{d L_{E}}}\left[\frac{d L_{K}}{d L_{E}}\left(\frac{\partial L_{E}^{*}}{\partial \delta_{E}}+\frac{d L_{E}^{*}}{d c_{E}} \frac{\partial c_{E}^{*}}{\partial \delta_{E}}\right)\right],
$$

which are both strictly negative given that $\partial L_{E}^{*} / \partial \delta_{E}<0$ and $\partial c_{j}^{*} / \partial \delta_{E}<0$ for $j=$ $E, K$.

(iii-b) The proof is analogous to that carried out in (iii-a) and is then omitted.

(iv) $d L_{j}^{*} / d \phi \gtrless 0$. We have

$$
L_{E}^{*}=\frac{\sigma E G^{E}\left(c_{E}^{*}\left(\phi, L_{K}(\phi)\right)\right)}{\sigma G^{E}\left(c_{E}^{*}\left(\phi, L_{K}(\phi)\right)\right)+\delta_{E}},
$$

and

$$
L_{K}^{*}=\frac{K G^{K}\left(c_{K}^{*}\left(\phi, L_{E}(\phi)\right)\right)}{G^{K}\left(c_{K}^{*}\left(\phi, L_{E}(\phi)\right)\right)+\delta_{K}},
$$

where, in both cases, $\phi$ affects $L_{j}^{*}$ only via $c_{j}^{*}$, which contains $\phi$ both directly and through $L_{-j}$.

We then have

$$
\frac{d L_{E}^{*}}{d \phi}=\frac{1}{1-\frac{d L_{E}}{d L_{K}} \frac{d L_{K}}{d L_{E}}}\left[\frac{d L_{E}^{*}}{d c_{E}} \frac{\partial c_{E}^{*}}{\partial \phi}+\frac{d L_{E}}{d L_{K}} \frac{d L_{K}^{*}}{d c_{K}} \frac{\partial c_{K}^{*}}{\partial \phi}\right]
$$

and

$$
\frac{d L_{K}^{*}}{d \phi}=\frac{1}{1-\frac{d L_{E}}{d L_{K}} \frac{d L_{K}}{d L_{E}}}\left[\frac{d L_{K}^{*}}{d c_{K}} \frac{\partial c_{K}^{*}}{\partial \phi}+\frac{d L_{K}}{d L_{E}} \frac{d L_{E}^{*}}{d c_{E}} \frac{\partial c_{E}^{*}}{\partial \phi}\right],
$$

which can be either positive or negative given that $d L_{E} / d L_{K} \lessgtr d L_{K} / d L_{E}, d L_{K}^{*} / d c_{K} \lessgtr$ $d L_{E}^{*} / d c_{E}$, and that $\partial c_{K}^{*} / \partial \phi<0<\partial c_{E}^{*} / \partial \phi$.

Parameter restrictions (extended model). We here proceed in analogy to the baseline model. In particular, the two conditions on $V_{E}^{0}(F)$ and $V_{K}^{0}(F)$ can be written as

$$
V_{E}^{0}(F)=\frac{\sigma\left(\alpha_{E} \theta \pi H^{C}\left(\hat{F}_{-1}+F\right) G^{E}\left(c_{E}^{*}\right)-\left(\delta_{E}+r\right) \int_{0}^{c_{E}^{*}} c_{E} d G^{E}\left(c_{E}\right)\right)}{r\left[\delta_{E}+r+\sigma G^{E}\left(c_{E}^{*}\right)\right]}>0
$$


$V_{K}^{0}(F)=\frac{\alpha_{K} G^{K}\left(c_{K}^{*}\right) \int_{0}^{\hat{F}_{-1}+F}\left[(1-\theta) \pi+\hat{F}_{-1}+F-C\right] d H^{C}-\left(\delta_{K}+r\right) \int_{0}^{c_{K}^{*}} c_{K} d G^{K}\left(c_{K}\right)}{r\left[\delta_{K}+r+G^{K}\left(c_{K}^{*}\right)\right]}>0$.

Denoting by $\overline{\bar{\pi}}^{E}, \overline{\bar{\pi}}^{K}$ the profit values that solve, respectively, $V_{E}^{0}(F)=0$ and $V_{K}^{0}(F)=0$ as a function of all the model parameters, condition (i) is satisfied for any $\pi>\max \left\{\overline{\bar{\pi}}^{E}, \overline{\bar{\pi}}^{K}\right\}$. In the extended model, we then restrict the attention to a set of parameters that satisfies that inequality (Assumption 2).

In fact, it is possible to prove that $\overline{\bar{\pi}}^{E}>\bar{\pi}^{E}$ and $\bar{\pi}^{K}>\overline{\bar{\pi}}^{K} \cdot{ }^{33}$ Assumptions 1 and 2 could thus merged to a unique condition for the stationary equilibrium to be well-defined in both the baseline and in the extended model: that condition is $\pi>$ $\max \left\{\overline{\bar{\pi}}^{E}, \bar{\pi}^{K}\right\}$.

The remaining two sets of conditions $-V_{j}^{1}-V_{j}^{0}>0, S_{j}>0$ for $j=E, K$ - are always trivially satisfied (as in the baseline model).

Proof of Proposition 1. We tackle the four points in order.

(i-a) It is $d L_{K} / d L_{E} \equiv \partial L_{K} / \partial L_{E}+\partial L_{K} / \partial F \cdot \partial F / \partial L_{E}$. We now show that all these terms are strictly positive. First, that $\partial L_{K} / \partial L_{E}$ is strictly positive is already shown in the proof of Lemma 1. The argument would be analogous here, and we omit it for brevity. Secondly, $\partial L_{K} / \partial F=\partial L_{K} / \partial c_{K}^{*} \cdot \partial c_{K}^{*} / \partial F$ is also strictly positive, as all the terms composing the expression are strictly positive (intuitively, in (17) a higher $F$ implies a higher expected net payoff for capitalists, and thus a higher $c_{K}^{*}$ and a higher $\left.L_{K}\right)$. Proving that $\partial F / \partial L_{E}>0$ is more demanding. Let us denote the solution to the no arbitrage condition (15) as $F^{*}$, that is, $F^{*}: V_{K}^{1}\left(F^{*}\right)=F^{*}$, where $V_{K}^{1}\left(F^{*}\right)$ is given in (14). $F^{*}$ is defined by the following implicit function:

$$
T\left(F^{*}, L_{E}, L_{K}\right) \equiv \frac{\alpha_{K}\left[r+G\left(c_{K}^{*}\right)\right] \int_{0}^{\hat{F}_{-1}+F}\left[(1-\theta) \pi+\hat{F}_{-1}+F-C\right] d H^{C}-\delta_{K} \int_{0}^{c_{K}^{*}} c_{K} d G^{K}\left(c_{K}\right)}{r\left[\delta_{K}+r+G\left(c_{K}^{*}\right)\right]}-F^{*}=0
$$

${ }^{33}$ The fact that $H^{C}(\cdot)<1$ implies that $V_{E}^{0}(F)<V_{E}^{0}$. As a result, condition $V_{E}^{0}(F)>0$ is more stringent in the extended model than in the baseline model, and thus $\overline{\bar{\pi}}^{E}>\bar{\pi}^{E}$. An opposite reasoning holds for $V_{K}^{0}$. Given that $\int_{0}^{\hat{F}_{-1}+F}\left(\hat{F}_{-1}+F-C\right) d H^{C}>0$, we have $V_{K}^{0}(F)>V_{K}^{0}$. Condition $V_{K}^{0}>0$ is then more stringent in the baseline model than in the extended model, and hence $\bar{\pi}^{K}>\overline{\bar{\pi}}^{K}$. 
It is now easy to prove, via the implicit function theorem, that

$$
\frac{\partial F}{\partial L_{E}}=-\frac{\partial T / \partial L_{E}}{\partial T / \partial F}>0
$$

On the one hand, it is $\partial T / \partial L_{E}>0$, given that $V_{K}^{1}\left(F^{*}\right)$ is increasing in $L_{E}$ (in fact, a higher $L_{E}$ implies a higher $\alpha_{K}$ and thus, other things equal, a higher marginal benefit of raising an additional dollar). On the other hand, by definition of function $T$, it is $\partial T / \partial F<0$ if and only if

$$
\left.\frac{\partial V_{K}^{1}(F)}{\partial F}\right|_{F=F^{*}}=\frac{\alpha_{K}\left[r+G^{K}\left(c_{K}^{*}\right)\right]\left[H^{\prime C}\left(\hat{F}_{-1}+F\right)\left[(1-\theta) \pi+\hat{F}_{-1}+F\right]-\left(\hat{F}_{-1}+F\right) H^{C}\left(\hat{F}_{-1}+F\right)\right]}{r\left[\delta_{K}+r+G^{K}\left(c_{K}^{*}\right)\right]}<1 .
$$

This is easy to prove. In fact, the $F$ that maximizes the returns of each capitalist -denote it by $F^{o}$ - is defined as the solution to the equation $d V_{K}^{1}(F) / d F=1 .{ }^{34}$ Hence it can never be $\partial V_{K}^{1}(F) / \partial F>1$, as it would be profitable for each capitalist to unilaterally reduce $F$. On the other hand, only by chance and for particular function configuration, the no-arbitrage condition $\left(V_{K}^{1}\left(F^{*}\right)=F^{*}\right)$ and the optimum condition $\left(\partial V_{K}^{1}(F) / \partial F=1\right)$ deliver the same solution. Hence, we conclude that, almost surely, it is $\partial V_{K}^{1}(F) / \partial F<1$ when $F=F^{*}$, thus implying $\partial F / \partial L_{E}>0$. This concludes the proof of point (i-a).

(i-b) It is $d F / d L_{E} \equiv \partial F / \partial L_{E}+\partial F / \partial L_{K} \cdot \partial L_{K} / \partial L_{E}$. That $\partial F / \partial L_{E}, \partial L_{K} / \partial L_{E}>0$ has already been proven. On the other hand, we have $\partial F / \partial L_{K}<0$. Hence, the proof is not trivial. After a few algebraic steps, the total derivative defining $d F / d L_{E}$ can decomposed and rearranged into

$$
\frac{d F}{d L_{E}} \equiv \frac{\partial F}{\partial \alpha_{K}} \frac{\partial \alpha_{K}}{\partial L_{E}}\left(1+\frac{\partial \alpha_{K}}{\partial L_{K}} \frac{\partial L_{K}}{\partial c_{K}} \frac{\partial c_{K}}{\partial \alpha_{K}}\right)
$$

The second term inside the brackets is negative (as $\partial \alpha_{K} / \partial L_{K}<0$ ) but is strictly higher than -1 given that $\partial L_{K} / \partial c_{K} \cdot \partial c_{K} / \partial \alpha_{K} \in(0,1)$ and that $\partial \alpha_{K} / \partial L_{K} \in(-1,0)$. As a result, (28) is strictly positive.

(ii-a) It is $d L_{E} / d L_{K} \equiv \partial L_{E} / \partial L_{K}+\partial L_{E} / \partial F \cdot \partial F / \partial L_{K}>0$. Given that $\partial F / \partial L_{K}<$ 0 , it must be $\partial L_{E} / \partial L_{K}>-\partial L_{E} / \partial F \cdot \partial F / \partial L_{K}$. The two following facts are sufficient to ensure the validity of the last inequality: (i) $\partial L_{E} / \partial F<\partial L_{E} / \partial L_{K}$; (ii) $\partial F / \partial L_{K}>-1$. Start from Fact (i). It is

\footnotetext{
${ }^{34}$ This would be the "short run solution" to the fundraising problem (Silveira and Wright, 2016), as it assumes a fixed number of capitalists.
} 


$$
\begin{gathered}
\frac{\partial L_{E}}{\partial F}=\frac{\sigma\left(E-L_{E}\right)\left(G^{E}\right)^{\prime} \frac{\partial c_{E}^{*}}{\partial F}}{-\sigma G^{E}+\sigma\left(E-L_{E}\right)\left(G^{E}\right)^{\prime} \frac{\partial c_{E}^{*}}{\partial L_{E}}-1} \\
\frac{\partial L_{E}}{\partial L_{K}}=-\frac{\sigma\left(E-L_{E}\right)\left(G^{E}\right)^{\prime} \frac{\partial c_{E}^{*}}{\partial L_{K}}}{-\sigma G^{E}+\sigma\left(E-L_{E}\right)\left(G^{E}\right)^{\prime} \frac{\partial c_{E}^{*}}{\partial L_{E}}-1}
\end{gathered}
$$

Then it is $\partial L_{E} / \partial L_{K}>\partial L_{E} / \partial F$ if and only if $\partial c_{E}^{*} / \partial L_{K}>\partial c_{E}^{*} / \partial F$. Working on the expression implicitly defining $c_{E}^{*}$ in this model (that is, expression (18)), we obtain that $\partial c_{E}^{*} / \partial L_{K}>\partial c_{E}^{*} / \partial F$ if and only if

$$
\frac{H^{C}\left(\hat{F}_{-1}+F^{*}\right)}{\partial \alpha_{E} / \partial L_{K}}>\frac{H^{\prime C}\left(\hat{F}_{-1}+F^{*}\right)}{\alpha_{E}},
$$

which is true given that $H^{C}(\cdot)>H^{\prime C}(\cdot) \forall F$ and that $\alpha_{E}>\partial \alpha_{E} / \partial L_{K} \cdot{ }^{35}$ Turning to Fact (ii), totally differentiating (27), we obtain

$$
\frac{\partial F}{\partial L_{K}}=-\frac{\left(r+G\left(c_{K}^{*}\right)\right) \frac{\partial \alpha_{K}}{\partial L_{K}} \int_{0}^{\hat{F}_{-1}+F}\left[(1-\theta) \pi+\hat{F}_{-1}+F-C\right] d H^{C}-\frac{\partial \theta}{\partial L_{K}} \alpha_{K}\left(r+G\left(c_{K}^{*}\right)\right) r}{\alpha_{K}\left(r+G\left(c_{K}^{*}\right)\right)\left[H^{\prime C}\left(\hat{F}_{-1}+F^{*}\right)\left[(1-\theta) \pi+\hat{F}_{-1}+F^{*}\right]-\left(\hat{F}_{-1}+F\right) H^{C}\left(\hat{F}_{-1}+F^{*}\right)\right]-r\left[\delta_{K}+r+G\left(c_{K}^{*}\right)\right]},
$$

which is higher than -1 given that the numerator and the denominator are both strictly negative and that the numerator is lower than the denominator.

(ii-b) It is $d L_{E} / d F \equiv \partial L_{E} / \partial F+\partial L_{E} / \partial L_{K} \cdot \partial L_{K} / \partial F$. The proof of this statement is straightforward given that all terms defining $d L_{E} / d F$ have already been proven strictly positive.

Proof of Corollary 2. (i) Consider $L_{E}\left(L_{K}, F, \rho_{E}\right)$ first. By convention, suppose that the demand shock is positive, so that $\partial L_{E} / \partial \rho_{E}>0$. Then we have

$$
\frac{d L_{E}}{d \rho_{E}}=\frac{\partial L_{E}}{\partial \rho_{E}}+\frac{d L_{E}}{d L_{K}} \frac{d L_{K}}{d \rho_{E}}+\frac{d L_{E}}{d F} \frac{d F}{d \rho_{E}},
$$

where

$$
\frac{d L_{K}}{d \rho_{E}}=\frac{d L_{K}}{d L_{E}} \frac{d L_{E}}{d \rho_{E}} \text { and } \frac{d F}{d \rho_{E}}=\frac{d F}{d L_{E}} \frac{d L_{E}}{d \rho_{E}} .
$$

Substituting for the last two expressions into the first and rearranging, we obtain

$$
\frac{d L_{E}}{d \rho_{E}}=m_{E} \frac{\partial L_{E}}{\partial \rho_{E}}
$$

\footnotetext{
${ }^{35}$ In fact, using the expressions for $\alpha_{E}$ and for $\partial \alpha_{E} / \partial L_{K}$, the second inequality can be rearranged as $M>\partial M / \partial L_{K}$, which is always verified for any $L_{K}>1$.
} 
where

$$
m_{E}=\frac{1}{1-\frac{d L_{E}}{d L_{K}} \frac{d L_{K}}{d L_{E}}-\frac{d L_{E}}{d F} \frac{d F}{d L_{E}}}
$$

is the demand multiplier, which is strictly higher than 1 given that all the derivatives at the denominator of its expression are strictly positive (as proven in Proposition 1).

(ii) Let us now calculate the supply multiplier, $m_{K}$, following a positive supply shock $\left(\rho_{K}\right)$. Its algebraic expression depends on whether the supply shock hits the economy via $L_{K}$ or $F$. Suppose that the shock hits the supply through $L_{K}$ (an analogous reasoning can be carried out when the shock passes through $F$; see footnote 36 below). Given the supply function as $\Omega_{K}=L_{K} \cdot F$, we have

$$
\frac{d \Omega_{K}}{d \rho_{K}}=\frac{\partial \Omega_{K}}{\partial \rho_{K}}+\frac{d \Omega_{K}}{d L_{E}} \frac{d L_{E}}{d \rho_{K}},
$$

where

$$
\frac{d L_{E}}{d \rho_{K}}=\frac{d L_{E}}{d L_{K}} \frac{d L_{K}}{d \rho_{K}} .
$$

Substituting for the last expression into the first, we obtain

$$
\frac{d \Omega_{K}}{d \rho_{K}}=\frac{\partial \Omega_{K}}{\partial \rho_{K}}+\frac{d \Omega_{K}}{d L_{E}} \frac{d L_{E}}{d L_{K}} \frac{d L_{K}}{d \rho_{K}} .
$$

Noticing that

$$
\frac{d \Omega_{K}}{d \rho_{K}}=\frac{d L_{K}}{d \rho_{K}} F
$$

we can plug the expression for $d L_{K} / d \rho_{K}$ from (30) into (29) to finally obtain

$$
\frac{d \Omega_{K}}{d \rho_{K}}=m_{K} \frac{\partial \Omega_{K}}{\partial \rho_{K}}
$$

where

$$
m_{K}=\frac{1}{1-\frac{d \Omega_{K}}{d L_{E}} \frac{d L_{E}}{d L_{K}} \frac{1}{F}}
$$

which is strictly higher than 1 as long as $F>1 .^{36}$

\footnotetext{
${ }^{36}$ Via a totally symmetric argument, it can be proven that, if the shock on $\Omega$ passes by $F$ (call it $\left.\rho_{F}\right)$, we have

$$
\frac{d \Omega_{K}}{d \rho_{F}}=m_{F} \frac{\partial \Omega_{K}}{\partial \rho_{F}},
$$
}

where

$$
m_{F}=\frac{1}{1-\frac{d \Omega_{K}}{d L_{E}} \frac{d L_{E}}{d F} \frac{1}{L_{K}}},
$$

which is strictly higher than 1 as long as $L_{K}>1$. 


\section{B Data}

The stock of early-stage innovative entrepreneurs. This data is obtained from the Global Entrepreneurship Monitor (GEM) database. In particular, the GEM questions for early-stage entrepreneurs are the following: 1) Are you, alone or with others, currently trying to start a new business, including any self-employment or selling any goods or services to others? 2) Are you, alone or with others, currently trying to start a new business or a new venture for your employer as part of your normal work? In order for the individual to classified as an early-stage entrepreneur, it is also required that the individual has conducted any concrete activities over the past 12 months, that he/she be one of the owners, or the sole owner of the business-in-gestation.

The following three questions, instead, identify whether early-stage entrepreneurs are innovative or not: 1) Will all, some, or none of your potential customers consider this product or service new and unfamiliar? 2) Right now, are there many, few, or no other businesses offering the same products or services to your potential customers? 3 ) Have the technologies or procedures required for this product or service been available for less than a year, or between one to five years, or longer than five years? We adopt a restrictive definition of innovative entrepreneur: if at least one answer is either "all" to the first question, or "no other business" to the second question, or "less than a year" to the third question, the early-stage entrepreneur is considered innovative.

\section{INSERT TABLES A1, A2 HERE}


Figure 1. Volatility of business enterprises investments in R\&D, volatility of investments provided by Venture Capitalists (VC) and Private Equity (PE) funds, and volatility of private sector gross fixed capital formation, years 2006-2015, main innovative sectors (IT, Healthcare and Energy).

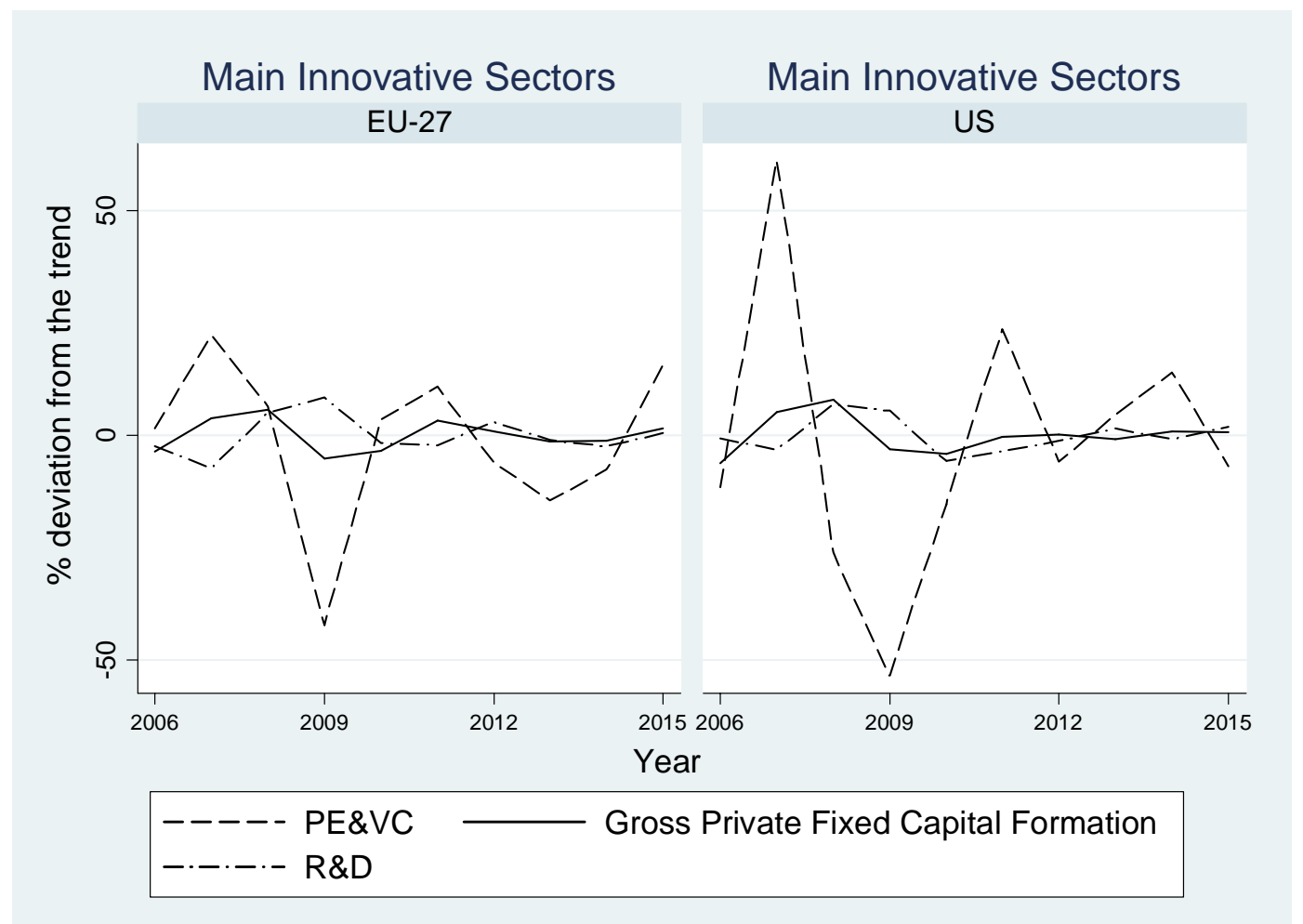

Source: Own elaborations from PitchBook reports, PwC Global Innovation Study on Bloomberg data and Capital IQ data, OECD data. 
Table 1 - Total early-stage innovative entrepreneurs (as \% 18-64 pop.)

\begin{tabular}{|c|c|c|c|c|c|c|c|c|c|}
\hline country & 2007 & 2008 & 2009 & 2010 & 2011 & 2012 & 2013 & 2014 & 2015 \\
\hline Australia & & & 1.280 & 2.777 & 4.274 & 4.792 & 5.311 & 5.830 & 5.734 \\
\hline Austria & 1.056 & 1.766 & 2.477 & 3.187 & 3.898 & 4.608 & 4.358 & 4.107 & 3.857 \\
\hline Belgium & 1.519 & 1.247 & 1.470 & 1.517 & 1.938 & 2.756 & 1.862 & 2.572 & 3.497 \\
\hline Canada & 2.928 & 3.416 & 3.904 & 4.392 & 4.880 & 5.368 & 5.856 & 6.344 & 8.408 \\
\hline China & 11.988 & 11.756 & 11.524 & 9.144 & 14.376 & & 8.778 & 9.408 & 9.203 \\
\hline Denmark & 3.024 & 1.800 & 1.980 & 2.280 & 3.082 & 3.294 & 3.213 & 3.131 & 3.050 \\
\hline Finland & 3.312 & 3.212 & 2.288 & 1.938 & 2.772 & 2.640 & 2.438 & 2.421 & 2.790 \\
\hline France & 1.472 & 2.688 & 2.451 & 2.900 & 3.021 & 3.588 & 1.702 & 2.749 & 3.797 \\
\hline Germany & 3.408 & 3.149 & 2.898 & 2.916 & 2.254 & 2.905 & 2.898 & 3.086 & 2.875 \\
\hline Greece & 2.052 & 5.049 & 4.664 & 2.475 & 3.440 & 2.600 & 2.640 & 2.916 & 2.657 \\
\hline Ireland & 3.675 & 3.692 & 3.613 & 3.533 & 3.571 & 2.989 & 4.261 & 3.275 & 5.168 \\
\hline Israel & 2.856 & 2.887 & 2.968 & 2.179 & 2.692 & 3.206 & 5.720 & 6.093 & 6.466 \\
\hline Italy & 2.500 & 1.886 & 1.332 & 0.960 & 2.179 & 3.397 & 2.108 & 3.044 & 3.224 \\
\hline Japan & 2.083 & 2.607 & 1.568 & 1.152 & 1.869 & 1.799 & 2.065 & 1.815 & 1.566 \\
\hline Luxembourg & 7.884 & 7.485 & 7.085 & 6.685 & 6.286 & 5.886 & 5.486 & 5.087 & 6.631 \\
\hline Netherlands & 2.080 & 2.132 & 2.952 & 2.592 & 4.264 & 4.326 & 4.092 & 3.771 & 3.010 \\
\hline Norway & 1.612 & 3.654 & 4.165 & 3.290 & 2.415 & 1.904 & 1.638 & 1.500 & 1.119 \\
\hline Poland & 6.678 & 6.696 & 6.714 & 6.732 & 6.750 & 6.768 & 6.045 & 5.852 & 5.574 \\
\hline Portugal & 3.168 & 2.523 & 1.877 & 1.232 & 2.400 & 3.311 & 3.772 & 3.386 & 3.262 \\
\hline Spain & 3.724 & 3.570 & 1.887 & 1.333 & 2.088 & 2.394 & 1.768 & 2.148 & 1.963 \\
\hline Sweden & 1.260 & 1.526 & 1.792 & 2.058 & 2.378 & 2.304 & 3.772 & 3.044 & 3.232 \\
\hline Switzerland & 3.026 & 3.288 & 3.549 & 2.507 & 2.985 & 2.526 & 3.716 & 3.096 & 3.869 \\
\hline United Kingdom & 1.925 & 2.478 & 2.052 & 1.920 & 3.796 & 3.420 & 3.053 & 3.339 & 3.760 \\
\hline United States & 4.704 & 4.320 & 2.960 & 2.432 & 5.535 & 6.016 & 5.715 & 6.691 & 5.594 \\
\hline Total & 3.389 & 3.601 & 3.310 & 3.005 & 3.881 & 3.600 & 3.844 & 3.946 & 4.179 \\
\hline
\end{tabular}

Table 2 - VC annually raised funds as percentage of GDP

\begin{tabular}{|c|c|c|c|c|c|c|c|c|c|}
\hline country & 2007 & 2008 & 2009 & 2010 & 2011 & 2012 & 2013 & 2014 & 2015 \\
\hline Australia & 0.030 & 0.024 & 0.013 & 0.010 & 0.005 & 0.011 & 0.007 & 0.006 & 0.019 \\
\hline Austria & 0.008 & 0.001 & 0.015 & 0.007 & 0.014 & 0.004 & 0.005 & 0.002 & 0.029 \\
\hline Belgium & 0.027 & 0.013 & 0.015 & 0.009 & 0.019 & 0.003 & 0.003 & 0.014 & 0.017 \\
\hline Canada & 0.054 & 0.059 & 0.070 & 0.056 & 0.052 & 0.086 & 0.070 & 0.061 & 0.116 \\
\hline China & 0.139 & 0.144 & 0.104 & 0.166 & 0.337 & 0.099 & 0.065 & 0.058 & 0.057 \\
\hline Denmark & 0.172 & 0.012 & 0.000 & 0.064 & 0.051 & 0.028 & 0.000 & 0.000 & 0.021 \\
\hline Finland & 0.103 & 0.066 & 0.023 & 0.026 & 0.047 & 0.038 & 0.033 & 0.023 & 0.046 \\
\hline France & 0.038 & 0.035 & 0.019 & 0.035 & 0.041 & 0.049 & 0.054 & 0.031 & 0.056 \\
\hline Germany & 0.036 & 0.036 & 0.012 & 0.017 & 0.037 & 0.011 & 0.015 & 0.022 & 0.022 \\
\hline Greece & 0.000 & 0.010 & 0.000 & 0.008 & 0.000 & 0.000 & 0.000 & 0.000 & 0.000 \\
\hline Ireland & 0.071 & 0.029 & 0.053 & 0.042 & 0.005 & 0.000 & 0.021 & 0.041 & 0.008 \\
\hline Israel & 0.538 & 0.454 & 0.099 & 0.011 & 0.291 & 0.317 & 0.175 & 0.354 & 0.308 \\
\hline Italy & 0.006 & 0.003 & 0.004 & 0.000 & 0.000 & 0.000 & 0.005 & 0.010 & 0.002 \\
\hline Japan & 0.025 & 0.021 & 0.013 & 0.012 & 0.011 & 0.008 & 0.013 & 0.024 & 0.031 \\
\hline Luxembourg & 0.209 & 0.326 & 0.000 & 0.000 & 0.086 & 0.027 & 0.000 & 0.192 & 0.044 \\
\hline Netherlands & 0.093 & 0.020 & 0.023 & 0.013 & 0.015 & 0.023 & 0.024 & 0.076 & 0.034 \\
\hline Norway & 0.070 & 0.089 & 0.004 & 0.041 & 0.048 & 0.046 & 0.042 & 0.038 & 0.000 \\
\hline Poland & 0.003 & 0.002 & 0.003 & 0.002 & 0.001 & 0.004 & 0.004 & 0.023 & 0.022 \\
\hline Portugal & 0.042 & 0.000 & 0.101 & 0.024 & 0.017 & 0.004 & 0.002 & 0.002 & 0.002 \\
\hline Spain & 0.027 & 0.020 & 0.012 & 0.008 & 0.013 & 0.011 & 0.004 & 0.014 & 0.006 \\
\hline Sweden & 0.123 & 0.026 & 0.106 & 0.009 & 0.005 & 0.023 & 0.007 & 0.001 & 0.003 \\
\hline Switzerland & 0.137 & 0.182 & 0.122 & 0.004 & 0.096 & 0.031 & 0.028 & 0.010 & 0.080 \\
\hline United Kingdom & 0.059 & 0.035 & 0.025 & 0.023 & 0.027 & 0.037 & 0.054 & 0.044 & 0.061 \\
\hline United States & 0.185 & 0.152 & 0.100 & 0.079 & 0.110 & 0.110 & 0.095 & 0.160 & 0.141 \\
\hline Total & 0.092 & 0.073 & 0.039 & 0.028 & 0.055 & 0.040 & 0.030 & 0.050 & 0.047 \\
\hline
\end{tabular}


Table 3: Vectors of endogeneous, predetermined and strictly exogenous variables

\begin{tabular}{|c|c|c|c|c|}
\hline & & Predetermined variables & Endogenous variables & Strictly exogenous variables \\
\hline $\begin{array}{l}\text { Early-stage } \\
\text { innovative } \\
\text { entrepreneurs } \\
\text { (\% pop) }\end{array}$ & $\begin{array}{l}\text { Model } \\
\text { (1) } \\
\text { Model } \\
\quad(2)\end{array}$ & $\begin{array}{c}\text { Lag } 1 \text { of Early-stage } \\
\text { innovative entrepreneurs } \\
(\% \text { pop })\end{array}$ & $\begin{array}{l}\text { Lag } 0 \text { to } 1 \text { of: VC funds raised (\% GDP), } \\
\text { Early-stage non-innovative entrepreneurs (\% pop) } \\
\text { Lag } 0 \text { to } 1 \text { of: VC funds raised ( } \% \text { GDP), } \\
\text { Early-stage non-innovative entrepreneurs ( } \% \text { pop), } \\
\text { PE funds raised (\% GDP) }\end{array}$ & $\begin{array}{l}\text { No. scientific articles (as \% of pop), Researchers (per million } \\
\text { people), No. and cost of startup business procedures (and their } \\
\text { interactions), No. days to startup a business, Patent applications } \\
\text { from residents (per million people), Domestic credit provided by } \\
\text { banks (as \% GDP), Domestic credit provided by financial sector } \\
\text { (as \% GDP), Market capitalization (as \% GDP), GDP growth, Ln } \\
\text { of GDP, Ln of Population, Trend, Country dummies }\end{array}$ \\
\hline $\begin{array}{l}\text { VC funds raised } \\
\quad(\% \text { GDP })\end{array}$ & $\begin{array}{l}\text { Model } \\
(1) \\
\text { Model } \\
(2)\end{array}$ & $\begin{array}{c}\text { Lag } 1 \text { of } \mathrm{VC} \text { funds raised } \\
(\% \mathrm{GDP})\end{array}$ & $\begin{array}{l}\text { Lag } 0 \text { to } 1 \text { of: Early-stage innovative entrepreneurs (\% } \\
\text { pop), PE funds raised (\% GDP) } \\
\text { Lag } 0 \text { to } 1 \text { of: Early-stage innovative entrepreneurs ( } \% \\
\text { pop), PE funds raised ( } \% \text { GDP), } \\
\text { Early-stage non-Innovative entrepreneurs ( } \% \text { pop) }\end{array}$ & $\begin{array}{l}\text { CIC, CIC CTV, CIC CDV, CIC*CIC CTV, CIC*CIC CDV, } \\
\text { Depth of credit information index, Patent applications from } \\
\text { residents (per million people), Domestic credit provided by banks } \\
\text { (as \% GDP), Domestic credit provided by financial sector (as \% } \\
\text { GDP), Market capitalization (as \% GDP), GDP growth, Ln of } \\
\text { GDP, Ln of Population, Trend, Country dummies }\end{array}$ \\
\hline
\end{tabular}


Table 4: Synthesis of instruments used in the one-step system GMM estimation Standard

\begin{tabular}{|c|c|c|c|}
\hline \multicolumn{2}{|r|}{ Standard } & \multicolumn{2}{|c|}{ GMM-type } \\
\hline $\begin{array}{l}\text { Instruments for Early- } \\
\quad \text { stage Innovative } \\
\text { entrepreneurs estimates }\end{array}$ & All estimates & $\begin{array}{c}\text { A-B (1) - Early-stage innovative } \\
\text { entrepreneurs (\% pop) }\end{array}$ & $\begin{array}{c}\text { A-B (2) - Early-stage innovative } \\
\text { entrepreneurs (\% pop) }\end{array}$ \\
\hline $\begin{array}{c}\text { First differences } \\
\text { equation }\end{array}$ & $\begin{array}{l}\text { First difference of: No. scientific articles (as \% of pop), } \\
\text { Researchers (per million people), No. and cost of startup } \\
\text { business procedures (and their interactions), No. days to } \\
\text { startup a business, Patent applications from residents (per } \\
\text { million people), Domestic credit provided by banks (as \% } \\
\text { GDP), Domestic credit provided by financial sector (as \% } \\
\text { GDP), Market capitalization (as \% GDP), GDP growth, Ln } \\
\text { of GDP, Ln of Population, Trend, Country dummies }\end{array}$ & $\begin{array}{c}\text { Lag } 2 \text { to } 9 \text { of: Early-stage innovative } \\
\text { entrepreneurs ( } \% \text { pop), Early-stage non- } \\
\text { innovative entrepreneurs (\% pop); VC } \\
\text { funds raised (\%GDP). }\end{array}$ & $\begin{array}{l}\text { Lag } 2 \text { to } 9 \text { of: Early-stage innovative } \\
\text { entrepreneurs (\% pop), Early-stage non- } \\
\text { innovative entrepreneurs (\% pop); VC funds } \\
\text { raised (\%GDP); PE funds raised (\%GDP). }\end{array}$ \\
\hline Levels equation & $\begin{array}{l}\text { No. scientific articles (as \% of pop), Researchers (per } \\
\text { million people), No. and cost of startup business procedures } \\
\text { (and their interactions), No. days to startup a business, } \\
\text { Patent applications from residents (per million people), } \\
\text { Domestic credit provided by banks (as \% GDP), Domestic } \\
\text { credit provided by financial sector (as \% GDP), Market } \\
\text { capitalization (as \% GDP), GDP growth, Ln of GDP, Ln of } \\
\text { Population, Trend, Country dummies }\end{array}$ & $\begin{array}{c}\text { Lagged differences of: Early-stage } \\
\text { innovative entrepreneurs (\% pop), t- } 1 \\
\text { Early-stage non-innovative entrepreneurs } \\
\text { (\% pop), t \& t-1; VC funds raised } \\
(\% \text { GDP }), \mathrm{t} \& \mathrm{t}-1 .\end{array}$ & $\begin{array}{l}\text { Lagged differences of: Early-stage innovative } \\
\text { entrepreneurs (\% pop), t-1; Early-stage non- } \\
\text { innovative entrepreneurs (\% pop), t \& t- } 1 \text {; } \\
\text { VC funds raised (\%GDP), t \& t-1; PE funds } \\
\text { raised (\%GDP), t \& t-1. }\end{array}$ \\
\hline
\end{tabular}

\begin{tabular}{|c|c|c|c|}
\hline \multirow[b]{2}{*}{$\begin{array}{l}\text { Instruments for VC } \\
\text { funds raised estimates }\end{array}$} & \multirow{2}{*}{$\begin{array}{c}\text { Standard } \\
\text { All estimates }\end{array}$} & \multicolumn{2}{|c|}{ GMM-type } \\
\hline & & A-B (1) - VC funds raised (\%GDP) & A-B (2) - VC funds raised (\%GDP) \\
\hline $\begin{array}{l}\text { First differences } \\
\text { equation }\end{array}$ & $\begin{array}{c}\text { First difference of: CIC CTV, CIC CDV, CIC, CIC*CIC } \\
\text { CTV, CIC*CIC CDV, Depth of credit information index, } \\
\text { Patent applications from residents (per million people), } \\
\text { Domestic credit provided by banks (as \% GDP), Domestic } \\
\text { credit provided by financial sector (as \% GDP), Market } \\
\text { capitalization (as \% GDP), GDP growth, Ln of GDP, Ln of } \\
\text { Population, Trend, Country dummies }\end{array}$ & $\begin{array}{l}\text { Lag } 2 \text { to } 9 \text { of: VC funds raised (\%GDP), } \\
\text { Early-stage innovative entrepreneurs (\% } \\
\text { pop); PE funds raised (\%GDP). }\end{array}$ & $\begin{array}{l}\text { Lag } 2 \text { to } 9 \text { of: VC funds raised (\%GDP); } \\
\text { Early-stage innovative entrepreneurs (\% } \\
\text { pop); PE funds raised (\%GDP); Early-stage } \\
\text { non-innovative entrepreneurs (\% pop). }\end{array}$ \\
\hline Levels equation & \begin{tabular}{|c|} 
CIC CTV, CIC CDV, CIC, CIC*CIC CTV, CIC*CIC \\
CDV, Depth of credit information index, Patent \\
applications from residents (per million people), Domestic \\
credit provided by banks (as \% GDP), Domestic credit \\
provided by financial sector (as \% GDP), Market \\
capitalization (as \% GDP), GDP growth, Ln of GDP, Ln of \\
Population, Trend, Country dummies
\end{tabular} & $\begin{array}{l}\text { Lagged difference of: VC funds raised } \\
\text { (\%GDP), t- } 1 \text {; Early-stage innovative } \\
\text { entrepreneurs (\% pop), t \& t-1; PE funds } \\
\text { raised (\%GDP), t \& t- } 1 \text {. }\end{array}$ & $\begin{array}{l}\text { Lagged difference of: VC funds raised } \\
\text { (\%GDP), t-1; Early-stage innovative } \\
\text { entrepreneurs (\% pop), t \& t-1; PE funds } \\
\text { raised (\%GDP), t \& t-1; Early-stage non- } \\
\text { innovative entrepreneurs (\% pop), t \& t-1. }\end{array}$ \\
\hline
\end{tabular}


Table 5: Estimation Results - Static Model

(1)

FE (1) -

Early-stage

innovative

entrepreneurs

VARIABLES (\% pop)

VC funds raised (\%GDP)

$2.825^{* *}$

(1.131)

Early-stage innovative entrepreneurs (\% pop)

$\mathrm{PE}$ funds raised (\% GDP)

Early-stage non-innovative entrepreneurs

(\% pop)

No. scientific articles ( $\%$ pop)

Researchers (per million people)

No. procedures to startup a business

$(>5 \& \leq 10)$

No. procedures to startup a business

$(>10)$

Cost of startup business procedures

(no. procedures $\leq 5$ )

Cost of startup business procedures

(no. procedures $>5 \& \leq 10$ )

Cost of startup business procedures

(no. procedures $>10$ )

No. days to startup a business

Patent applications from residents

(per million people)

Domestic credit provided by banks

(\% GDP)

Domestic credit provided by financial sector (\% GDP)

Market capitalization (\% GDP)

GDP growth

Ln of GDP

Ln of Population

CIC CTV

\section{CIC CDV}

CIC

\section{$\mathrm{CIC}^{*} \mathrm{CIC} \mathrm{CTV}$}

CIC* CIC CDV

Depth of credit information index

Country - specific Trend

Country level FE

Multiplier effect

Underidentification Test: Kleibergen-Paap

rk Wald test of rank p-value

Weak identification test:

Kleibergen-Paap rk Wald F statistic

Overidentification test:

Hansen J statistic p-value

Hansen J statistic p-value (excluding Early-

stage non-innovative entrepreneurs (\% pop))

$\mathrm{C}$ statistic (exogeneity of Early-stage non-

innovative entrepreneurs (\% pop))

Observations

R-squared

Robust standard errors in parentheses

*** $\mathrm{p}<0.01, * * \mathrm{p}<0.05, * \mathrm{p}<0.1$

(0.)

$0.431^{* *}$

(2.728)

$(0.000)$

$-0.369$

$(0.692)$

(0.888)

$-0.015$

$(0.052)$

$(0.061)$

$-0.020$

(0.078)

$-0.053^{* *}$

(0.026)

40.309

(28.139)

0.002

$(0.009)$

$-0.001$

$(0.003)$

0.001

$(0.002)$

$-0.043$

(0.030)

4.240

(3.238)

$-22.657$

(14.345)

213

(5)

(6)

(7)

(8)

FE (1) FE (2) -

FE (2) -

$\mathrm{VC}$ funds

raised

innovative

FE (2) -

2SLS (1) -

Early-stage

$\mathrm{VC}$ funds

raised

itrepreneurs

(\%GDP)

innovative

trepreneurs

2SLS (1) -

$\mathrm{VC}$ funds

raised

2SLS (2) -

Early-stage

innovative

entrepreneurs (\% pop)

2SLS (2) -

$\mathrm{VC}$ funds

raised

(\%GDP)

(\% pop)

\begin{tabular}{|c|c} 
& $2.686^{* *}$ \\
& $(1.131)$
\end{tabular}

\begin{tabular}{|l|l}
\hline & $2.692^{* * *}$
\end{tabular}

$(0.008)$

$0.059^{*}$

$(0.008)$

(0.939)

(0.032)

$\begin{array}{ll}(0.216) & (0.041)\end{array}$

$0.433^{* * *} \quad 0.004$

$(0.116) \quad(0.003)$

$-3.432$

(2.800)

$-0.000$

$(0.000)$

$-0.372$

(0.693)

0.094

$(0.893)$

$-0.016$

(0.052)

$-3.764^{*}$

0.048

$(0.061)$

$-0.017$

(0.078)

$-0.053^{* *}$

(0.026)

38.289

(0.003)

(0.058)

$-2.208$

(1.749)

$-0.000^{* * *}$

$(0.000)$

$-0.346$

$(0.347)$

$-0.010$

(0.488)

$-0.022$

(0.031)

0.053

(0.033)

$-0.021$

$(0.054)$

$-0.054^{* * *}$

(0.011)

(27.664)

0.003

$-3.564$

$38.019^{* * *}$

0.001

(0.010)

(3.129)

(12.587)

0.002

$(0.001)$

(0.005)

$-0.000$

$-0.001$

$-0.000$

$(0.003) \quad(0.000)$

$-0.000$

(0.001)

$-0.000$

0.001

$-0.000$

0.001

$(0.001)$

$\begin{array}{ll}(0.002) & (0.000) \\ -0.043 & 0.001\end{array}$

(0.030)

0.001

$-0.035^{* * *}$

0.001

(0.002)

0.159

3.795

$(0.001)$

(0.013)

$2.766^{*}$

(3.340)

(0.315)

0.485

$-23.347$

0.539

(1.558)

(0.996)

(14.578)

(1.263)

$-18.447^{* *}$

(6.869)

$-0.046$

(0.065)

(0.085)

$-0.192$

$-0.205$

(0.170)

$(0.197)$

$-0.002$

(0.002)

$-0.000$

(0.003)

0.002

(0.002)

$0.009^{*}$

(0.005)

$-0.002$

$(0.002)$

$-0.000$

(0.003)

0.002

(0.002)

0.010

(0.007)

$-0.043$

(0.036)

$-0.080$

(0.082)

$-0.001$

$(0.001)$

0.000

(0.001)

0.000

(0.001)

$0.006^{* *}$

$2.589^{* * *}$

(0.991)

\begin{tabular}{|c|c|}
\hline $\begin{array}{l}013^{\text {*** }} \\
0.004)\end{array}$ & $\begin{array}{c}0.005 \\
(0.006)\end{array}$ \\
\hline
\end{tabular}

$(0.019)$

$0.100 \quad 0.050^{* * *}$

$(0.168) \quad(0.019)$

$0.410^{* * *} \quad 0.006$

(0.057)

$-2.448$

(1.733)

$-0.000^{* * *}$

$(0.000)$

$-0.317$

$(0.353)$

0.003

(0.489)

$-0.022$

(0.031)

0.049

$(0.033)$

$-0.023$

(0.054)

$-0.054^{* * *}$

(0.012)

$37.947^{* * *}$

(12.200)

0.003

$(0.005)$

$-0.001$

(0.004)

YES

YES YES

YES

YES

YES YES

\begin{tabular}{r|r}
1.054 & 1.045 \\
\hline
\end{tabular}

Y

213
0.3

0.736

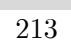

213

0.937

0.343

(0.003) 
Table 6: Estimation Results - Dynamic Model

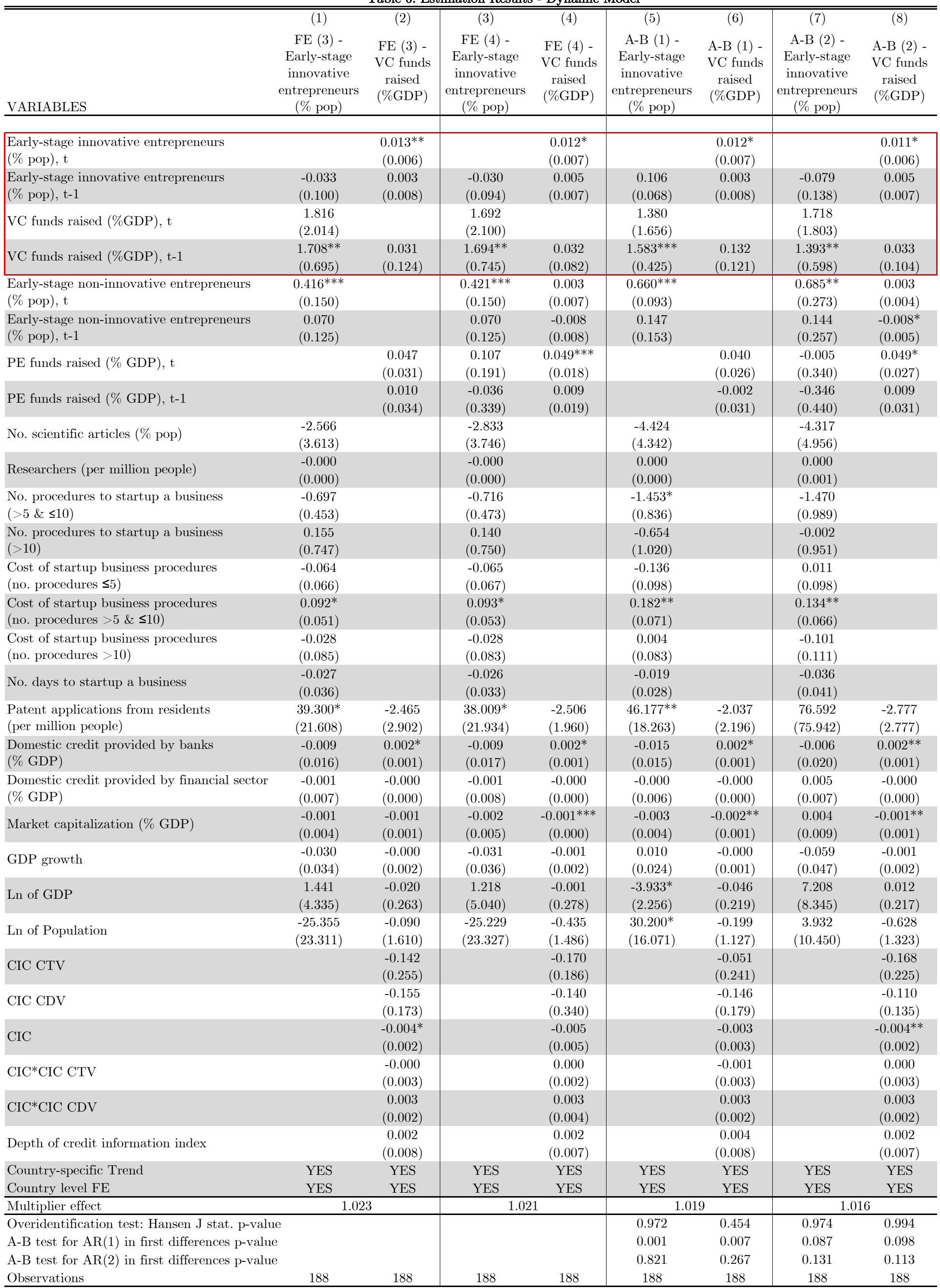

Robust standard errors in parentheses

$* * * \mathrm{p}<0.01,{ }^{* *} \mathrm{p}<0.05,{ }^{*} \mathrm{p}<0.1$ 
Table 7: Estimation Results - Alternative Measures of Demand

\begin{tabular}{|c|c|c|c|c|c|c|}
\hline VARIABLES & $\begin{array}{c}(1) \\
\text { FE (2) - } \\
\text { Business } \\
\text { STEM } \\
\text { Researchers } \\
\text { (\% pop) }\end{array}$ & $\begin{array}{c}(2) \\
\text { FE - } \\
\text { VC funds } \\
\text { raised } \\
(\% \text { GDP })\end{array}$ & $\begin{array}{c}(3) \\
\text { DYN FE } \\
(2)- \\
\text { Business } \\
\text { STEM } \\
\text { Researchers } \\
\text { (\% pop) } \\
\end{array}$ & $\begin{array}{c}(4) \\
\text { DYN FE - } \\
\text { VC funds } \\
\text { raised } \\
(\% \mathrm{GDP})\end{array}$ & $\begin{array}{c}(5) \\
\text { AB - } \\
\text { Business } \\
\text { STEM } \\
\text { Researchers } \\
\text { (\% pop) }\end{array}$ & $\begin{array}{c}(6) \\
\mathrm{AB}- \\
\mathrm{VC} \text { funds } \\
\text { raised } \\
(\% \mathrm{GDP})\end{array}$ \\
\hline Business STEM Researchers (\% pop), t & & $\begin{array}{c}0.043^{*} \\
(0.022)\end{array}$ & & $\begin{array}{c}0.041^{*} \\
(0.021)\end{array}$ & & $\begin{array}{c}0.037^{*} \\
(0.021)\end{array}$ \\
\hline Business STEM Researchers (\% pop), t-1 & & & $\begin{array}{c}0.213 \\
(0.143)\end{array}$ & $\begin{array}{l}-0.013 \\
(0.015)\end{array}$ & $\begin{array}{l}0.235^{* *} \\
(0.105)\end{array}$ & $\begin{array}{l}-0.034 \\
(0.032)\end{array}$ \\
\hline VC funds raised (\%GDP), $\mathrm{t}$ & $\begin{array}{c}2.956^{* *} \\
(1.202)\end{array}$ & & $\begin{array}{c}2.692^{* * *} \\
(0.506)\end{array}$ & & $\begin{array}{c}2.460^{* * *} \\
(0.699)\end{array}$ & \\
\hline $\mathrm{VC}$ funds raised (\%GDP), $\mathrm{t}-1$ & & & $\begin{array}{l}1.185 \\
(0.724)\end{array}$ & $\begin{array}{c}0.194 \\
(0.228)\end{array}$ & $\begin{array}{l}1.318^{* *} \\
(0.590)\end{array}$ & $\begin{array}{c}0.217^{* * *} \\
(0.080) \\
\end{array}$ \\
\hline $\mathrm{PE}$ funds raised $(\% \mathrm{GDP}), \mathrm{t}$ & $\begin{array}{c}0.249 \\
(0.263)\end{array}$ & $\begin{array}{l}0.083^{*} \\
(0.044)\end{array}$ & $\begin{array}{l}-0.115 \\
(0.168)\end{array}$ & $\begin{array}{l}0.065^{*} \\
(0.035)\end{array}$ & $\begin{array}{c}-0.124 \\
(0.122)\end{array}$ & $\begin{array}{c}0.082^{* *} \\
(0.040)\end{array}$ \\
\hline $\mathrm{PE}$ funds raised (\% GDP), $\mathrm{t}-1$ & & & $\begin{array}{l}-0.191 \\
(0.226)\end{array}$ & $\begin{array}{l}-0.052 \\
(0.033)\end{array}$ & $\begin{array}{l}-0.178 \\
(0.237)\end{array}$ & $\begin{array}{l}-0.041 \\
(0.032)\end{array}$ \\
\hline No. scientific articles (\% pop) & $\begin{array}{l}-3.391 \\
(4.937)\end{array}$ & & $\begin{array}{l}-3.018 \\
(6.635)\end{array}$ & & $\begin{array}{l}-3.163 \\
(6.181)\end{array}$ & \\
\hline $\begin{array}{l}\text { Patent applications from residents } \\
\text { (per million people) }\end{array}$ & $\begin{array}{c}-4.475 \\
(14.630)\end{array}$ & $\begin{array}{l}-1.230 \\
(1.771)\end{array}$ & $\begin{array}{l}-2.465 \\
(7.475)\end{array}$ & $\begin{array}{c}0.371 \\
(1.936)\end{array}$ & $\begin{array}{c}17.756 \\
(23.587)\end{array}$ & $\begin{array}{l}-0.669 \\
(2.446)\end{array}$ \\
\hline $\begin{array}{l}\text { Domestic credit provided by banks } \\
\text { (\% GDP) }\end{array}$ & $\begin{array}{c}0.011 \\
(0.011)\end{array}$ & $\begin{array}{l}-0.000 \\
(0.001)\end{array}$ & $\begin{array}{c}0.003 \\
(0.010)\end{array}$ & $\begin{array}{l}0.003^{*} \\
(0.002)\end{array}$ & $\begin{array}{c}0.000 \\
(0.007)\end{array}$ & $\begin{array}{c}0.005 \\
(0.005)\end{array}$ \\
\hline Domestic credit provided by financial sector (\% GDP) & $\begin{array}{c}0.000 \\
(0.002)\end{array}$ & $\begin{array}{c}0.000 \\
(0.000)\end{array}$ & $\begin{array}{l}-0.000 \\
(0.007)\end{array}$ & $\begin{array}{c}0.001 \\
(0.000)\end{array}$ & $\begin{array}{c}-0.003 \\
(0.008)\end{array}$ & $\begin{array}{c}0.001 \\
(0.001)\end{array}$ \\
\hline Market capitalization (\% GDP) & $\begin{array}{c}-0.002 \\
(0.003)\end{array}$ & $\begin{array}{c}0.000 \\
(0.000)\end{array}$ & $\begin{array}{c}-0.004^{* *} \\
(0.002)\end{array}$ & $\begin{array}{l}-0.001 \\
(0.001)\end{array}$ & $\begin{array}{c}-0.005^{* *} \\
(0.003)\end{array}$ & $\begin{array}{l}-0.001 \\
(0.001)\end{array}$ \\
\hline GDP growth & $\begin{array}{l}-0.010 \\
(0.020)\end{array}$ & $\begin{array}{c}0.001 \\
(0.002)\end{array}$ & $\begin{array}{l}-0.017 \\
(0.019)\end{array}$ & $\begin{array}{l}-0.001 \\
(0.003)\end{array}$ & $\begin{array}{c}0.001 \\
(0.013)\end{array}$ & $\begin{array}{l}-0.000 \\
(0.003)\end{array}$ \\
\hline Ln of GDP & $\begin{array}{c}1.788 \\
(1.413)\end{array}$ & $\begin{array}{l}-0.175 \\
(0.212)\end{array}$ & $\begin{array}{c}4.877 \\
(2.845)\end{array}$ & $\begin{array}{l}-0.070 \\
(0.337)\end{array}$ & $\begin{array}{c}2.649^{* * *} \\
(0.840)\end{array}$ & $\begin{array}{l}-0.451 \\
(0.450)\end{array}$ \\
\hline Ln of Population & $\begin{array}{c}-21.859^{*} \\
(13.153)\end{array}$ & $\begin{array}{c}0.505 \\
(1.058)\end{array}$ & $\begin{array}{c}0.970 \\
(9.947)\end{array}$ & $\begin{array}{l}-4.271 \\
(2.606)\end{array}$ & $\begin{array}{c}8.876 \\
(10.136)\end{array}$ & $\begin{array}{l}-23.113 \\
(19.644)\end{array}$ \\
\hline CIC CTV & & $\begin{array}{l}-0.008 \\
(0.146)\end{array}$ & & $\begin{array}{c}0.592^{* *} \\
(0.271)\end{array}$ & & $\begin{array}{c}0.960^{* *} \\
(0.376)\end{array}$ \\
\hline CIC CDV & & $\begin{array}{c}-0.147 \\
(0.209)\end{array}$ & & $\begin{array}{c}-0.182 \\
(0.205)\end{array}$ & & $\begin{array}{c}-0.564 \\
(0.520)\end{array}$ \\
\hline $\mathrm{CIC}$ & & $\begin{array}{c}0.000 \\
(0.002)\end{array}$ & & $\begin{array}{l}-0.003 \\
(0.003)\end{array}$ & & $\begin{array}{c}-0.008^{*} \\
(0.004)\end{array}$ \\
\hline $\mathrm{CIC}^{*} \mathrm{CIC} \mathrm{CTV}$ & & $\begin{array}{c}-0.001 \\
(0.004)\end{array}$ & & $\begin{array}{c}-0.009^{* *} \\
(0.004)\end{array}$ & & $\begin{array}{c}-0.015^{* *} \\
(0.006)\end{array}$ \\
\hline $\mathrm{CIC}^{*} \mathrm{CIC} \mathrm{CDV}$ & & $\begin{array}{c}0.001 \\
(0.002)\end{array}$ & & $\begin{array}{c}0.004 \\
(0.002)\end{array}$ & & $\begin{array}{c}0.008 * * \\
(0.003)\end{array}$ \\
\hline Depth of credit information index & & $\begin{array}{c}0.014^{* *} \\
(0.006)\end{array}$ & & $\begin{array}{c}0.019 * * \\
(0.009)\end{array}$ & & $\begin{array}{c}0.018 \\
(0.012)\end{array}$ \\
\hline Country-specific Trend & YES & YES & YES & YES & YES & YES \\
\hline Country level FE & YES & YES & YES & YES & YES & YES \\
\hline Multiplier effect & \multicolumn{2}{|c|}{1.146} & \multicolumn{2}{|c|}{1.124} & \multicolumn{2}{|c|}{1.100} \\
\hline $\begin{array}{l}\text { Overidentification test: Hansen J stat. p-value } \\
\text { A-B test for } \operatorname{AR}(1) \text { in first differences p-value } \\
\text { A-B test for } \operatorname{AR}(2) \text { in first differences p-value } \\
\text { Observations }\end{array}$ & 152 & 152 & 106 & 106 & $\begin{array}{c}0.998 \\
0.064 \\
0.238 \\
106\end{array}$ & $\begin{array}{c}0.425 \\
0.112 \\
0.160 \\
106\end{array}$ \\
\hline
\end{tabular}

Robust standard errors in parentheses

*** $\mathrm{p}<0.01,{ }^{* *} \mathrm{p}<0.05, * \mathrm{p}<0.1$ 
Table 8: Estimation Results - Alternative Measures of Supply

\begin{tabular}{|c|c|c|c|c|c|c|c|c|c|}
\hline VARIABLES & $\begin{array}{c}(1) \\
\text { FE - Early- } \\
\text { stage } \\
\text { innovative } \\
\text { entrepreneurs } \\
\text { (\% pop) } \\
\end{array}$ & $\begin{array}{c}(2) \\
\text { FE - Early- } \\
\text { stage VC } \\
\text { Funds } \\
\text { (\%GDP) }\end{array}$ & $\begin{array}{c}(3) \\
\mathrm{FE}-\text { Other } \\
\mathrm{VC} \text { and PE } \\
\text { Funds } \\
(\% \mathrm{GDP})\end{array}$ & $\begin{array}{c}(4) \\
\text { DYN FE - } \\
\text { Early-stage } \\
\text { innovative } \\
\text { entrepreneurs } \\
\text { (\% pop) } \\
\end{array}$ & $\begin{array}{c}(5) \\
\text { DYN FE - } \\
\text { Early-stage } \\
\text { VC Funds } \\
\text { (\%GDP) }\end{array}$ & $\begin{array}{c}(6) \\
\text { DYN FE - } \\
\text { Other VC } \\
\text { and PE } \\
\text { Funds } \\
(\% \text { GDP }) \\
\end{array}$ & $\begin{array}{c}(7) \\
\text { AB - Early- } \\
\text { stage } \\
\text { innovative } \\
\text { entrepreneurs } \\
\text { (\% pop) } \\
\end{array}$ & $\begin{array}{c}(8) \\
\text { AB -Early- } \\
\text { stage VC } \\
\text { Funds } \\
(\% \text { GDP })\end{array}$ & $\begin{array}{c}(9) \\
\mathrm{AB}-\text { Other } \\
\mathrm{VC} \text { and PE } \\
\text { Funds } \\
(\% \mathrm{GDP})\end{array}$ \\
\hline $\begin{array}{l}\text { Early-stage innovative entrepreneurs } \\
(\% \text { pop), t }\end{array}$ & & $\begin{array}{l}0.007^{*} \\
(0.004)\end{array}$ & $\begin{array}{c}0.015 \\
(0.022)\end{array}$ & & $\begin{array}{l}0.008^{*} \\
(0.005)\end{array}$ & $\begin{array}{c}0.019 \\
(0.024)\end{array}$ & & $\begin{array}{c}0.017 \\
(0.013)\end{array}$ & $\begin{array}{c}-0.012 \\
(0.066)\end{array}$ \\
\hline $\begin{array}{l}\text { Early-stage innovative entrepreneurs } \\
(\% \text { pop }), \mathrm{t}-1\end{array}$ & & & & $\begin{array}{c}0.349^{* * *} \\
(0.107)\end{array}$ & $\begin{array}{l}0.005^{*} \\
(0.003)\end{array}$ & $\begin{array}{l}-0.009 \\
(0.013)\end{array}$ & $\begin{array}{c}0.349^{* * *} \\
(0.099)\end{array}$ & $\begin{array}{l}0.005^{*} \\
(0.003)\end{array}$ & $\begin{array}{l}-0.003 \\
(0.029)\end{array}$ \\
\hline Early-stage VC funds raised (\%GDP), $\mathrm{t}$ & $\begin{array}{l}2.308^{*} \\
(1.142)\end{array}$ & & & $\begin{array}{l}2.034^{*} \\
(1.019)\end{array}$ & & & $\begin{array}{c}1.510 \\
(1.112)\end{array}$ & & \\
\hline Early-stage VC funds raised (\%GDP), t-1 & & & & $\begin{array}{l}2.807^{* *} \\
(1.003)\end{array}$ & $\begin{array}{l}-0.194 \\
(0.137)\end{array}$ & & $\begin{array}{l}2.214^{* *} \\
(1.050)\end{array}$ & $\begin{array}{l}-0.068 \\
(0.136)\end{array}$ & \\
\hline $\mathrm{PE}$ and Later stage VC funds raised (\%GDP), $\mathrm{t}$ & $\begin{array}{l}-0.100 \\
(0.225)\end{array}$ & & & $\begin{array}{l}-0.082 \\
(0.181)\end{array}$ & & & $\begin{array}{c}0.152 \\
(0.153)\end{array}$ & & \\
\hline $\mathrm{PE}$ and Later stage $\mathrm{VC}$ funds raised (\%GDP), t-1 & & & & $\begin{array}{l}-0.034 \\
(0.409)\end{array}$ & & $\begin{array}{l}-0.110 \\
(0.135)\end{array}$ & $\begin{array}{c}0.063 \\
(0.337)\end{array}$ & & $\begin{array}{c}0.213^{* * *} \\
(0.052)\end{array}$ \\
\hline $\begin{array}{l}\text { Early-stage non-innovative entrepreneurs } \\
(\% \text { pop), t }\end{array}$ & $\begin{array}{c}0.265^{* *} \\
(0.122)\end{array}$ & $\begin{array}{c}0.002 \\
(0.003)\end{array}$ & $\begin{array}{l}-0.031 \\
(0.021)\end{array}$ & $\begin{array}{c}0.202 \\
(0.123)\end{array}$ & $\begin{array}{c}0.004 \\
(0.004)\end{array}$ & $\begin{array}{l}-0.027 \\
(0.019)\end{array}$ & $\begin{array}{c}0.217^{* *} \\
(0.103)\end{array}$ & $\begin{array}{l}-0.009 \\
(0.010)\end{array}$ & $\begin{array}{l}-0.027 \\
(0.031)\end{array}$ \\
\hline $\begin{array}{l}\text { Early-stage non-innovative entrepreneurs } \\
\text { (\% pop), t-1 }\end{array}$ & & & & $\begin{array}{c}0.087 \\
(0.105)\end{array}$ & $\begin{array}{c}0.005 \\
(0.003)\end{array}$ & $\begin{array}{l}0.008 \\
(0.022)\end{array}$ & $\begin{array}{c}0.046 \\
(0.100)\end{array}$ & $\begin{array}{c}0.007 \\
(0.006)\end{array}$ & $\begin{array}{c}0.036 \\
(0.028)\end{array}$ \\
\hline No. scientific articles (\% pop) & $\begin{array}{l}-1.881 \\
(3.481)\end{array}$ & & & $\begin{array}{l}-3.625 \\
(3.441)\end{array}$ & & & $\begin{array}{l}-3.562^{*} \\
(1.819)\end{array}$ & & \\
\hline Researchers (per million people) & $\begin{array}{l}0.000 * * \\
(0.000)\end{array}$ & & & $\begin{array}{c}0.000 \\
(0.000)\end{array}$ & & & $\begin{array}{c}0.000 \\
(0.000)\end{array}$ & & \\
\hline $\begin{array}{l}\text { No. procedures to startup a business } \\
(>5 \& \leq 10)\end{array}$ & $\begin{array}{l}-0.297 \\
(0.672)\end{array}$ & & & $\begin{array}{c}0.054 \\
(0.486)\end{array}$ & & & $\begin{array}{l}-0.023 \\
(0.367)\end{array}$ & & \\
\hline $\begin{array}{l}\text { No. procedures to startup a business } \\
(>10)\end{array}$ & $\begin{array}{l}-0.738 \\
(0.970)\end{array}$ & & & $\begin{array}{c}0.060 \\
(0.877)\end{array}$ & & & $\begin{array}{c}0.010 \\
(0.677)\end{array}$ & & \\
\hline $\begin{array}{l}\text { Cost of startup business procedures } \\
\text { (no. procedures } \leq 5 \text { ) }\end{array}$ & $\begin{array}{c}-0.014 \\
(0.054)\end{array}$ & & & $\begin{array}{c}0.029 \\
(0.052)\end{array}$ & & & $\begin{array}{l}-0.011 \\
(0.053)\end{array}$ & & \\
\hline $\begin{array}{l}\text { Cost of startup business procedures } \\
\text { (no. procedures }>5 \& \leq 10 \text { ) }\end{array}$ & $\begin{array}{c}0.028 \\
(0.064)\end{array}$ & & & $\begin{array}{l}0.013 \\
(0.045)\end{array}$ & & & $\begin{array}{c}0.024 \\
(0.045)\end{array}$ & & \\
\hline $\begin{array}{l}\text { Cost of startup business procedures } \\
\text { (no. procedures }>10 \text { ) }\end{array}$ & $\begin{array}{c}0.126 \\
(0.118)\end{array}$ & & & $\begin{array}{c}0.026 \\
(0.099)\end{array}$ & & & $\begin{array}{c}0.037 \\
(0.088)\end{array}$ & & \\
\hline No. days to startup a business & $\begin{array}{l}0.015 \\
(0.020)\end{array}$ & & & $\begin{array}{l}-0.012 \\
(0.018)\end{array}$ & & & $\begin{array}{l}-0.014 \\
(0.018)\end{array}$ & & \\
\hline $\begin{array}{l}\text { Patent applications from residents } \\
\text { (per million people) }\end{array}$ & $\begin{array}{c}29.409 \\
(42.173)\end{array}$ & $\begin{array}{l}-5.365 \\
(3.490)\end{array}$ & $\begin{array}{c}6.005 \\
(11.563)\end{array}$ & $\begin{array}{c}19.751 \\
(28.170)\end{array}$ & $\begin{array}{c}-8.669^{* * *} \\
(2.239)\end{array}$ & $\begin{array}{c}5.468 \\
(11.833)\end{array}$ & $\begin{array}{c}-8.934 \\
(26.137)\end{array}$ & $\begin{array}{c}-6.384^{* *} \\
(3.084)\end{array}$ & $\begin{array}{c}7.527 \\
(12.764)\end{array}$ \\
\hline $\begin{array}{l}\text { Domestic credit provided by banks } \\
(\% \text { GDP })\end{array}$ & $\begin{array}{l}-0.001 \\
(0.012)\end{array}$ & $\begin{array}{c}0.000 \\
(0.001)\end{array}$ & $\begin{array}{c}0.002 \\
(0.001)\end{array}$ & $\begin{array}{l}-0.001 \\
(0.009)\end{array}$ & $\begin{array}{c}0.002^{* * *} \\
(0.001)\end{array}$ & $\begin{array}{c}0.002 \\
(0.001)\end{array}$ & $\begin{array}{l}-0.004 \\
(0.008)\end{array}$ & $\begin{array}{c}0.001 \\
(0.001)\end{array}$ & $\begin{array}{c}0.001 \\
(0.002)\end{array}$ \\
\hline Domestic credit provided by financial sector (\% GDP) & $\begin{array}{l}-0.007 \\
(0.009)\end{array}$ & $\begin{array}{l}-0.000 \\
(0.000)\end{array}$ & $\begin{array}{l}-0.000 \\
(0.001)\end{array}$ & $\begin{array}{l}-0.002 \\
(0.007)\end{array}$ & $\begin{array}{l}-0.000 \\
(0.000)\end{array}$ & $\begin{array}{l}-0.000 \\
(0.002)\end{array}$ & $\begin{array}{c}0.001 \\
(0.006)\end{array}$ & $\begin{array}{c}0.000 \\
(0.000)\end{array}$ & $\begin{array}{l}-0.001 \\
(0.002)\end{array}$ \\
\hline Market capitalization (\% GDP) & $\begin{array}{l}0.015^{*} \\
(0.007)\end{array}$ & $\begin{array}{l}-0.001 \\
(0.001)\end{array}$ & $\begin{array}{c}0.000 \\
(0.001)\end{array}$ & $\begin{array}{c}0.011^{* *} \\
(0.005)\end{array}$ & $\begin{array}{c}-0.001^{* * *} \\
(0.000)\end{array}$ & $\begin{array}{l}-0.000 \\
(0.001)\end{array}$ & $\begin{array}{c}0.004 \\
(0.004)\end{array}$ & $\begin{array}{c}-0.001^{* *} \\
(0.001)\end{array}$ & $\begin{array}{c}0.001 \\
(0.002)\end{array}$ \\
\hline GDP growth & $\begin{array}{l}0.072^{*} \\
(0.039)\end{array}$ & $\begin{array}{l}-0.001 \\
(0.002)\end{array}$ & $\begin{array}{c}0.015^{* *} \\
(0.007)\end{array}$ & $\begin{array}{c}0.070^{* *} \\
(0.031)\end{array}$ & $\begin{array}{c}0.001 \\
(0.001)\end{array}$ & $\begin{array}{c}0.013 \\
(0.009)\end{array}$ & $\begin{array}{c}0.020 \\
(0.026)\end{array}$ & $\begin{array}{c}0.000 \\
(0.002)\end{array}$ & $\begin{array}{c}0.018^{* *} \\
(0.009)\end{array}$ \\
\hline Divestment through IPO (\% of all Divestments€) & $\begin{array}{l}0.027^{*} \\
(0.015)\end{array}$ & $\begin{array}{l}-0.000 \\
(0.001)\end{array}$ & $\begin{array}{c}0.005 \\
(0.006)\end{array}$ & $\begin{array}{c}0.003 \\
(0.013)\end{array}$ & $\begin{array}{l}-0.000 \\
(0.001)\end{array}$ & $\begin{array}{c}0.005 \\
(0.006)\end{array}$ & $\begin{array}{c}0.003 \\
(0.011)\end{array}$ & $\begin{array}{l}-0.002 \\
(0.001)\end{array}$ & $\begin{array}{c}0.003 \\
(0.006)\end{array}$ \\
\hline $\begin{array}{l}\text { Divestment through Mergers and Acquisitions ( } \% \text { of all } \\
\text { Divestments } € \text { ) }\end{array}$ & $\begin{array}{l}-0.014 \\
(0.013)\end{array}$ & $\begin{array}{c}0.001 \\
(0.001)\end{array}$ & $\begin{array}{l}-0.003 \\
(0.004)\end{array}$ & $\begin{array}{c}-0.033^{* *} \\
(0.013)\end{array}$ & $\begin{array}{c}0.002^{* * *} \\
(0.001)\end{array}$ & $\begin{array}{l}-0.003 \\
(0.004)\end{array}$ & $\begin{array}{c}-0.026^{* *} \\
(0.013)\end{array}$ & $\begin{array}{c}0.000 \\
(0.001)\end{array}$ & $\begin{array}{l}-0.005 \\
(0.006)\end{array}$ \\
\hline Divestment through Buyout (\% of all Divestments€) & $\begin{array}{l}-0.014 \\
(0.021)\end{array}$ & $\begin{array}{l}-0.001 \\
(0.001)\end{array}$ & $\begin{array}{l}-0.004 \\
(0.005)\end{array}$ & $\begin{array}{c}-0.028^{*} \\
(0.016)\end{array}$ & $\begin{array}{l}-0.001 \\
(0.001)\end{array}$ & $\begin{array}{l}-0.004 \\
(0.004)\end{array}$ & $\begin{array}{c}-0.014 \\
(0.016)\end{array}$ & $\begin{array}{l}-0.002^{*} \\
(0.001)\end{array}$ & $\begin{array}{l}-0.007 \\
(0.005)\end{array}$ \\
\hline Divestment through Writeoff (\% of all Divestments€) & $\begin{array}{c}0.005 \\
(0.012)\end{array}$ & $\begin{array}{c}-0.000 \\
(0.001)\end{array}$ & $\begin{array}{l}-0.002 \\
(0.003)\end{array}$ & $\begin{array}{c}-0.026^{* *} \\
(0.009)\end{array}$ & $\begin{array}{l}-0.000 \\
(0.001)\end{array}$ & $\begin{array}{c}-0.002 \\
(0.003)\end{array}$ & $\begin{array}{c}-0.026^{* * *} \\
(0.010)\end{array}$ & $\begin{array}{l}-0.001 \\
(0.001)\end{array}$ & $\begin{array}{l}-0.003 \\
(0.005)\end{array}$ \\
\hline Value Added ICT (\% GDP) & $\begin{array}{l}-23.445 \\
(21.205)\end{array}$ & $\begin{array}{c}0.095 \\
(0.992)\end{array}$ & $\begin{array}{l}-0.665 \\
(2.776)\end{array}$ & $\begin{array}{c}-21.978 \\
(19.671)\end{array}$ & $\begin{array}{c}0.781 \\
(0.862)\end{array}$ & $\begin{array}{c}0.101 \\
(3.007)\end{array}$ & $\begin{array}{l}-22.512 \\
(18.662)\end{array}$ & $\begin{array}{c}-0.013 \\
(1.127)\end{array}$ & $\begin{array}{l}-6.781 \\
(4.924)\end{array}$ \\
\hline Ln of GDP & $\begin{array}{l}-4.455 \\
(4.467)\end{array}$ & $\begin{array}{l}-0.008 \\
(0.116)\end{array}$ & $\begin{array}{c}0.626 \\
(0.564)\end{array}$ & $\begin{array}{l}-3.294 \\
(3.261)\end{array}$ & $\begin{array}{c}0.211 \\
(0.184)\end{array}$ & $\begin{array}{c}0.596 \\
(0.579)\end{array}$ & $\begin{array}{l}-0.030 \\
(2.802)\end{array}$ & $\begin{array}{c}0.031 \\
(0.145)\end{array}$ & $\begin{array}{c}0.370 \\
(0.573)\end{array}$ \\
\hline Ln of Population & $\begin{array}{l}8.985 \\
(6.320)\end{array}$ & $\begin{array}{l}-0.522 \\
(0.388)\end{array}$ & $\begin{array}{c}0.535 \\
(1.680)\end{array}$ & $\begin{array}{l}12.261^{*} \\
(6.954)\end{array}$ & $\begin{array}{c}1.867^{* * *} \\
(0.664)\end{array}$ & $\begin{array}{c}1.042 \\
(1.929)\end{array}$ & $\begin{array}{c}8.148 \\
(5.502)\end{array}$ & $\begin{array}{l}-0.759 \\
(0.544)\end{array}$ & $\begin{array}{c}1.811 \\
(1.830)\end{array}$ \\
\hline CIC CTV & & $\begin{array}{c}0.114 \\
(0.163)\end{array}$ & $\begin{array}{l}-1.003 \\
(0.858)\end{array}$ & & $\begin{array}{c}0.232^{*} \\
(0.141)\end{array}$ & $\begin{array}{l}-0.988 \\
(0.867)\end{array}$ & & $\begin{array}{l}-0.221 \\
(0.367)\end{array}$ & $\begin{array}{c}-1.778^{*} \\
(0.921)\end{array}$ \\
\hline CIC CDV & & $\begin{array}{c}0.029 \\
(0.138)\end{array}$ & $\begin{array}{l}-0.436 \\
(0.592)\end{array}$ & & $\begin{array}{c}-0.490^{* * *} \\
(0.157)\end{array}$ & $\begin{array}{l}-0.535 \\
(0.487)\end{array}$ & & $\begin{array}{l}-0.141 \\
(0.303)\end{array}$ & $\begin{array}{l}-0.395 \\
(0.607)\end{array}$ \\
\hline $\mathrm{CIC}$ & & $\begin{array}{l}-0.001 \\
(0.001)\end{array}$ & $\begin{array}{l}-0.005 \\
(0.008)\end{array}$ & & $\begin{array}{c}-0.006^{* * *} \\
(0.001)\end{array}$ & $\begin{array}{l}-0.005 \\
(0.010)\end{array}$ & & $\begin{array}{l}-0.003 \\
(0.005)\end{array}$ & $\begin{array}{l}-0.006 \\
(0.012)\end{array}$ \\
\hline $\mathrm{CIC}^{*} \mathrm{CIC} \mathrm{CTV}$ & & $\begin{array}{c}0.001 \\
(0.003)\end{array}$ & $\begin{array}{c}0.002 \\
(0.016)\end{array}$ & & $\begin{array}{l}-0.000 \\
(0.002)\end{array}$ & $\begin{array}{c}0.002 \\
(0.016)\end{array}$ & & $\begin{array}{c}0.006 \\
(0.007)\end{array}$ & $\begin{array}{c}0.017 \\
(0.012)\end{array}$ \\
\hline $\mathrm{CIC}^{*} \mathrm{CIC} \mathrm{CDV}$ & & $\begin{array}{c}0.001 \\
(0.001)\end{array}$ & $\begin{array}{c}0.004 \\
(0.006)\end{array}$ & & $\begin{array}{c}0.004^{* * *} \\
(0.001)\end{array}$ & $\begin{array}{c}0.005 \\
(0.006)\end{array}$ & & $\begin{array}{c}0.001 \\
(0.004)\end{array}$ & $\begin{array}{c}0.003 \\
(0.007)\end{array}$ \\
\hline Depth of credit information index & & $\begin{array}{c}0.003 \\
(0.004)\end{array}$ & $\begin{array}{c}0.007 \\
(0.015)\end{array}$ & & $\begin{array}{c}0.002 \\
(0.002)\end{array}$ & $\begin{array}{c}0.014 \\
(0.019)\end{array}$ & & $\begin{array}{c}0.002 \\
(0.003)\end{array}$ & $\begin{array}{l}-0.015 \\
(0.022)\end{array}$ \\
\hline Trend & YES & YES & YES & YES & YES & YES & YES & YES & YES \\
\hline Country-level FE & YES & YES & YES & YES & YES & YES & YES & YES & YES \\
\hline Multiplier effect & & 1.016 & 1.000 & & 1.017 & 1.000 & & 1.011 & 1.000 \\
\hline Overidentification test: Hansen J stat. p-value & & & & & & & 0.187 & 0.117 & 0.606 \\
\hline $\mathrm{A}-\mathrm{B}$ test for $\mathrm{AR}(1)$ in first differences $\mathrm{p}$-value & & & & & & & 0.000 & 0.032 & 0.067 \\
\hline A-B test for $\mathrm{AR}(2)$ in first differences p-value & & & & & & & 0.291 & 0.155 & 0.422 \\
\hline Observations & 144 & 144 & 144 & 144 & 144 & 144 & 144 & 144 & 144 \\
\hline
\end{tabular}

(4)

144

$* * * \mathrm{p}<0.01,{ }^{* *} \mathrm{p}<0.05, * \mathrm{p}<0.1$ 
Table A1 - Control variables summary statistics by country

\begin{tabular}{|c|c|c|c|c|c|c|c|c|c|c|c|c|c|c|c|c|c|}
\hline country & $\begin{array}{l}\text { Early-stage } \\
\text { non- } \\
\text { innovative } \\
\text { entrepreneur } \\
\text { s (\% pop) }\end{array}$ & $\begin{array}{l}\text { No. days } \\
\text { to startup } \\
\text { a business }\end{array}$ & $\begin{array}{l}\text { No. } \\
\text { procedures } \\
\text { to startup } \\
\text { a business }\end{array}$ & $\begin{array}{l}\text { Cost of } \\
\text { startup } \\
\text { business } \\
\text { procedures }\end{array}$ & $\begin{array}{c}\text { No. } \\
\text { scientific } \\
\text { articles } \\
\text { (\% pop) }\end{array}$ & $\begin{array}{l}\text { Researcher } \\
\text { s (per } \\
\text { million } \\
\text { people) }\end{array}$ & $\begin{array}{l}\text { Patent } \\
\text { application } \\
\text { s from } \\
\text { residents } \\
\text { (per } \\
\text { million } \\
\text { people) }\end{array}$ & $\begin{array}{l}\text { CIC } \\
\text { CTV }\end{array}$ & $\begin{array}{c}\text { CIC } \\
\text { CDV }\end{array}$ & CIC & $\begin{array}{l}\text { Depth of } \\
\text { credit } \\
\text { information } \\
\text { index }\end{array}$ & $\begin{array}{l}\text { Domestic } \\
\text { credit } \\
\text { provided } \\
\text { by banks } \\
(\% \text { GDP })\end{array}$ & $\begin{array}{l}\text { Domestic } \\
\text { credit provided } \\
\text { by financial } \\
\text { sector (\% } \\
\text { GDP) }\end{array}$ & $\begin{array}{c}\text { Market } \\
\text { capitalizatio } \\
\text { n }(\% \text { GDP })\end{array}$ & $\begin{array}{l}\text { GDP } \\
\text { growth }\end{array}$ & GDP & Population \\
\hline Australia & 5.215 & 2.556 & 3.000 & 0.733 & 0.193 & 4546.500 & 0.012 & 0.019 & 1.414 & 100.000 & 5.444 & 125.478 & 157.022 & 102.389 & 2.724 & 27.794 & 16.922 \\
\hline Austria & 3.647 & 24.333 & 8.000 & 4.033 & 0.139 & 4292.333 & 0.027 & 0.089 & 1.319 & 47.033 & 6.222 & 93.800 & 130.500 & 29.033 & 0.933 & 26.712 & 15.946 \\
\hline Belgium & 2.474 & 4.000 & 3.000 & 5.178 & 0.149 & 3741.111 & 0.006 & 0.103 & 1.414 & 75.456 & 4.111 & 59.044 & 121.244 & 62.356 & 1.021 & 26.915 & 16.212 \\
\hline Canada & 5.645 & 4.833 & 2.111 & 0.444 & 0.164 & 4561.778 & 0.014 & 0.000 & 1.414 & 100.000 & 6.444 & 90.456 & 184.947 & 114.222 & 1.539 & 28.144 & 17.353 \\
\hline China & 6.680 & 35.200 & 13.000 & 3.933 & 0.022 & 1021.556 & 0.028 & 0.888 & 1.414 & 28.089 & 4.778 & 127.678 & 150.011 & 63.067 & 9.192 & 29.497 & 21.019 \\
\hline Denmark & 2.040 & 5.389 & 4.000 & 0.089 & 0.213 & 6585.556 & 0.027 & 0.318 & 1.414 & 7.189 & 4.444 & 186.100 & 228.778 & 76.663 & -0.009 & 26.507 & 15.533 \\
\hline Finland & 3.457 & 14.000 & 3.000 & 1.022 & 0.189 & 7461.333 & 0.032 & 0.066 & 1.414 & 17.589 & 4.889 & 88.556 & 148.578 & 71.524 & 0.094 & 26.249 & 15.500 \\
\hline France & 2.384 & 6.056 & 5.000 & 0.922 & 0.106 & 3849.444 & 0.022 & 0.394 & 1.414 & 37.533 & 4.444 & 94.611 & 144.244 & 73.478 & 0.650 & 28.620 & 17.996 \\
\hline Germany & 1.677 & 15.111 & 9.000 & 5.078 & 0.119 & 4021.222 & 0.058 & 0.056 & 1.387 & 99.244 & 6.444 & 87.422 & 140.900 & 43.511 & 1.162 & 28.886 & 18.218 \\
\hline Greece & 4.001 & 17.444 & 10.778 & 15.733 & 0.101 & 2181.778 & 0.006 & 0.519 & 1.414 & 66.733 & 5.222 & 106.011 & 133.044 & 30.544 & -2.896 & 26.357 & 16.215 \\
\hline Ireland & 3.830 & 10.778 & 4.000 & 0.311 & 0.154 & 3243.333 & 0.014 & 0.000 & 1.414 & 100.000 & 5.444 & 122.911 & 206.378 & 44.500 & 1.702 & 26.170 & 15.332 \\
\hline Israel & 3.647 & 17.111 & 5.000 & 4.078 & 0.147 & 6337.000 & 0.018 & 0.047 & 1.414 & 92.011 & 5.333 & 67.778 & 87.200 & 78.689 & 3.591 & 26.215 & 15.865 \\
\hline Italy & 1.712 & 7.833 & 6.111 & 16.722 & 0.100 & 1746.556 & 0.014 & 0.150 & 0.920 & 89.378 & 5.444 & 89.356 & 158.667 & 29.078 & -0.771 & 28.378 & 17.903 \\
\hline Japan & 2.277 & 20.100 & 8.000 & 7.500 & 0.076 & 5228.333 & 0.236 & 0.130 & 1.414 & 88.422 & 6.000 & 106.544 & 343.244 & 80.033 & 0.380 & 29.344 & 18.665 \\
\hline Luxembourg & 5.796 & 20.111 & 6.000 & 3.433 & 0.111 & 4743.667 & 0.014 & 0.000 & 0.000 & 0.000 & 0.000 & 94.667 & 199.422 & 155.511 & 2.539 & 24.715 & 13.163 \\
\hline Netherlands & 4.450 & 6.333 & 5.222 & 5.400 & 0.182 & 3617.889 & 0.014 & 0.110 & 1.414 & 82.778 & 5.444 & 115.256 & 212.178 & 80.611 & 0.681 & 27.462 & 16.629 \\
\hline Norway & 4.568 & 5.889 & 4.778 & 1.667 & 0.195 & 5388.889 & 0.023 & 0.000 & 1.414 & 100.000 & 4.444 & 78.219 & 215.522 & 53.811 & 1.202 & 26.812 & 15.415 \\
\hline Poland & 2.257 & 31.111 & 6.222 & 15.200 & 0.064 & 1698.667 & 0.009 & 0.256 & 1.414 & 74.589 & 5.444 & 53.161 & 85.333 & 33.511 & 3.579 & 26.923 & 17.455 \\
\hline Portugal & 4.926 & 3.722 & 4.222 & 4.178 & 0.106 & 3560.889 & 0.005 & 0.112 & 0.929 & 86.011 & 5.111 & 145.600 & 185.767 & 33.533 & -0.336 & 26.168 & 16.167 \\
\hline Spain & 3.444 & 38.333 & 9.556 & 9.478 & 0.108 & 2750.111 & 0.007 & 0.090 & 0.889 & 50.033 & 5.556 & 155.211 & 224.244 & 79.989 & 0.068 & 27.980 & 17.652 \\
\hline Sweden & 3.456 & 15.000 & 3.000 & 0.556 & 0.204 & 5641.222 & 0.024 & 0.008 & 1.414 & 100.000 & 4.222 & 125.656 & 149.433 & 91.793 & 1.513 & 26.934 & 16.062 \\
\hline Switzerland & 3.619 & 16.222 & 6.000 & 2.056 & 0.266 & 3884.500 & 0.020 & 0.051 & 1.414 & 24.922 & 5.222 & 163.133 & 174.500 & 204.911 & 1.637 & 27.107 & 15.884 \\
\hline UK & 4.305 & 9.778 & 5.778 & 0.567 & 0.153 & 4117.444 & 0.025 & 0.106 & 1.414 & 98.289 & 6.444 & 170.456 & 190.100 & 110.813 & 1.107 & 28.545 & 17.962 \\
\hline USA & 6.169 & 5.800 & 6.000 & 1.122 & 0.125 & 3942.556 & 0.080 & 0.000 & 1.414 & 100.000 & 6.444 & 52.778 & 235.567 & 120.956 & 1.268 & 30.366 & 19.557 \\
\hline Total & 3.820 & 14.044 & 5.866 & 4.560 & 0.141 & 4090.153 & 0.031 & 0.146 & 1.287 & 69.388 & 5.125 & 108.328 & 175.284 & 77.689 & 1.357 & 27.450 & 16.859 \\
\hline
\end{tabular}

Table A2- Control variables summary statistics by year

\begin{tabular}{|c|c|c|c|c|c|c|c|c|c|c|c|c|c|c|c|c|c|}
\hline year & $\begin{array}{c}\text { Early-stage } \\
\text { non- } \\
\text { innovative } \\
\text { entrepreneur } \\
\text { s (\% pop) }\end{array}$ & $\begin{array}{l}\text { No. days } \\
\text { to startup } \\
\text { a business }\end{array}$ & $\begin{array}{l}\text { No. } \\
\text { procedures } \\
\text { to startup } \\
\text { a business }\end{array}$ & $\begin{array}{c}\text { Cost of } \\
\text { startup } \\
\text { business } \\
\text { procedures }\end{array}$ & $\begin{array}{c}\text { No. } \\
\text { scientific } \\
\text { articles } \\
\text { (\% pop) }\end{array}$ & $\begin{array}{c}\text { Researcher } \\
\text { s (per } \\
\text { million } \\
\text { people) }\end{array}$ & $\begin{array}{c}\text { Patent } \\
\text { application } \\
\text { s from } \\
\text { residents } \\
\text { (per } \\
\text { million } \\
\text { people) }\end{array}$ & $\begin{array}{c}\text { CIC } \\
\text { CTV }\end{array}$ & $\begin{array}{c}\mathrm{CIC} \\
\mathrm{CDV}\end{array}$ & CIC & $\begin{array}{l}\text { Depth of } \\
\text { credit } \\
\text { information } \\
\text { index }\end{array}$ & $\begin{array}{l}\text { Domestic } \\
\text { credit } \\
\text { provided } \\
\text { by banks } \\
(\% \text { GDP) }\end{array}$ & $\begin{array}{c}\text { Domestic } \\
\text { credit provided } \\
\text { by financial } \\
\text { sector ( } \% \\
\text { GDP) }\end{array}$ & $\begin{array}{c}\text { Market } \\
\text { capitalizatio } \\
\text { n }(\% \text { GDP })\end{array}$ & $\begin{array}{l}\text { GDP } \\
\text { growth }\end{array}$ & GDP & Population \\
\hline 2007 & 3.301 & 17.063 & 6.500 & 6.021 & 0.121 & 3580.396 & 0.031 & 0.127 & 1.300 & 61.467 & 4.708 & 107.364 & 165.408 & 116.280 & 4.070 & 27.426 & 16.831 \\
\hline 2008 & 3.646 & 16.292 & 6.333 & 5.763 & 0.125 & 3674.302 & 0.031 & 0.130 & 1.302 & 63.000 & 4.667 & 109.933 & 165.687 & 55.591 & 0.993 & 27.436 & 16.840 \\
\hline 2009 & 3.511 & 16.125 & 6.167 & 5.188 & 0.130 & 3914.583 & 0.032 & 0.129 & 1.298 & 64.642 & 4.750 & 113.162 & 173.601 & 76.997 & -2.856 & 27.406 & 16.847 \\
\hline 2010 & 3.427 & 15.292 & 6.167 & 5.279 & 0.133 & 3958.552 & 0.030 & 0.132 & 1.288 & 67.029 & 4.750 & 110.800 & 180.557 & 80.741 & 2.672 & 27.432 & 16.854 \\
\hline 2011 & 4.116 & 13.958 & 5.958 & 4.546 & 0.139 & 4099.021 & 0.030 & 0.140 & 1.284 & 71.942 & 4.708 & 108.905 & 182.502 & 62.635 & 1.796 & 27.450 & 16.860 \\
\hline 2012 & 4.217 & 13.625 & 5.917 & 4.292 & 0.144 & 4231.448 & 0.030 & 0.161 & 1.281 & 73.192 & 4.792 & 108.641 & 180.758 & 69.909 & 0.323 & 27.453 & 16.866 \\
\hline 2013 & 3.983 & 13.000 & 5.500 & 3.825 & 0.145 & 4313.583 & 0.031 & 0.167 & 1.278 & 73.929 & 4.833 & 107.298 & 174.729 & 80.151 & 0.988 & 27.462 & 16.873 \\
\hline 2014 & 4.227 & 11.008 & 5.167 & 3.267 & 0.170 & 4474.677 & 0.031 & 0.167 & 1.276 & 74.050 & 6.375 & 104.791 & 178.554 & 76.483 & 1.945 & 27.481 & 16.878 \\
\hline 2015 & 3.950 & 10.029 & 5.083 & 2.858 & 0.164 & 4564.813 & 0.030 & 0.165 & 1.281 & 75.238 & 6.542 & 104.063 & 175.763 & 80.412 & 2.286 & 27.504 & 16.884 \\
\hline Total & 3.820 & 14.044 & 5.866 & 4.560 & 0.141 & 4090.153 & 0.031 & 0.146 & 1.287 & 69.388 & 5.125 & 108.328 & 175.284 & 77.689 & 1.357 & 27.450 & 16.859 \\
\hline
\end{tabular}

